UNIVERSIDAD NACIONAL DE LA PLATA

FACULTAD DE HUMANIDADES Y CIENCIAS DE LA EDUCACIÓN

SECRETARÍA DE POSTGRADO

MAESTRÍA EN LINGÜÍSTICA

\title{
UN ESTUDIO SISTÉMICO-FUNCIONAL DE LA RELACIÓN PARTICIPANTE-PROCESO EN RESÚMENES EN ESPAÑOL DE NOTICIAS PERIODÍSTICAS EN INGLÉS
}

Maestrando: Ana María Coria

Director: Dra. Ann Montemayor-Borsinger

AÑO: 2013

Tesis presentada como requisito para la obtención del grado de Magíster 
Esta Tesis está dedicada a la memoria de mi padre. 


\section{AGRADECIMIENTOS}

Son muchas las personas a quienes ofrecer mi agradecimiento y, después del desafío en múltiples dimensiones que la escritura de esta tesis me demandó, espero que mis palabras en esta sección del trabajo logren captar lo que exactamente deseo significar.

En primer lugar, quisiera agradecer a la Dra. Luisa Granato, por haber creído en el proyecto de esta maestría, que concibió e implementó, sin duda no sin esfuerzo y frustraciones, y que, sin embargo, llevó adelante. Quiero agradecerle, a Luisa, por haberme contagiado el amor por el estudio de la lengua, mucho antes de ser la Dra. Granato y haber influido en mi elección profesional hace ya mucho tiempo, casi sin que ella o yo nos diéramos cuenta.

Quiero agradecer también a mis compañeros de ruta en mis cursos de maestría, profesores de inglés y de francés, en particular aquellos con quienes pude estrechar lazos y a quienes aprendí a apreciar no sólo como profesionales sino también como personas. Tampoco quiero olvidarme de aquellos profesores que me enseñaron desde sus palabras y sus acciones y que me enriquecieron en mi tarea como docente.

Quiero agradecer a mis colegas: Marcela, sobre todo en los primeros tramos de esta carrera y Cristina, que me ayudó a no decaer en el último tramo, no sólo a partir de su lectura de secciones de esta tesis sino también con sus palabras de aliento y sus oportunos consejos.

Muy especialmente, quiero agradecer a la Dra. Ann Montemayor-Borsinger, mi directora de tesis, por creer en mí más que yo misma y por ver siempre lo bueno que mis avances le entregaban, aún cuando, sobre todo en las primeras etapas, tuvo que trabajar mucho para enseñarme a pensar el género. Quiero principalmente destacar su paciencia y su calidez humana, tan importantes para mí como su solidez profesional, virtudes que me permitieron disfrutar y seguir disfrutando de aprender a su lado. 
A mis alumnos, que también son mis maestros y el motor de este trabajo, sin cuya presencia poco sentido hubiera tenido para mí seguir creciendo y aprendiendo.

Por último, quiero agradecer a aquellas amigas que, aún sin pertenecer al ámbito académico, supieron entender tantos encuentros postergados. A Daniel, mi esposo, por su amor y su generosidad para alentar todas mis iniciativas intelectuales, incluso sabiendo lo que eso significaba viniendo de mí. A mi hijo Mariano, quien en sus rebeldes años adolescentes, debió entender mi pasión y aceptar mis altibajos de humor durante mis años de estudio y de redacción de esta tesis. Quiero, finalmente, agradecer a mi madre, quien con sus valores me enseñó que "si la respuesta fuera el atajo, no existiría el camino". 


\section{ÍNDICE}

Capítulo 1 NTRODUCCIÓN..................................................... 1

Capítulo 2 MARCO TEÓRICO Y ANTECEDENTES DEL TEMA............ 11

2.1. MARCO TEÓRICO........................................................ 11

2.1.1.El lenguaje en una perspectiva semiótico-social..................... 14

2.1.2. Texto y Contexto................................................. 17

2.1.3. El Contexto de Situación y de Cultura: antecedentes.................. 19

2.1.4. El Contexto de Situación en LSF y su relación con los significados en el texto....................................................................... 22

2.1.5. La Teoría del Registro y el Género............................... 26

2.1.6. La relación participante-proceso y la Perspectiva Funcional de la Oración.......................................................................... $\quad 33$

2.2. ANTECEDENTES DEL TEMA: EL RESUMEN COMO GÉNERO 37

Capítulo 3 CORPUS Y METODOLOGÍA................................... 43

3.1.INTRODUCCIÓN.................................................. 43

3.2. EL CORPUS........................................................ 44

3.3. LA METODOLOGÍA DE ANÁLISIS................................. 47

3.3.1. La segmentación y el análisis cualitativo de los textos...................... $\quad 48$

3.3.2. El análisis tripartito y sus resultados................................. $\quad 54$

3.3.3. La evaluación de los informantes.................................. 55

Capítulo 4 RESULTADOS Y DISCUSIÓN................................. 58

4.1. SISTEMA DE TRANSITIVIDAD.................................. 61

4.1.1. Textos Más Efectivos............................................ $\quad 62$

4.1.1.1. Texto 1....................................................... 62

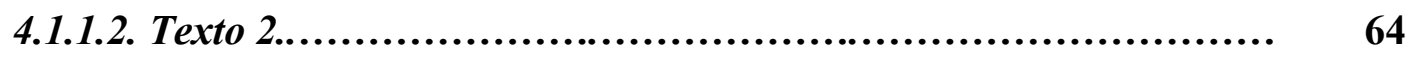




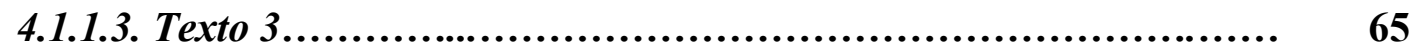

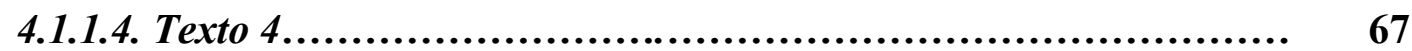

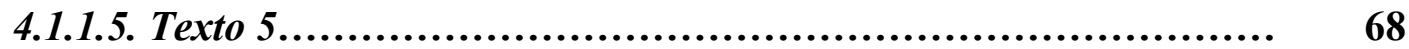

4.1.2. Textos Menos Efectivos.................................................. 69

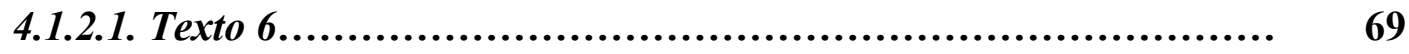

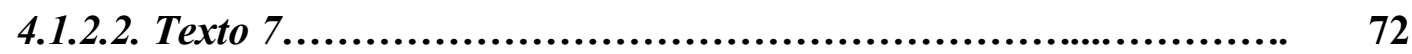

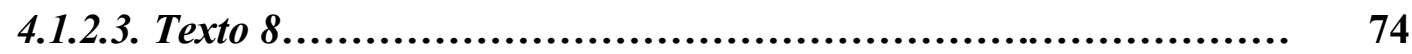

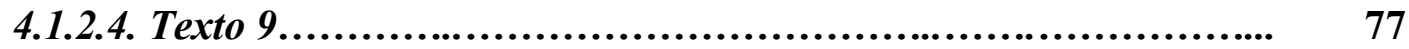

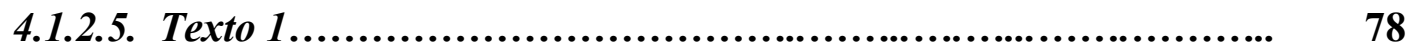

4.1.3. Comparaciones en el Sistema de Transitividad.......................... 80

4.2. SISTEMA DE MODO/TEMPLE........................................ 83

4.2.1.Textos Más Efectivo.................................................... $\quad 86$

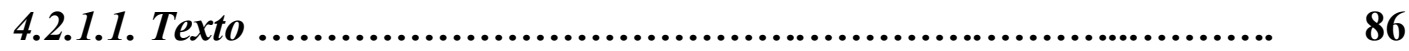

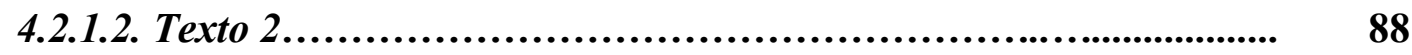

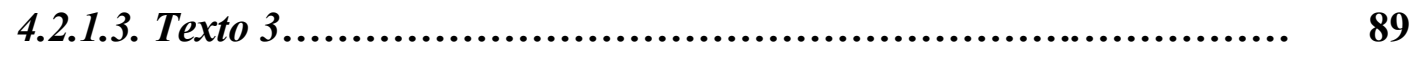

4.2.1.4. Texto 4............................................................... 91

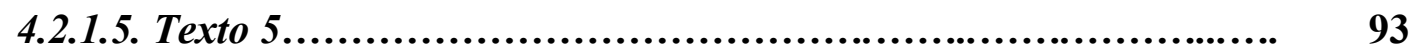

4.2.2. Textos Menos Efectivos.................................................. 94

4.2.2.1. Texto 6............................................................... 94

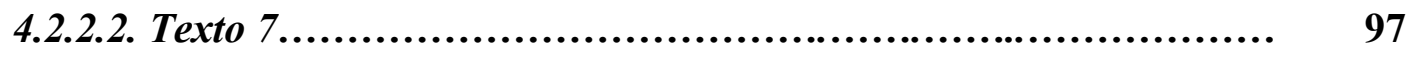

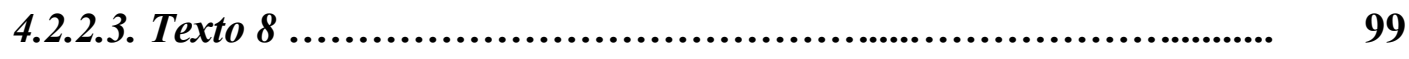

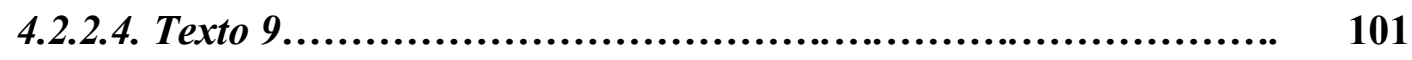

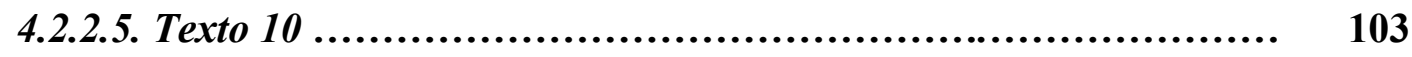

4.2.3. Comparaciones en el Sistema de Modo/Temple........................... 105

4.3. SISTEMA DE TEMA/REMA.................................................. 108

4.3.1. Textos Más Efectivos................................................... 110 
4.3.1.1 Texto 1.................................................................. 110

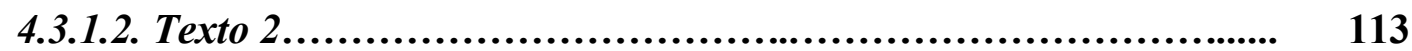

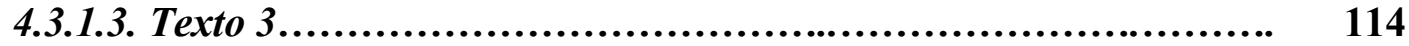

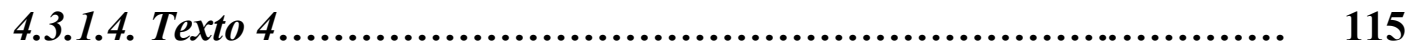

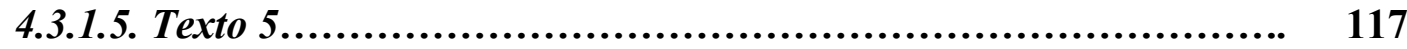

4.3.2. Textos Menos Efectivos........................................... 119

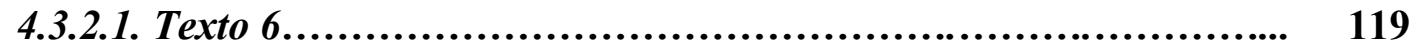

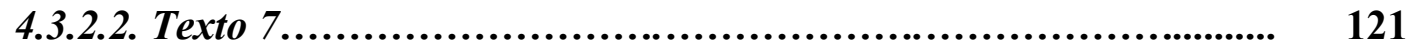

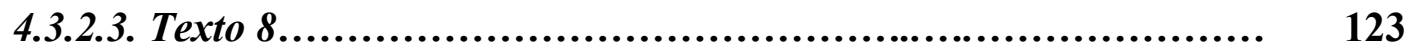

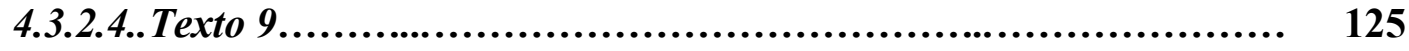

4.3.2.5 Texto 10........................................................ 127

4.3.3. Comparaciones en el Sistema de Tema/Rema.......................... 130

Capítulo 5 CONCLUSIONES............................................... 136

5.1. INTRODUCCIÓN........................................................ 136

5.2. EL TEXTO MÁS EFECTIVO Y EL TEXTO MENOS EFECTIVO..... 138

5.3. EL TEXTO FUENTE Y SU INTERPRETACIÓN.................... 141

5.4. RESPUESTAS A LAS PREGUNTAS QUE GUIARON EL ESTUDIO. 144

BIBLIOGRAFÍA............................................................. 153

APÉNDICES ................................................................. 162 


\section{RESUMEN}

Un estudio sistémico-funcional de la relación participante-proceso en resúmenes en español de noticias periodísticas en inglés

El objetivo de este trabajo es analizar la interpretación léxico-gramatical de la relación participante-proceso en textos en inglés y evaluar su incidencia en la efectividad de los resúmenes de dichos textos en español. Utilizando el marco de la Lingüística SistémicoFuncional (Halliday, 1985, 1994, 2004), se realizó un análisis tripartito de diez resúmenes en español de una noticia periodística en inglés sobre deportes, escritos por alumnos de la carrera de Profesorado de Educación Física de la Universidad Nacional de La Plata en una instancia de evaluación final de la asignatura Capacitación en Inglés-Nivel II. En base a la Teoría del Registro y el Género (Martin y Eggins, 1997), se evaluó la incidencia de las relaciones lingüísticas a nivel de Contexto de Situación (Registro) y Contexto de Cultura (Género). También se solicitó la colaboración de un grupo de colegas para que dieran una opinión adicional sobre la efectividad de los resúmenes. A partir del análisis de los textos meta se pudo observar que aquellos escritores que muestran más dificultades para identificar la relación participante-proceso construyen resúmenes menos efectivos. Este menor grado de efectividad aparece como consecuencia de determinadas selecciones léxico-gramaticales. Por otro lado, la identificación de la relación participante-proceso en el texto fuente parece incidir directamente en la construcción de la adecuada estructura genérica del texto meta. En conclusión, la identificación de la relación participante-proceso en textos en inglés puede considerarse central para la construcción de resúmenes efectivos en español.

Palabras clave: resumen, relación participante-proceso, interpretación léxico-gramatical, estructura genérica, efectividad 


\section{ABSTRACT \\ A systemic functional study of the participant-process relation of summaries in Spanish from news reports in English}

The aim of this study is to analyse the lexico-grammatical interpretation of the participantprocess relation of texts in English and evaluate its influence on the effectiveness of the summaries of those texts in Spanish. We employed the Functional Systemic Linguistics approach (Halliday, 1985, 1994, 2004) to carry out a tripartite analysis of ten summaries in Spanish of a news report in English which were written by students of Profesorado de Educación Física de la Universidad Nacional de La Plata in instances of final examinations of the subject Capacitación en Inglés-Level II. The influence of linguistic relations at the levels of Context of Situation (Register) and Context of Culture (Genre) was also analysed, with the help of the Genre and Register Theory (Martin and Eggins, 1997). A group of colleagues was asked to give additional information on the effectiveness of the target texts. The results of the analysis of the target texts showed that those writers who find it more difficult to identify the participant-process relation build less effective texts. This lack of effectiveness seems to be the consequence of certain lexico-grammatical choices. On the other hand, the identification of the participant-process relation in the source text may be directly associated to the appropriate construction of the generic structure of the target text. In conclusion, the identification of the participant-process relation in texts in English may be considered central to the construction of effective summaries in Spanish.

Keywords: summary, participant-process relation, lexico-grammatical interpretation, generic structure, effectiveness 


\section{Capítulo 1}

\section{INTRODUCCION}

Los procesos de comprensión de textos han sido estudiados desde diferentes ángulos y empleando las herramientas de análisis de diferentes enfoques teóricos. De todos modos, la complejidad de estos procesos justifica abordarlos nuevamente, en especial por las dificultades que se observan en los alumnos que se enfrentan a la tarea de comprender dichos textos.

Educadores en lectura como Kenneth y Yetta Goodman (Y. Goodman 1984; K.Goodman 1996) otorgan un rol central al contexto de los textos ya que éste puede facilitar o frustrar la tarea de lectura. Esto ocurre particularmente a los lectores en L2, quienes tienen menos recursos para resolver los problemas del texto. Si tomamos la idea desarrollada por Vygotsky (1962) acerca del principio de zona de desarrollo próximo los textos pueden cumplir ese rol de andamiaje para el lector de textos en L2.

Wallace (2003:17) sugiere que el lector que aborda un texto en lengua extranjera lo hace con identidad de lector marginal, como si el texto no hubiese sido pensado y escrito para él. 
Pocas veces ostenta igualdad de estatus con el lector de un texto en lengua materna. Esta desventaja puede ser el resultado de factores variados, ya sea lingüísticos o contextuales. Finalmente, no todas las interpretaciones de los textos son igualmente legítimas y algunos lectores se encuentran en una posición más sólida para ofrecer respuestas legítimas. Hay lectores que se encuentran mejor posicionados, por distintas razones, para interpretaciones más exitosas.

Una pregunta que surge al considerar el tema de la interpretación lectora en lengua extranjera es cómo debe analizarse el problema de la lecto-comprensión en una segunda lengua: ¿cómo un problema de lengua o como un problema de lectura (Alderson, 1984). Como respuesta a este interrogante han surgido dos hipótesis: la hipótesis del umbral lingüístico y la hipótesis de la interdependencia lingüística. La primera afirma que es necesario un determinado nivel de conocimiento lingüístico inicial para poder interpretar un texto en lengua extranjera y la segunda sostiene que el rendimiento en comprensión lectora en una segunda lengua está estrechamente relacionado a la competencia en lectura en la lengua materna. Ambas hipótesis parecen explicar, aunque parcialmente, el problema de la comprensión lectora en una lengua extranjera (Bernhardt y Kamil, 1995:15).

Grabe y Stroller (2002:19) establecen que la lectura es fundamentalmente un proceso lingüístico, aunque este aspecto de la lectura a menudo es minimizado. Sin embargo, poco sentido tiene tratar de interpretar un texto sin involucrarse lingüísticamente con él. Si no podemos entender ninguna palabra o estructura, no vamos a entender el texto. El lector de un texto, especialmente el lector en lengua extranjera, no podrá lograr un procesamiento eficiente si no posee los recursos lingüísticos necesarios para poder desarrollar esa eficiencia. 
Ahora bien, si la investigación en lecto-comprensión en L1 es compleja, la situación se complejiza mucho más en contextos en lengua extranjera. Los lectores en L2 a menudo enfrentan los textos con conocimientos lingüísticos muy bajos. La falta de conocimiento gramatical en L2 sugiere que el lector en L2 necesita una base de conocimiento estructural y organización textual para una más efectiva comprensión lectora en L2. (Graber y Stroller, 2002: 43). Tal como establece la hipótesis del umbral lingüístico, los lectores en lengua extranjera necesitan un umbral mínimo de conocimiento de vocabulario y estructuras para poder poner en práctica las estrategias lectoras que pueden emplear en su abordaje de textos en L1. Es decir, es necesario cruzar un determinado umbral lingüístico mínimo para que las habilidades lectoras en L1 puedan ser transferidas al contexto específico en L2 (Alderson, 2000). En palabras de Alderson (1984:4):

una lectura poco efectiva en una lengua extranjera se debe a que no se emplean las estrategias lectoras de la lengua materna en la lengua extranjera. Los buenos lectores en una primera lengua leerán bien en lengua extranjera una vez que hayan alcanzado un umbral lingüístico determinado en la lengua extranjera. (Traducción propia)

Para muchos de nuestros alumnos lectores, entonces, es muy difícil lograr eficiencia en su comprensión (y posterior producción) lectora en forma natural, sin la intervención del docente. Y, si bien es cierto que ese umbral de conocimiento mínimo varía según el lector, el texto y el tema, también es cierto que hay estructuras álgidas que tienen más peso a la hora de la comprensión textual y que, cuando no son interpretadas adecuadamente afectan en mayor grado la comprensión global y por eso, nuestra hipótesis es que esas estructuras deben ser reconocidas e interpretadas con la ayuda del docente.

Sin embargo, también entendemos que es crucial que nuestros alumnos comprendan cómo funciona la gramática en combinación con las palabras y sus contextos para lograr una interpretación eficiente. Es decir, la instrucción en gramática debe funcionar como 
mediadora para llegar a los significados. Más aún, si pensamos en contextos como el nuestro, de alumnos universitarios con muy escaso conocimiento de la lengua extranjera, alumnos que muchas veces arrastran experiencias frustrantes con el idioma, la función de andamiaje que cumple el aprendizaje de cómo funciona la lengua extranjera y su análisis puede aumentar la motivación y mejorar su desempeño en el momento de abordar los textos. Después de todo, el aprendizaje de un idioma es esencialmente el aprendizaje de cómo funciona su gramática para realizar los significados. (Widdowson, 1990:97)

El presente trabajo de análisis de resúmenes en L1 a partir de un texto en L2 busca indagar en aspectos de lecto-comprensión y sus efectos en la posterior producción. El resumen es un género que se crea a partir de ideas desarrolladas en otro texto. Sólo debe contener la información esencial sin perder coherencia ni cohesión. Como toda actividad de escritura, la redacción de un resumen supone la resolución de problemas. Sin embargo, el escritor del resumen debe resolver dos tipos de problemas: por un lado, los de comprensión (en tanto lector, atendiendo al contenido semántico y pragmático del texto fuente); y, por otro, los de producción (en tanto escritor, tratando de recoger la información de la manera más neutra posible).

Según Alvarez Angulo (2005: 255) un gran resumidor debe usar todos los medios que ofrece la léxico-gramática ya que la condensación de información y su reformulación requieren la puesta en marcha de operaciones de alto nivel que suponen dominio de conocimientos lingüísticos y de contenidos. Entiende que en el origen de todo resumen efectivo se encuentra una comprensión adecuada de la información del texto de partida y, coincide con van Dijk (1996[1983]:220) cuando afirma que desde un punto de vista textual el resumen es uno de los medios más directos para comprobar la comprensión de un texto. 
Ahora bien, aunque hay trabajos teóricos acerca de la actividad resumidora, son todavía pocos los trabajos que abarcan de manera exhaustiva un análisis lingüístico de resúmenes en L1 a partir de texto fuente en L2. Nuestra experiencia evaluando resúmenes en español a partir de textos fuente en inglés en instancias de acreditación final de la asignatura Capacitación en Inglés- Nivel 2 indica dificultades por parte de los alumnos para lograr una adecuada interpretación de distintas relaciones en el nivel léxico-gramatical. Como docentes, somos capaces de evaluar la calidad de dichos textos y observar que algunos son más exitosos que otros. Entonces, motivados por un interés pedagógico, intentaremos en este estudio de carácter exploratorio poder responder a por qué algunos textos son más efectivos que otros.

Para ello, analizaremos el procesamiento de ciertas estructuras gramaticales en los diez resúmenes que constituyen nuestro corpus. La efectividad de los resúmenes parece estar ligada al reconocimiento, en el texto fuente que nos ocupa, de determinadas estructuras léxico-gramaticales que resuenan a nivel de registro y género. En otras palabras, el reconocimiento en el texto fuente de determinadas estructuras léxico-gramaticales incide en la efectividad del texto de segundo grado.

Partiendo de la Lingüística Sistémico-Funcional (LSF) ${ }^{1}$, el método de análisis utilizado permitió estudiar los textos del corpus desde una perspectiva léxico-gramatical. Se consideraron luego los textos desde un punto de vista semántico discursivo para poder determinar su efectividad a nivel genérico, es decir como resúmenes del texto original con el fin de establecer la incidencia de la interpretación adecuada o inadecuada de la relación participante-proceso en la efectividad de los textos.

\footnotetext{
${ }^{1}$ En inglés, Systemic Functional Linguistics (SFL). Para la traducción de los términos técnicos empleados por esta teoría, se recurrió a traducciones estándar o ya consensuadas; en el caso de términos de dificultosa traducción, se aclararon a pie de página las razones que motivaron la traducción realizada
} 
Evaluar un texto desde la perspectiva del análisis lingüístico implica la posibilidad de identificar los aspectos más y menos exitosos en dicho texto (Halliday, 1994: xv). La LSF nos permitió no sólo una interpretación de los textos sino también una explicación de cómo los escritores construyeron sus significados de modo que algunos textos resultaran más efectivos que otros. La teoría es a la vez funcional y semántica precisamente porque describe las estructuras gramaticales de una lengua en referencia a significados y funciones. La pregunta es: “¿cómo se expresan estos significados?” (Halliday, 1985: xiiii)

La teoría también nos permitió, a partir del análisis de patrones lingüísticos, ver cómo los distintos haces de significados en los distintos textos construían o intentaban construir según el caso, sus contextos de situación. Por otra parte, para que el texto funcione como una unidad semántica debe tener, además de la variación de registro, una estructura genérica. Registro y Género (Eggins y Martin, 1997:234) pertenecen a distintos niveles de abstracción. El nivel del género es más abstracto. Corresponde al Contexto de Cultura. Sin embargo, tanto el Contexto de Situación (Registro) como el Contexto de Cultura (Género) se realizan a través de los patrones lingüísticos. Entonces, a través de nuestro análisis clausular podemos evaluar los textos y dar respuesta al objetivo más ambicioso de todo análisis gramatical que, en palabras de Halliday, es el siguiente: "el análisis lingüístico puede permitirle a uno decir por qué el texto es, o no es, un texto efectivo según sus propósitos -en qué aspectos fracasa, o es menos exitoso" (Halliday 1985: xv-Xvi) ${ }^{2}$.

Por todo esto, entendemos que el análisis propuesto nos permite establecer una correlación entre la efectividad de los textos meta y la interpretación de ciertas estructuras lingüísticas en el texto fuente. Con este propósito, esta investigación analiza la importancia que la

\footnotetext{
${ }^{2}$ Las versiones en español de todas las citas en el presente trabajo son traducción de la autora.
} 
adecuada interpretación de la relación participante-proceso tiene en la construcción de resúmenes evaluados como efectivos. De este modo, centramos nuestro interés en la interpretación de dicha relación, particularmente en el primer párrafo de los textos meta y puntualmente en su oración tópico como punto de partida para la codificación de significados efectivos en la organización de la información, en la selección del registro y en la estructuración del texto. Nos interesa fundamentalmente el procesamiento de la voz pasiva.

Este trabajo, además, intenta hacer un aporte que pueda contribuir en los contextos educacionales en los que se desarrolla mi actividad como docente. Si podemos probar que existe una relación entre la interpretación de ciertas estructuras gramaticales, en nuestro caso la voz pasiva, en un texto escrito en L2 y la efectividad en la producción de un resumen en L1, utilizaremos los resultados obtenidos para desarrollar intervenciones pedagógicas que faciliten la tarea de comprensión lectora de nuestros alumnos y la posterior producción de textos en L1 a partir de textos fuente en L2.

Como objetivo general de este trabajo, entonces, nos proponemos analizar el efecto que ejerce la adecuada interpretación de la relación participante-proceso del primer párrafo y, más puntualmente, de la oración tópico de un texto fuente en L2 en la reformulación de resúmenes en L1. Como objetivo aplicado, intentaremos contribuir a desarrollar estrategias que permitan la apropiada identificación de la oración tópico para asistir a nuestros alumnos en una efectiva producción del resumen.

Dichos objetivos responden a las preguntas específicas que orientaron esta investigación y que se detallan a continuación: 
I) i) ¿Cómo influye un umbral bajo de conocimiento lingüístico en L2 en la interpretación de la relación participante-proceso? ii) ¿Qué ocurre en el posterior proceso de escritura en L1 cuando no se interpreta adecuadamente la relación participante-proceso en un texto en L2? iii) ¿Cómo afecta la adecuada interpretación de la relación participante-proceso (Sistema de Transitividad) las relaciones a nivel de los Sistemas de Modo/Temple y Tema/Rema?

II) i) ¿Qué relación existe entre la inadecuada interpretación de la relación participanteproceso en la interpretación global de los significados del texto fuente y la efectividad del resumen? ii) ¿En qué aspectos textuales debemos poner énfasis como docentes para ayudar a nuestros alumnos a reformular textos efectivos en L1 a partir de un texto fuente en L2?

A su vez, en base a las características del corpus y nuestra experiencia como evaluadores del texto en cuestión, surgen las siguientes hipótesis como una primera aproximación a los interrogantes de investigación:

I) i) La inapropiada interpretación de la relación participante-proceso refleja un umbral bajo de reconocimiento de ciertas estructuras gramaticales más álgidas. En el caso de nuestro estudio nos interesa en particular ver cómo los escritores procesan la voz pasiva en el primer párrafo y dentro de éste, en la oración tópico. iia) La redacción de resúmenes escritos en L1 a partir de un texto fuente en inglés permite ver rastros de lecto-comprensión. Un buen resumen refleja que los alumnos captaron las ideas principales del texto: actores, procesos, agentes afectados. iib) La inapropiada interpretación de la relación participante-proceso conduce a tratar de imitar formas. Los productores de los textos se obnubilan con las formas, se quedan 
con formas desfiguradas en un nivel léxico-gramatical y no pueden remontar al nivel semántico-discursivo. iii) La inapropiada interpretación de la relación participante-proceso (Sistema de Transitividad) repercute en los Sistemas de Modo/Temple y Tema/Rema.

II) i) La inapropiada interpretación de la relación participante-proceso afecta la comprensión global de los significados del texto fuente y eventualmente resuena a nivel de Registro y Género en el texto meta. ii) La relación participante-proceso y su efecto en los significados textuales puede ser descripta en términos sistémicofuncionales y utilizada con fines pedagógicos para lograr buenos resúmenes en L1 a partir de un texto fuente en L2.

Con respecto a la organización de este trabajo de tesis, el Capítulo 2 presenta y fundamenta el encuadre teórico del estudio: la visión del lenguaje desde una perspectiva semióticosocial y el aporte de la Teoría del Registro y el Género. Adicionalmente, y de manera accesoria, utilizaremos también algunos conceptos de la Perspectiva Funcional de la Oración (Firbas, 1992) que nos parecieron útiles para una contribución de elementos remáticos al presente estudio. Asimismo se reseñan algunos antecedentes de trabajos sobre el género resumen para analizar qué sucede con los patrones lingüísticos cuando el texto es sometido a un proceso de traducción. El Capítulo 3 describe cómo se constituyó el corpus, la metodología utilizada y hace referencia a la contribución de los informantes. El Capítulo 4 informa los resultados del estudio. Finalmente, el Capítulo 5 presenta las conclusiones generales e intenta dar respuesta a las preguntas de investigación planteadas en la presente Introducción. 
Además, este trabajo incluye 5 Apéndices: en el Apéndice 1 se incluye el texto fuente y un análisis sistémico-funcional tripartito del mismo. En el Apéndice 2 se incluyen los diez textos que conforman el Corpus: del 1 al 5 los más efectivos y del 6 al 10 los menos efectivos. En los Apéndices 3, 4 y 5 se incluye el análisis de los Sistemas de Transitividad, Modo/Temple y Tema/Rema de los diez textos respectivamente. 


\section{Capítulo 2}

\section{MARCO TEÓRICO Y ANTECEDENTES DEL TEMA}

\subsection{MARCO TEÓRICO}

El presente trabajo, como ya anticipáramos en nuestra Introducción, se enmarca en el enfoque de la Lingüística Sistémico-Funcional (LSF) propuesta por M.A.K. Halliday en los años 60 y desarrollada en su Introduction to Functional Grammar (1985, 1994, 2004) y en las contribuciones de trabajos como M.A.K. Halliday y R. Hasan (1976); M.A.K. Halliday (1982) M.A.K. Halliday y R. Hasan (1990 [1985]); S. Eggins (1994); J. Martin, C. Matthiesen y C. Painter (1997); G. Thompson (1997); J.R Martin and D. Rose (2003) and J.R. Martin and D. Rose (2008).

La Lingüística Sistémico-Funcional busca desarrollar una teoría del lenguaje como proceso social y una metodología de análisis que permita una descripción detallada y sistemática de 
patrones lingüísticos. La unidad de análisis para dicha descripción de patrones lingüísticos es la cláusula. El análisis léxico-gramatical de las claúsulas nos permite llegar a los significados (nivel semántico-discursivo) del texto. Es decir que, si queremos describir los significados en el texto, debemos concentrarnos en la estructura de la cláusula.

La LSF no es un conjunto de reglas sino un conjunto de recursos para describir, interpretar y construir significados. Su marco conceptual es funcional en tres aspectos diferentes pero relacionados: en su interpretación de 1) los textos; 2) el sistema; 3) los elementos de las estructuras lingüísticas. Está diseñada para dar cuenta de cómo se usa la lengua. (Halliday, 1985:xiii)

Halliday entiende que cada texto se despliega en un contexto de uso. Más aún, explica que son esos usos de la lengua los que han dado forma al sistema:

El lenguaje ha evolucionado para satisfacer las necesidades humanas; y la forma en la que está organizado es funcional con respecto a esas necesidades - no es arbitrario. Una gramática funcional es esencialmente una gramática "natural", en el sentido de que todo en ella puede ser explicado, en última instancia, en referencia a cómo se usa la lengua. (Halliday, 1985: xiii)

Por otra parte, la teoría sistémica es una teoría del significado como elección por la cual una lengua, como cualquier otro sistema semiótico, es interpretada como redes de opciones. En una gramática funcional, el lenguaje es interpretado como un sistema de opciones acompañado por formas que realizan esos significados. De modo que las formas son un medio para alcanzar un fin: significar. Por eso, la teoría nos permite analizar nuestro corpus y evaluarlo desde la importancia de no confundir forma con significado. El lenguaje, 
entonces, es un sistema semántico, el sistema completo de significados de una lengua, expresado por su gramática y su vocabulario.

El enfoque funcional permite la interpretación de las formas lingüísticas. Sin embargo, no es posible aislar un símbolo ${ }^{3}$ y obtener su significado; el significado está en las palabras como un todo integrado. Cada "sistema" de opciones hace su contribución a la forma. La elección de un ítem en particular puede tener un significado; su lugar en la cadena sintagmática, otro; su combinación con otros ítems otro significado y su organización interna aún otro significado. En los textos de nuestro corpus, entonces, debemos evaluar la selección de las formas en función de los significados que deben realizar en el texto.

La gramática es al mismo tiempo una gramática del sistema y una gramática del texto. Para el enfoque, no puede entenderse uno sin el otro. De poco sirve una teoría sofisticada del sistema si no puede dar cuenta de cómo ese sistema genera textos; tampoco sirve explicar el texto si no se lo puede relacionar con el sistema que le subyace. Es decir, tanto el sistema como el texto deben ser el foco de atención. Es este enfoque el que permite comparar un texto con otro o un determinado texto con lo que pudo haber sido y no fue. Por eso, es este enfoque el que nos puede permitir evaluar por qué algunos de los textos de nuestro corpus son más exitosos que otros.

\footnotetext{
${ }^{3}$ Se puede consultar la dicotomía a la que hace referencia Widdowson $(1984,1990,2007)$ entre símbolo vs índice
} 


\subsubsection{EI lenguaje en una perspectiva semiótico-social}

El enfoque sistémico entiende el lenguaje desde una perspectiva semiótico-social. El concepto de "semiótica" deriva del concepto de signo. La semiótica ha sido definida tradicionalmente como el estudio general de los signos. Sin embargo, el signo ha sido visto como algo aislado, en una concepción atomística del término. Halliday, en cambio, prefiere considerar a la semiótica como el estudio de sistemas de signos, es decir, el estudio del significado en su sentido más general. Vista de este modo, la lingüística es un tipo de semiótica. Tal vez la más importante pero tan sólo una forma de significar (Halliday and Hasan, (1990 [1985]:4).

Lo que hace del lenguaje el más sofisticado de los sistemas semióticos es que otros sistemas semióticos pueden por lo general ser expresados por medio del lenguaje. Como todo sistema semiótico, los sistemas lingüísticos son sistemas que permiten construir significados. La construcción de esos significados es posible mediante el ordenamiento del mundo de dos formas: contenido y expresión. (Eggins, 1994:19)

Por un lado, el plano del contenido está ordenado por el sistema lingüístico de acuerdo a convenciones establecidas culturalmente. Cada sistema semiótico construye la realidad a través de las oposiciones que codifica. Por lo tanto, no todas las lenguas ordenarán la experiencia del mismo modo. La teoría semiótica demuestra que el mundo no es una realidad absoluta que pueda ser etiquetada de una única forma. 
Además, los signos lingüísticos ordenan el mundo a partir del plano de la expresión. De modo que de todos los sonidos posibles que somos fisiológicamente capaces de producir, cada lenguaje reconoce los suyos como significativamente diferentes. Dicho de otro modo, el inventario de sonidos significativos variará de lenguaje en lenguaje.

En el lenguaje, los sistemas de elección se dan a nivel lexical y a nivel gramatical (mediante el ordenamiento de los elementos gramaticales en estructuras). A su vez, esas estructuras se realizarán en palabras y éstas a su vez en sonidos. De modo que en el lenguaje debemos reconocer tres estratos: dos de construcción de significado o de contenido (uno superior semántico-discursivo y uno intermedio léxico-gramatical) y uno de expresión (fonológico/grafológico).

El modelo de lenguaje como sistema semiótico explicado es el que muestra la siguiente figura:

\begin{tabular}{|l|l|l|}
\hline \multirow{5}{*}{ CONTENIDO } & Nombres Populares/Familiares & Términos técnicos \\
& significados & (semática-discursiva) \\
\cline { 2 - 3 } & Formulaciones & Léxico-gramática \\
& (palabras y estructuras) & Fonología/ \\
\hline EXPRESION & Sonidos/ & grafología \\
\hline
\end{tabular}

Niveles de estratos de la lengua (Esquema utilizado por Eggins, 1994:21) 
Entonces, la noción de sistema semiótico implica entender el lenguaje como un sistema de opciones. El proceso de lenguaje en uso es un proceso de construcción de significados por elección. Al hacer una elección en el sistema lingüístico, lo que alguien dice o escribe debe ser interpretado frente a lo que pudo haberse dicho o escrito en ese contexto y no fue. Es decir que las elecciones lingüísticas reales deben relacionarse con las elecciones lingüísticas potenciales.

Además, como ya dijimos, en el enfoque que nos ocupa el lenguaje es visto como un hecho social. Surge en la vida del individuo mediante un intercambio continuo de significados con otros significantes. Un niño crea, primero, su lengua infantil, luego su lengua materna en interacción con quienes lo rodean. Al mismo tiempo, el niño aprende otras cosas mediante el lenguaje, formándose una imagen de la realidad a su alrededor y en su interior. La lengua es el canal principal por el que el niño aprende los modelos de vida, a actuar como miembro de una sociedad y a adoptar sus creencias y sus valores. En ese sentido el lenguaje es producto del proceso social (Halliday, 1982:9).

En ese proceso social, la construcción de la realidad es inseparable de la construcción del sistema semántico en el que se halla codificada dicha realidad. En el aspecto más concreto, significa que las personas se hablan unas a otras. El intercambio de significados se produce en contextos interpersonales de uno $\mathrm{u}$ otro tipo. Los contextos en que se intercambian significados no están desprovistos de valor social; un contexto verbal es en sí una construcción semiótica, con una forma (derivada de una cultura) que capacita a los participantes para predecir características del registro prevaleciente $\mathrm{y}$, por tanto, para comprenderse los unos a los otros. 
Entonces, lenguaje como semiótica social significa interpretar el lenguaje dentro de un contexto sociocultural. En dicho contexto, la propia cultura se interpreta en términos semióticos, como un sistema de información. En este sentido, el lenguaje consiste en intercambio de significados en diferentes contextos interpersonales. Mediante sus actos de significación la gente representa la estructura social afirmando sus propias posiciones y sus propios papeles, estableciendo y transmitiendo sistemas comunes de valores $\mathrm{y}$ conocimientos.

\subsubsection{Texto y Contexto}

Halliday define al texto como:

... lengua que es funcional. Por funcional, simplemente queremos decir lengua que está haciendo algo en un contexto (...) De modo que, cualquier instancia de lengua que cumple una función determinada en un contexto, la llamaremos texto. Puede ser oral o escrita, o cualquier otra forma de expresión... (Halliday y Hasan, (1990[1985]:10)

Además, para Halliday el texto es una unidad de significado y es, al mismo tiempo, proceso y producto. Es proceso en el sentido de ser un proceso continuo de selección semántica, un movimiento a través de redes de selecciones de significados potenciales donde cada selección constituye el punto de partida o marco para el conjunto de selecciones siguientes. Esta idea de marco para el conjunto de selecciones siguientes es particularmente pertinente para el análisis de los textos de nuestro corpus, en algunos de los cuales pareciera que los escritores ignoran ese marco de elecciones realizadas y comienzan cada cláusula desde un nuevo punto de partida. Asimismo, el texto es producto ya que puede ser estudiado como 
un todo, el resultado de una construcción que puede ser representada en términos sistémicos.

Halliday (1985: xxii) explica que la distinción proceso/producto es importante porque nos remite al hecho de que el texto escrito es visto básicamente como producto. Es visto como proceso, nos dice, sólo desde el punto de vista del escritor. Sin embargo, como lectores o analistas podemos focalizarnos en las actividades que condujeron a su construcción y entender ese proceso de construcción de significados. Siguiendo a Halliday, en nuestro trabajo como analistas podemos recorrer el proceso de construcción de significados de los textos de nuestro corpus y evaluar los distintos grados de efectividad de los mismos. En otras palabras, si pretendemos entender por qué algunos textos de nuestro corpus son más efectivos que otros debemos focalizarnos en las actividades que condujeron a su producción, es decir ver el texto como proceso.

Por otro lado, un texto debe entenderse al mismo tiempo como objeto de estudio y como una instancia de significado social en un contexto particular. Es una corriente continua de selecciones, cada opción en su entorno paradigmático de lo que pudo haberse significado y no se significó. Ahora bien, el Contexto de Situación, es decir, el contexto en el que se despliega el texto, está encapsulado en el texto a través de una relación sistemática entre el entorno social por un lado y la organización funcional del lenguaje, por otro. Si consideramos tanto al texto como al contexto diferentes formas de significar, podemos ir de uno a otro y descubrir relaciones entre ambos. (Halliday y Hasan, (1990 [1985]:11-12) 


\subsubsection{El Contexto de Situación y de Cultura: antecedentes}

Es fácil ver que los usos de la lengua varían según el Contexto de Situación en que se desarrollan; es decir, algunos aspectos del contexto influyen en las elecciones lingüísticas y a los lingüistas sistémicos les interesa explorar cómo el texto refleja el contexto. Uno de los primeros investigadores en estudiar el tema fue el antropólogo Branislaw Malinowski (1946 [1923], 1935). Para transcribir la vida diaria y los hechos de los habitantes de las islas Trobriand (en el Pacífico Sur), el antropólogo observó que era imposible transmitir el sentido literal, palabra por palabra del lenguaje de origen al inglés.

Para hacer los textos comprensibles al lector inglés, Malinowsky optó por incluir comentarios explicativos. La función de estos comentarios era ubicar el texto en su entorno real. Malinowsky necesitaba referirse al contexto no en el sentido de las palabras y oraciones vecinas a la palabra u oración que se estuviera estudiando sino al entorno total, verbal y de la situación en que se emitía. Así, utilizó en 1923 por primera vez el término Contexto de Situación para referirse al entorno del texto.

Sin embargo, Malinowsky observó que era necesario considerar otro contexto además del entorno inmediato. Para una descripción lingüística adecuada era necesario dar información del contexto cultural en su totalidad. Observó que en cualquier tipo de interacción, de intercambio conversacional estaban presentes no sólo indicios del entorno inmediato sino toda una historia cultural detrás de los participantes y del tipo de prácticas que ellos intercambian. A este otro contexto lo llamó Contexto de Cultura. Ambos contextos son necesarios para la comprensión del texto. 
Si bien en un principio Malinowsky creyó que el concepto de Contexto de Situación se necesitaba sólo para el estudio de lenguajes "primitivos" de culturas que carecían de lenguaje escrito, años más tarde llegaría a la conclusión de que la restricción no era tal. Refiriéndose a su trabajo anterior escribió:

Opuse el habla civilizada y científica al habla primitiva, y desarrollé mi argumento como si los usos teóricos de las palabras en la escritura filosófica y científica moderna estuvieran completamente separados de sus fuentes pragmáticas. Este fue un error, y ciertamente un grave error. Entre el uso primitivo de las palabras y el más abstracto y teórico existe sólo una diferencia de grado. En última instancia todo el significado de las palabras deriva de la experiencia personal. (Malinowsky, 1935, vol. 2, p.58)

Malinowsky no era lingüista sino etnógrafo y su interés principal era explicar la cultura; sólo que en el curso de su trabajo se interesó por el lenguaje como objeto de estudio en sí mismo. En la Universidad de Londres, un colega suyo, Firth, desarrolló una teoría más general de significados-en-contexto. Firth estaba interesado en el entorno cultural del lenguaje y retomó la idea de Contexto de Situación de Malinowsky que se transformó en el punto de partida de su propia teoría lingüística. Para Firth toda lingüística es estudio del significado y todo significado es función en un contexto. (Halliday y Hasan, (1990 [1985]:8)

En cierto sentido, Firth encontró que la idea de Contexto de Situación de Malinowsky no se ajustaba bien a los propósitos de una teoría lingüística porque no era lo suficientemente general. Malinowsky se había circunscripto al estudio de determinados textos y por lo tanto su noción de Contexto de Situación fue concebida para explicar los significados de 
determinadas instancias de uso de la lengua. Firth necesitaba un concepto de contexto que pudiera ajustarse a una teoría lingüística general. Por lo tanto, en su descripción de Contexto de Situación desarrollada en 1950, Firth consideró:

- los Participantes en la situación: las personas y personalidades; aproximadamente lo que para los sociólogos constituyen estatus y roles de los participantes

- la Acción de los participantes: lo que están haciendo, incluyendo acción verbal y no verbal

- otros Componentes Relevantes de la Situación: los objetos y eventos del entorno, en tanto y en cuanto tengan alguna influencia en la situación

- los Efectos de la acción verbal: qué cambios se produjeron a partir de lo que los participantes en la situación tenían para decir

Firth explicó que a partir de la descripción de un Contexto de Situación es posible predecir el lenguaje que se usará. Entendía que aprender a usar el lenguaje es un proceso de:

... aprender a decir lo que el otro participante espera que digamos según las circunstancias (...) Una vez que alguien nos habla, nos encontramos en un contexto relativamente restringido y ya no tenemos libertad para decir lo que nos plazca $(1935 / 57: 28)$

La posibilidad de predecir también actúa en sentido inverso: dado un determinado ejemplo de uso de la lengua, podemos hacer predicciones acerca del contexto en el cual dicha instancia se produjo. 


\subsubsection{El Contexto de Situación en LSF y su relación con los significados en el texto}

M.A.K. Halliday (1985) ha sugerido que hay tres componentes en cualquier Contexto de Situación que influyen y se ven reflejados en las elecciones lingüísticas del texto:

1. El CAMPO DEL DISCURSO: refiere a lo que está pasando, la naturaleza de la acción social que tiene lugar, en qué están involucrados los participantes

2. El TENOR DEL DISCURSO: refiere a quién participa, la naturaleza de los participantes, sus estatus y roles: los tipos de relaciones entre los participantes, incluyendo relaciones temporarias y permanentes, los tipos de roles de habla que adoptan y el conjunto de relaciones socialmente significativas en las que están involucrados.

3. El MODO/MEDIO DEL DISCURSO ${ }^{4}$ : refiere al rol que cumple el lenguaje, qué esperan los participantes que el lenguaje haga para ellos en esa situación: la organización simbólica del texto, su función en el contexto, incluyendo el canal (si se trata de lenguaje escrito, oral o una combinación de los dos), la estructura retórica. (Halliday y Hasan, (1990 [1985]:12)

Sin embargo, Halliday no sólo sugiere que las variables de Campo, Tenor y Modo/Medio tienen influencia en el uso de la lengua. Halliday además explica que: 1) cada una de las variables del Contexto de Situación tiene una relación predecible y sistemática con patrones léxico-gramaticales; y que 2) el Campo, el Tenor y el Modo/Medio son las variables del contexto que importan por su correlato a nivel de los tres significados que el lenguaje está estructurado para construir: experienciales, interpersonales y textuales. Entonces, en todos

\footnotetext{
${ }^{4}$ Montemayor Borsinger, A. (2004) diferencia entre Modo/Medio y Modo/Temple para traducir los términos "Mode" y "Mood" respectivamente, que hasta ahora han sido traducidos ambos como "Modo" aunque refieren a distintos conceptos de la teoría sistémica. Utilizamos su terminología.
} 
los usos que hacemos de la lengua (que son ilimitados y cambiantes) la lengua está diseñada para cumplir tres funciones principales: una función para referirse a la experiencia, una función para crear relaciones interpersonales y una función para organizar la información. (Eggins, 1994:78)

Podemos concluir entonces que, según Halliday:

- el Campo de un texto puede asociarse a la realización de significados experienciales; estos significados experienciales, a su vez, se realizan a través de patrones gramaticales del Sistema de Transitividad;

- el Tenor de un texto puede asociarse a la realización de significados interpersonales; estos significados interpersonales, a su vez, se realizan a través de patrones gramaticales del Sistema de Modo/Temple.

- el Modo/Medio de un texto puede asociarse a la realización de significados textuales; estos significados textuales, a su vez, se realizan a través de patrones gramaticales del Sistema de Tema.

Estas relaciones quedan representadas en la siguiente figura:

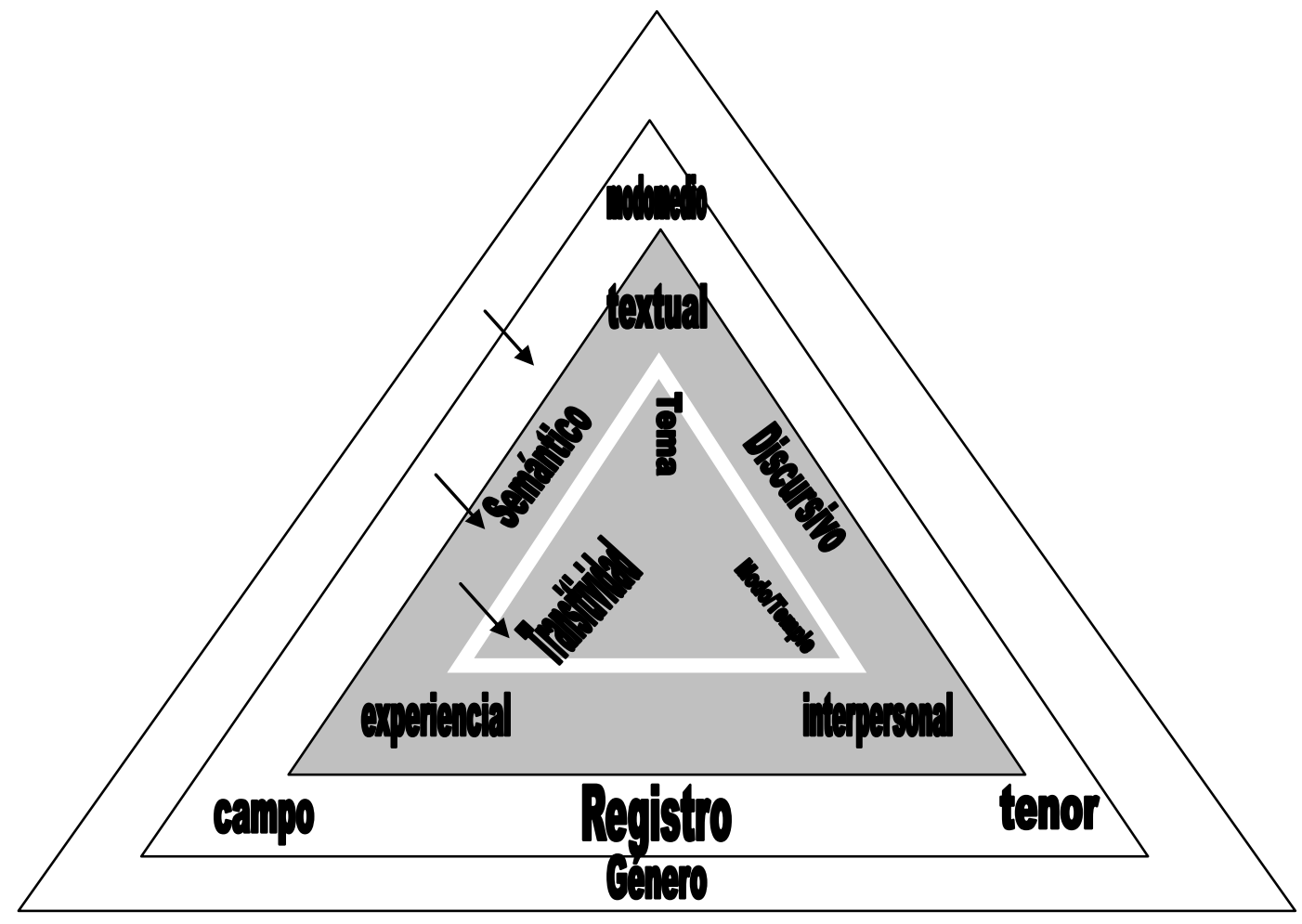


Contexto en relación a los niveles semántico-discursivo y léxico-gramatical (Esquema utilizado por Eggins, 1994:79)

Precisamente esta complejidad semántica de realización de tres significados conjuntos en las unidades lingüísticas es posible porque el lenguaje es, como ya dijimos, un sistema semiótico: un sistema de código convencionalizado organizado como conjuntos de opciones donde cada opción en el sistema adquiere su significado en contraposición a las selecciones que pudieron hacerse y no fueron. La interpretación semiótica del sistema lingüístico nos permite considerar lo apropiado o inapropiado de las selecciones lingüísticas en relación a sus contextos de uso.

Los tres significados deben interpretarse como funciones pero no en el sentido de usos del lenguaje sino como componentes funcionales del sistema semántico o metafunciones, que son los modos de significación presentes en toda utilización del lenguaje en todo contexto social. Vale decir que un texto es el resultado de tres vetas de significados que se entrelazan y se realizan en determinadas estructuras lexico-gramaticales.

Como ya dijimos, la unidad de análisis léxico-gramatical que selecciona Halliday (1985:58) es la cláusula (cf. p.10), que realiza los tres significados en forma simultánea: como representación (expresión de significados experienciales), como intercambio (expresión de significados interpersonales) y como mensaje (expresión de significados textuales). Eggins explica que con la identificación de unidades léxico-gramaticales desde una perspectiva funcional lo que se trata de hacer es “...identificar las unidades que poseen diferentes tipos de patrones lingüísticos. Por patrones entendemos diferentes organizaciones estructurales, o diferentes configuraciones estructurales. (Eggins, 1994:129). 
La relación entre el Contexto de Situación y los significados en el texto se puede resumir de la siguiente forma:

\begin{tabular}{|l|l|l|}
\hline \multicolumn{1}{|c|}{ SITUACIÓN } & \multicolumn{1}{|c|}{ TEXTO } \\
Componente del contexto & realizado por & $\begin{array}{c}\text { Componente funcional del } \\
\text { sistema semántico }\end{array}$ \\
\hline $\begin{array}{l}\text { Campo del discurso (lo que está } \\
\text { pasando) }\end{array}$ & & Significados experienciales \\
\hline $\begin{array}{l}\text { Tenor del discurso (quiénes están } \\
\text { involucrados) }\end{array}$ & & Significados interpersonales \\
\hline $\begin{array}{l}\text { Modo/Medio del discurso (rol que } \\
\text { cumple el lenguaje) }\end{array}$ & & \\
\hline
\end{tabular}

Relación texto-Contexto de Situación (Esquema utilizado por Halliday y Hasan, (1990 [1985]:26)

En el caso de nuestro estudio, el análisis clausular tanto del texto fuente como de los textos de nuestro corpus resultó sin duda apropiado para nuestro objetivo. Nos permitió evaluar cómo la interpretación de determinadas estructuras lingüísticas particularmente álgidas influyó, en primer lugar, en la comprensión global del texto y, en segundo lugar, en la posterior producción del texto de segundo grado. Patrones estructurales menos efectivos a nivel de Sistema de Transitividad resonaban en significados experienciales menos coherentes. Esa menor efectividad repercutía en los Sistemas de Modo/Temple y Tema/Rema afectando los significados interpersonales y textuales y finalmente, en los componentes del Contexto de Situación: Campo, Tenor y Modo/Medio.

Hasta aquí hemos explicado el Contexto de Situación y sus antecedentes para la LSF. En la siguiente sección, nos referiremos al aporte de la Teoría del Registro y el Género. 


\subsubsection{La Teoría del Registro y el Género}

La Teoría del Registro y el Género que se encuadra en el marco de la Lingüística Sistémico-Funcional es una teoría de variación funcional que intenta teorizar acerca de en qué los discursos o textos se parecen y se diferencian entre sí y por qué. Esta tarea implica el análisis de textos en sus contextos de situación y de cultura. Dicho análisis permite describir y explicar los significados en los textos a partir de los patrones lingüísticos seleccionados (palabras y estructuras) y evaluar lo apropiado o inapropiado de dichas selecciones dados determinados contextos de situación y de cultura. (Eggins y Martin, 1997: 230 y sig.)

Para poder lograr esos objetivos, el primer paso consiste en describir los patrones lingüísticos de los textos que son los que crean un determinado efecto. Las diferencias lingüísticas están relacionadas con el contexto inmediato de situación. La división del texto en sus cláusulas constitutivas nos permite ver cómo los significados experienciales e interpersonales están habilitados por los significados textuales; dichos significados, a la vez construyen y son construidos por las variables de registro (Campo, Tenor y Modo/Medio). Es decir, que desde la perspectiva del contexto, determinados tipos de Campo, Tenor y Modo/Medio condicionan determinados significados experienciales, interpersonales y textuales; y, desde la perspectiva de la lengua, determinadas elecciones de significados experienciales, interpersonales y textuales construyen diferentes tipos de Campo, Tenor y Modo/Medio. Entonces, si cada texto, a través de las elecciones lingüísticas, refleja influencias del contexto en que se genera, el concepto de registro es una explicación teórica de la observación de que la lengua se usa de diferente manera en distintas situaciones. 
Pero además, como ya adelantamos en nuestra introducción, para que el texto funcione como una unidad semántica debe tener, además de la variación de registro, una estructura genérica, que corresponde al Contexto de Cultura. En un texto determinado hacemos deducciones lingüísticas interpretando el lenguaje de modo tal que tiene sentido dentro de una cultura dada.

El concepto de género para la Teoría del Registro y el Género se basa en las ideas del teórico ruso Bajtín:

Cada enunciado separado es, por supuesto, individual, pero cada esfera del uso de la lengua elabora sus tipos relativamente estables de enunciados, a los que denominamos géneros discursivos. La riqueza y diversidad de los géneros discursivos es inmensa, porque las posibilidades de la actividad humana son inagotables y porque en cada esfera de la praxis existe todo un repertorio de géneros discursivos que se diferencia y crece a medida que se desarrolla y se complica la esfera misma (...) (Bajtin 1979: 248)

Luego, los lingüistas de la Teoría del Registro y el Género definen los géneros funcionalmente, en términos de propósito (Eggins y Martin, 1997:236). Así, los diferentes géneros son diferentes formas de usar la lengua para alcanzar diferentes tareas establecidas culturalmente, y textos de diferentes géneros son textos que alcanzan diferentes propósitos en la cultura. Por ejemplo, en el caso de los textos meta de nuestro corpus, uno de los propósitos básicos del género -resumen en L1 de un texto fuente escrito en L2- debe ser parafrasear en un texto meta los significados del texto fuente a partir de un cambio de código y actividad resuntiva efectivos.

Martin da dos definiciones de género: 1) "un género es una actividad que se desarrolla en etapas, dirigida hacia la obtención de un objetivo, con un propósito determinado y de la 
cual los hablantes participan como miembros de una cultura" (1984: 25); la segunda definición es algo menos técnica: 2) "los géneros expresan cómo se hacen las cosas cuando se usa el lenguaje para lograrlas" (1985b: 248).

Luego, de acuerdo a la manera en que diferentes tipos de significados co-ocurren en el texto, reconocemos patrones típicos de los distintos géneros; también reconocemos géneros a través de las secuencias de etapas en las que se despliega un texto determinado. La teoría del género sugiere que los textos que cumplen diferentes propósitos se despliegan de diferente forma. Entonces, una Teoría del Registro y el Género debe permitir predecir significados (probables) en un contexto dado y dado un texto deducir su contexto inmediato de producción y su identidad genérica; es decir, qué tarea cumple ese texto en la cultura (Eggins y Martin, 1997:236).

Entonces, mientras el texto es la expresión verbal de una actividad social, el género es el lenguaje cumpliendo la función apropiada al tipo de acontecimiento social. Es un marco de referencia general adaptado a los diferentes contextos de situación en las que esas interacciones son usadas. Las dos dimensiones fundamentales en las que el lenguaje realiza el género son: a) estructura esquemática; b) patrones de realización (Eggins, 1994:36).

Por un lado, la convención social ha establecido que los propósitos genéricos se alcanzan a través de una serie de etapas. Estas etapas se denominan la estructura esquemática de un género. Según Martin (1985b: 251) "la estructura esquemática representa la contribución positiva que el género hace al texto: una manera de pasar de A a B del modo en que una cultura determinada logra lo que el género en cuestión está tratando de hacer en esa cultura". Cada una de las etapas del género contribuye a lograr el propósito general que debe conseguirse para que el género tenga éxito. 
Por otro lado, las distintas etapas de estructura esquemática corresponden a patrones de realización lingüísticos, lo que constituye el procedimiento analítico central en el análisis genérico. Los límites entre las distintas etapas y la función de cada una de ellas se expresa precisamente a través de las elecciones lingüísticas específicas de cada texto (a nivel semántico-discursivo y léxico gramatical). Se deben analizar las diferentes elecciones léxico-gramaticales de los participantes de acuerdo con los propósitos que se quieren lograr. En otras palabras, se debe evaluar si las elecciones lingüísticas son efectivas.

Cuando describimos la estructura esquemática de un género, lo que describimos es su estructura constitutiva, es decir, de partes. En términos generales, las etapas constitutivas de un género son: un Comienzo, un Medio y un Final. Sin embargo, si queremos ver cómo las distintas partes se relacionan entre sí y contribuyen al propósito general del texto, es conveniente utilizar etiquetajes funcionales y no formales. Los etiquetajes funcionales nos permiten ver cómo cada parte constitutiva cumple una función relativa al todo en la instancia de análisis específica. En nuestras conclusiones (Cf. Capítulo 5) mostraremos cómo funcionan las distintas etapas genéricas en un texto efectivo y si, por el contrario, es posible identificar esas etapas en un texto menos efectivo.

Ahora bien, mientras hay elementos de la estructura esquemática que son obligatorios, que son los que definen el género, hay otros que son opcionales. Por lo tanto, un género se define en términos de los elementos obligatorios de su estructura esquemática y las variantes de un género son aquellos textos en los cuales se realizan los elementos de estructura esquemática obligatorios y, tal vez también, algunos de los opcionales. Para los textos de nuestro corpus, específicamente, no significa que los resúmenes más efectivos tengan que desplegarse exactamente del mismo modo, sino más bien que todos ellos 
incluyan aquellos elementos obligatorios que son esenciales para ser reconocidos como variantes del género en cuestión.

En este sentido, R. Hasan (Halliday and Hasan (1990 [1985]:63) distingue entre potencial de estructura genérica de un género en particular y estructura genérica real de un texto en particular. Si entendemos que los géneros son distintas maneras de usar la lengua, es de esperar que los hablantes utilicen distintas elecciones léxico-gramaticales de acuerdo con sus propósitos; es decir, con la variación de géneros. En segundo lugar, si un género está constituido por diferentes etapas con diferentes funciones también variarán los patrones de realización a través de las etapas de un mismo género.

De modo que, cuando describimos el propósito global de la interacción y las etapas para lograr dicho propósito (género) estamos relacionando el texto con un nivel más abstracto de contexto: el Contexto de Cultura. Interpretamos la lengua de modo que tenga sentido en nuestra cultura y así deducimos el género del texto, i.e., el tipo de actividad en etapas y con propósito determinado en la cual se usa la lengua. El proceso de realización de género está mediado, a su vez, por la realización a nivel de registro.

Realización es la relación que existe, para la LSF, entre cada uno de los estratos de lengua y el contexto social. Martin y Rose (2003) describen el concepto de la siguiente forma:

Realización es un tipo de recodificación (...) Otra forma de interpretar la idea es como simbolización (...) Simbolización es un aspecto importante de la realización, ya que la gramática simboliza y codifica el discurso al mismo tiempo, de la misma manera en que el discurso simboliza y codifica la actividad social. (Martin y Rose, 2003: 5) 
Halliday describió el contexto social como "el medio total en el que un texto se despliega" (Halliday, 1982) partiendo de Firth y Malinowsky para quienes el significado de una palabra, frase u oración es el cambio efectivo que surge en el contexto de que es parte. Partiendo de la cultura, la misma se pone de manifiesto en cada situación de interacción y esa interacción a su vez se manifiesta verbalmente cuando el texto se despliega, es decir como texto en contexto. Esta teoría de texto en contexto puede representarse de la siguiente manera:

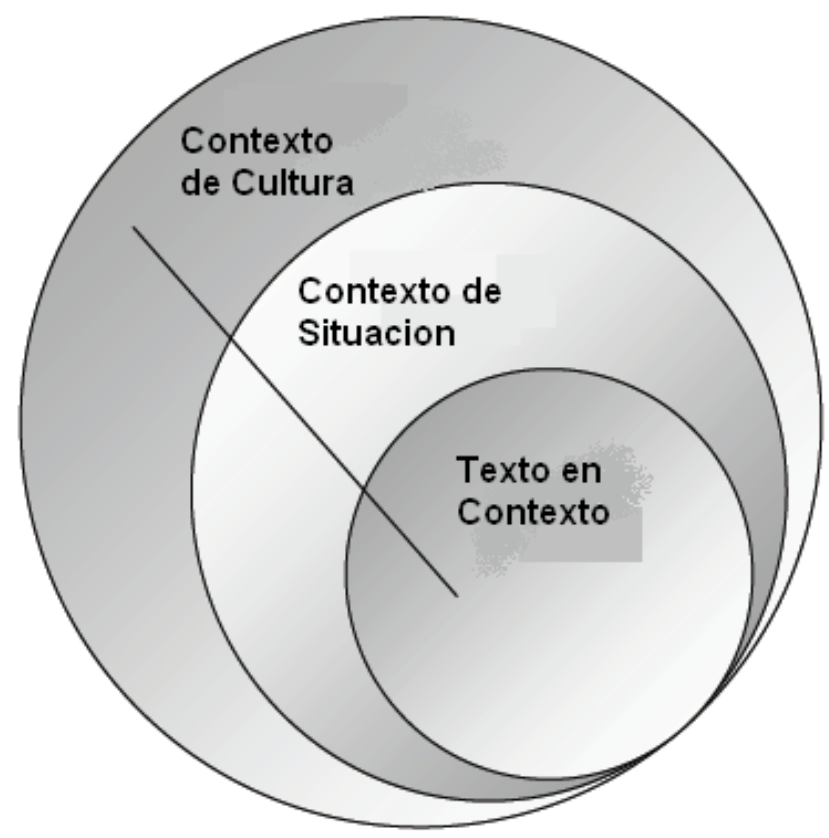

Relación entre los estratos de lengua y contexto (Esquema utilizado por Martin y Rose, 2008:9)

Por lo tanto, aunque para determinar la mucha o poca efectividad de un texto es necesario identificar su estructura esquemática, esto no será posible sin un análisis de las realizaciones de cada elemento de esa estructura esquemática. Son las elecciones léxicas y 
gramaticales las que deberemos analizar si tenemos presente que es a través del lenguaje como se realizan los géneros.

Por otro lado, el escritor debe darle suficientes indicios de registro y género al lector para que pueda encontrarle sentido al texto. Por supuesto, el escritor debe conocer la lengua pero también debe poder controlar los sistemas de registro y género que, obviamente, necesitan de la lengua para poder realizarse. Los géneros crean significados dando formas determinadas a las combinaciones posibles de las variables de registro, combinaciones que cambian de acuerdo a los distintos propósitos comunicativos que se persigan.

En el caso particular del corpus que nos ocupa, y según una de nuestras hipótesis (hipótesis Iiii) en aquellos textos en los que las relaciones en el Sistema de Transitividad sean mejor interpretadas, no sólo los significados experienciales se construirán de manera coherente sino también los significados interpersonales y textuales (Sistemas de Modo/Temple y Tema/Rema). Por lo tanto, la realización de Campo, Tenor y Modo/Medio será efectiva y, al mismo tiempo, se podrán reconocer las diferentes etapas de una estructura esquemática global genérica que responderá al texto meta esperado. Por el contrario, aquellos textos en que la menos exitosa interpretación de la relación participante-proceso no le permite a los escritores construir haces de significados en forma efectiva carecerán de coherencia situacional y genérica. En sentido estricto, no podrían considerarse "textos” (hipótesis IIi).

Entonces, el marco teórico de la Lingüística Sistémico Funcional, junto con la Teoría del Registro y el Género, permitirán describir las elecciones léxicas en los textos meta y también explicar, al menos parcialmente, porqué algunos resúmenes se evalúan como más efectivos que otros. 
El marco teórico hasta aquí presentado de la Lingüística Sistémico Funcional y la Teoría del Registro y el Género constituyen el enfoque central utilizado para analizar y evaluar la efectividad de los textos de nuestro corpus. Pasamos ahora a explicar por qué adicionalmente utilizaremos algunas ideas sobre la Perspectiva Funcional de la Oración.

\subsubsection{La relación participante-proceso y la Perspectiva Funcional de la Oración}

Vilem Mathesius, fundador del Círculo Lingüístico de Praga en 1926 planteó que el orden de las palabras era un sistema regido por principios que no eran únicamente gramaticales. Introdujo la noción de una Perspectiva Funcional de la Oración que ordena sus elementos en Tema y Rema. Para Mathesius, los principios más importantes que rigen el ordenamiento de las palabras son: 1) el principio gramatical que hace que la posición de un elemento en la oración esté determinada por su función sintáctica; 2) la Perspectiva Funcional de la Oración que implica un orden de Tema (lo que es conocido, obvio en el contexto y a partir de lo cual parte el emisor)-Transición-Rema; 3) el principio enfático que supone ordenar las palabras para llamar la atención del que recibe el mensaje (Montemayor-Borsinger, 2009:41).

Firbas (1992), que estaba interesado en distintos ordenamientos de las palabras, se centró en la noción de "Perspectiva Funcional de la Oración" de Mathesius, concepto que nos interesa para dar sustento a algunas de nuestras hipótesis (Iiii y IIi). Firbas entiende que una PFO puede mostrar cómo se distribuye la información en el acto de comunicar. En particular, se puede ver que la estructura de la oración, para cumplir su propósito, siempre contiene un elemento que hace culminar la comunicación y hacia el cual la oración se orienta. 
Además, Firbas (1992:7-8) introdujo la noción de "Dinamismo Comunicativo", muy relacionada con los conceptos de Tema y Rema, ya que el dinamismo comunicativo concierne al modo en que una expresión contribuye al proceso comunicativo, característica que se encuentra en distintos grados en todo elemento lingüístico. Hay un elemento hacia el cual se orienta la oración y que da la máxima contribución al desarrollo del mensaje y a su culminación. Este es el elemento que muestra el grado más alto de Dinamismo Comunicativo y constituye el Rema. Si bien para Firbas el criterio de interpretación de Tema/Rema es informacional y no posicional, este autor observa una tendencia general en los elementos de más alto grado de dinamismo comunicativo de ubicarse hacia el final de la oración.

Para Firbas el concepto de Rema es interesante puesto que se trata del elemento que completa el desarrollo de la comunicación y el que posee el más alto grado de "Dinamismo Comunicativo". En este sentido, el Rema contendría la información más importante. Todos los Remas de un texto, dice Firbas, constituyen su capa remática y es interesante ver la relación que existe entre la capa remática y la capa temática de un texto. ${ }^{5} \mathrm{Si}$, el desarrollo del texto se construye a partir de la Perspectiva Funcional de la Oración y de la relación entre las capas temáticas y remáticas es de esperar que la interpretación de la relación participante-proceso en el texto fuente afecte en forma más o menos exitosa según sea el caso los patrones de Tema/ Rema y el desarrollo general del texto meta. (hipótesis Iiii)

En lo que a nuestro análisis concierne, nos interesa observar cómo las selecciones de contenido experiencial en Tema (para nosotros, punto de partida del mensaje) de los textos meta repercuten en los patrones de Rema (para nosotros, información nueva; para Firbas, el elemento de más alto grado de Dinamismo Comunicativo) y, eventualmente, en el texto en su conjunto; nos interesa observar cómo varían los grados de efectividad de los textos meta

\footnotetext{
${ }^{5}$ Recordemos que para nuestro enfoque sistémico tomaremos los conceptos en términos hallidayanos; por capa temática entendemos los puntos de partida de las cláusulas y más específicamente la selección de participante en Tema y por capa remática lo que hemos llamado "puntos de llegada", es decir, la culminación de la oración, fundamentalmente la selección de proceso
} 
de acuerdo a: 1) si se seleccionan participantes o procesos en Tema; 2) qué relaciones se establecen entre participantes y procesos; 3) cómo afecta la selección de circunstancias en Tema. Las selecciones experienciales a nivel de Tema en nuestros textos meta, producto de la interpretación de la relación participante-proceso, condicionan las selecciones remáticas donde, y en esto coincidimos con Fries (1994: 234), aparece la información que tiene relación con los contenidos globales y en definitiva con el texto en su totalidad (hipótesis IIi). Por eso observamos que, cuando la información en Rema es confusa, los significados se desdibujan y se hace difícil para el lector procesar la información.

En este sentido, Firbas (1995: 214) dice “... la rematicidad es una de las raisons d'etre más significativas de la oración. El Rema provee la información que completa el desarrollo de la comunicación en la oración y hacia el cual la oración se proyecta." Y, si bien para Firbas el concepto de Rema no está asociado a "punto de llegada" del mensaje, es INFORMACION NUEVA y puede ser Temática en sentido sistémico, nosotros tomaremos el concepto de Rema como la "razón de ser más significativa" de la oración y lo integraremos a las ideas de la LSF, es decir como concepto asociado a lo posicional, es decir, a lo que se dice del punto de partida del mensaje (Tema).

Por eso, en los textos que constituyen nuestro corpus, el contenido experiencial en Tema, a partir del cual despega la relación participante-proceso, tiene consecuencias importantes a nivel global. Una mala interpretación de esa relación, en el caso específico de nuestro análisis asociado al concepto de voz (Activa/Pasiva), repercute en la capa remática y por ende en la coherencia textual en su conjunto. Ya que, como dice J.R. Martin "el Tema (Martin se refiere a textos en inglés, pero para nosotros lo mismo sucede en español) significa más de aquello de lo que se trata el mensaje...” (Martin, 1995:254) 
Por otra parte, Fries (1981) en el marco de un estudio de contenido temático en textos cortos elaboró entre sus hipótesis de trabajo la idea de que si se cambia el contenido experiencial en los Temas de un texto, se cambia la percepción de los lectores acerca del desarrollo del mismo. También Halliday (1993); Martin (1986; 1989; 1992); y Ragan (1987) a partir del estudio de textos individuales y grupos de textos informan sobre la relación entre el contenido experiencial de los Temas de las cláusulas y el efecto en los lectores de los textos examinados.

Como parte de su estudio de contenido experiencial en Tema, Fries (1981) también observó que Tema y Rema responden a diferentes fuerzas y contienen distinta información. Y, en un estudio de inglés escrito concluyó (Fries, 1994:234) que el Rema constituye la parte de la cláusula que el escritor quiere que el lector recuerde y que por lo tanto es de esperar que tenga correlación con los objetivos globales del texto mientras que el contenido temático tendrá más relación con aspectos locales del mensaje transmitido por la cláusula.

Entonces, el concepto de Perspectiva Funcional de la Oración que desarrolla Firbas y la importancia que el lingüista le atribuye a las capas remáticas en los significados globales de los textos nos proporcionan un sustento mayor para entender por qué algunos de los textos de nuestro corpus resultan más efectivos que otros. En este punto, es importante remarcar que nuestro corpus está constituido por resúmenes en español de artículos periodísticos escritos en inglés y en ese sentido nosotros debemos observar qué pasa con las estructuras de Tema/Rema y los patrones y desarrollos temáticos en español a partir de un texto fuente escrito en inglés. Es decir, ver qué sucede en el proceso de traducción que hace que algunos textos sean más efectivos que otros. 
En esta sección hemos hablado del aporte de la Perspectiva Funcional de la Oración a nuestro trabajo. Ahora nos referiremos a los aportes hechos por diferentes autores a la comprensión del género resumen.

\subsection{ANTECEDENTES DEL TEMA: EL RESUMEN COMO GÉNERO}

Nuestro corpus está constituido por resúmenes en español a partir de un texto-fuente en inglés. Por lo tanto, nos interesa referirnos en esta sección a aquellos aspectos que importan en cuanto al resumen como género y también a los antecedentes que puedan existir con respecto a lo que sucede con los patrones lingüísticos cuando el texto es sometido a un proceso de traducción.

El resumen es un texto que cumple la función de actuar como una "bisagra" entre leercomprender y escribir (López Casanova, Inza y Peralta, 2000). Por un lado, la comprensión consiste en reconocer las informaciones que no pueden faltar para reponer el contenido del texto leído y, complementariamente, la escritura vuelve a decir de otro modo, reformula esa información en un segundo texto, el resumen, que debe ser comprendido en sí mismo, es decir, sin que sea necesario reconocer el texto-fuente del cual parte. 
Resumir es producir un texto escrito coherente y claro que recupere el contenido global de otro, a partir de un proceso de transformación específica que implica operaciones de globalización. Es una reducción en el sentido de que ofrece materialmente menor cantidad de palabras con respecto al texto base, pero no resulta sólo de suprimir. Quien resume, un mediador entre el texto-fuente y el destinatario, realizará las transformaciones primero considerando las características genéricas específicas del texto original; luego, según su particular relación comunicativa con el destinatario del resumen. Finalmente, seleccionará el léxico y los patrones lingüísticos más apropiados para una situación comunicativa concreta.

El resumen se presenta como una clase particular de texto. M. C. Rébola y M. C. Stroppa (1998:19) lo definen como "un texto de segundo grado en relación con el texto base o texto de primer grado". Resumir presupone la comprensión del texto base y su reelaboración en un nuevo texto con todo lo que esto implica. Pero para poder organizar y reducir información en forma coherente se deben reconocer tanto las relaciones locales como las globales. En general, en nuestros resúmenes menos logrados los escritores parecen ignorar las relaciones globales que les permiten identificar el tópico del discurso y proceden como si cada cláusula no fuera parte de un contexto común. En este sentido, ya nos referimos al aporte de la Perspectiva Funcional de la Oración y la relación de las capas remáticas con los significados globales de los textos.

Por otro lado, Isabel Solé observa:

Resumir un texto requiere poder tratar la información que contiene de manera que pueda omitirse la que es poco importante o redundante, y que puedan sustituirse conjuntos de conceptos y proposiciones por otros que los engloben o integren. Requiere además que el resumen mantenga lazos especiales con el texto del que ha 
sido creado, es decir, debe conservar el significado genuino del texto del que procede. (Solé, 1997[1992]: 149)

En su definición, Solé se refiere a omitir información irrelevante, incluir conceptos que engloben o integren y mantener lazos con el texto fuente. En nuestros resúmenes menos efectivos, estas características no se encuentran presentes. Se trata de textos en los que los autores no omiten información. Más aún, en algunos casos, los textos meta resultan más extensos que el texto fuente y en ocasiones la información poco o nada tiene que ver con los hechos contados por el texto fuente.

Mónica Preiti (1998:168) explica: "el resumen opera como un programa organizado de recuperación de información e identificación del tema central. Un programa que resulta de la realización de un procesamiento global del texto que implica el almacenamiento de proposiciones y su vinculación jerárquica, intentando reservar sólo la información básica...Un lector no puede procesar la estructura del texto por vía estrictamente formal, sin considerar su contenido semántico y pragmático". En los resúmenes menos efectivos de nuestro corpus, observamos justamente que los escritores intentan procesar la estructura del texto fuente por vía estrictamente formal, sin considerar su contenido semántico y pragmático. No pueden procesar el texto-fuente globalmente y establecer las relaciones y jerarquías de las proposiciones.

Más aún, los escritores de los textos menos efectivos no son capaces de reconocer la incoherencia que resulta de su apego a las formas del texto fuente. No utilizan una de las estrategias que Palincsar y Brown (1984) reconocen para la comprensión que es la de "evaluar la consistencia interna del contenido que expresa el texto y su compatibilidad con el conocimiento previo y con lo que dicta el 'sentido común'." Algunas de estas preguntas 
son: “¿Tiene sentido este texto? ¿Presentan coherencia las ideas que en él se expresan? ¿Se entiende lo que se quiere expresar?"

Para producir un resumen no es suficiente excluir y conservar partes del texto fuente sino que es necesario crear enunciados que no estén presentes en el original, a través de procesos de abstracción y generalización, reuniendo varias ideas en una sola que las represente, y también por medio de procedimientos de construcción o integración, para los cuales no suele bastar la información provista en la fuente sino que ha de apelarse a conocimientos propios dados por sobreentendidos en ella. (van Dijk, (1996 [1983])

Ya dijimos que el resumen es una actividad de tipo textual compleja que tiene como base el doble proceso de comprensión y producción. El escritor del resumen debe ser capaz de decir lo mismo pero de forma más abreviada, es decir que la actividad de resumen reviste la forma de una paráfrasis reductora (Alvarez Angulo, 2005:257). La mayor parte de estas transformaciones, denominadas por Charolles (1991 ) "mecanismos de compactibilidad parafrástica" se basan en mecanismos léxicos o sintácticos.

¿Qué es lo que les pasa a los escritores de nuestros resúmenes menos efectivos? No pueden reconocer apropiadamente la relación participante-proceso pues poseen un umbral bajo de manejo léxico-gramatical (hipótesis Ii). Significa entonces que el proceso de comprensión de información del texto de partida es poco exitoso. El escritor que no es capaz de reconocer los participantes afectados como tales y/o no puede reconocer la relación entre el proceso central de prohibir y los participantes afectados, mal podrá reformular esas relaciones en un nuevo texto que mantenga equivalencia informativa con el texto fuente. Es decir, si su comprensión es poco efectiva también lo será su producción. (hipótesis Iiib) 
Esa limitación a nivel léxico-gramatical en el Sistema de Transitividad repercute en los Sistemas de Modo/Temple y Tema/Rema (hipótesis Iiii)). Desde el comienzo del texto fuente los escritores no pueden interpretar los significados experienciales en las cláusulas individuales. Tratan de reproducir, desde la forma (hipótesis Iiib), los participantes involucrados y para cuando llegan a la interpretación de los procesos es tan difícil (para ellos mismos) atribuir un valor semántico (hipótesis liib) a lo que construyen que no tienen un contexto claro que les permita entender de qué están hablando. (hipótesis IIi)

Van Dijk (1995 [1980]:25 y sig.) habla de dos niveles de coherencia en el texto: uno lineal o local y otro global. Si consideramos nuestros resúmenes, el nivel de coherencia local estaría dado por la interpretación de los participantes y sus procesos asociados en cada una de las cláusulas y la coherencia global queda de manifiesto en cuanto pueda asignársele un tema o asunto al texto como un todo. Ahora bien, si los escritores de los resúmenes menos efectivos no son capaces de identificar apropiadamente la relación participante-proceso en el párrafo inicial, ¿cómo podrían entonces encontrar el tema que dichas cláusulas tienen en común?

Más aún, ¿cómo lograrán los escritores que no pueden interpretar la relación participanteproceso en el primer párrafo y, por lo tanto no pueden asignar un tema al texto, decidir qué deben eliminar por superfluo y qué incluir como relevante en la totalidad del texto? Si tenemos en cuenta que el texto fuente a interpretar es un artículo periodístico podremos comprender la relevancia de la correcta interpretación del primer párrafo. No es nuestra intención detenernos en el género artículo periodístico ${ }^{6}$ pero baste mencionar que una característica típica del género es que su titular y primer párrafo funcionan como resumen. Por lo tanto, esa poco exitosa interpretación de la relación participante-proceso en el

\footnotetext{
${ }^{6}$ Para información sobre la estructura del artículo periodístico se puede consultar Van Dijk, 1996/1983: 68 y sig.
} 
párrafo inicial del texto fuente resulta en reformulaciones de patrones de registro que no constituyen textos que podamos identificar como dentro del género resumen (hipótesis IIi).

En este capítulo se han presentado las nociones teóricas que guiarán la investigación y algunos antecedentes sobre resumen que nos han servido de punto de partida para evaluar la relación entre la interpretación de la relación participante-proceso en el texto fuente en L2, su incidencia en los Sistemas de Modo/Temple y Tema/Rema y la efectividad de los textos meta escritos en L1. En el capítulo siguiente presentaremos los aspectos metodológicos y los detalles de la investigación. Nos referiremos a los sujetos seleccionados, el corpus analizado y las circunstancias en las que los textos fueron escritos. Por último, explicaremos la contribución de los informantes y su aporte a la evaluación final de los textos meta. 


\section{Capítulo 3}

\section{CORPUS Y METODOLOGÍA}

\subsection{INTRODUCCION}

En este capítulo se definirá el corpus utilizado en este trabajo, los sujetos y su criterio de selección, las características del texto fuente utilizado como punto de partida para la construcción de los resúmenes y las circunstancias en las que fueron escritos. A continuación, se explicará la metodología empleada en el análisis de los textos, los sucesivos pasos de la investigación y los resultados que nos permitieron, a través de nuestro estudio léxico-gramatical, llegar al nivel semántico-discursivo. Finalmente, nos referimos al aporte de los informantes y su contribución en la evaluación de los textos-meta. 


\subsection{EL CORPUS}

El corpus seleccionado para esta investigación está constituido por una muestra de diez resúmenes en español escritos por alumnos de las carreras de Licenciatura y Profesorado de Educación Física de la Facultad de Humanidades y Ciencias de la Educación de la Universidad Nacional de la Plata en una instancia de evaluación final de la asignatura Capacitación en Inglés-Nivel $2 .^{7}$ Aproximadamente el 80\% de los alumnos de estas carreras que rinden la Capacitación tienen entre 20 y 25 años, un $15 \%$ entre 25 y 30 años y un 5\% más de 30 años y hasta 40 años. El texto fuente se seleccionó por considerarse que su tema, longitud y grado de lecturabilidad resulta apropiado para los lectores a los que va dirigido. ${ }^{8}$

El criterio de selección del corpus fue que los textos correspondieran a alumnos que hubieran optado por rendir la materia en condición de libres. En general, los alumnos que optan por esta modalidad son aquellos que consideran que poseen los conocimientos lingüísticos necesarios en la lengua extranjera y las estrategias lectoras necesarias como para poder resolver la consigna en el tiempo y forma apropiados para aprobar el examen. Estos alumnos, además, ya rindieron Capacitación en Inglés-Nivel 1 y fueron evaluados en la interpretación de un texto de especialidad en inglés a partir de preguntas en inglés que deben responder en español sobre contenido textual y elementos de cohesión. Sin embargo, no contamos con ningún registro del exacto nivel en L2 de estos alumnos en el momento de rendir la prueba, ni de qué forma adquirieron los conocimientos o de cuánta práctica previa específica en redacción de resúmenes (sea en L1 o L2) tienen.

\footnotetext{
${ }^{7}$ Los textos completos se transcriben en el Apéndice 2, respetando el formato original de los párrafos.

${ }^{8}$ El texto fuente y las tablas de análisis de los tres Sistemas se transcriben en el Apéndice 1.
} 
La consigna que se pide completar a los alumnos en Capacitación en Inglés-Nivel 2 responde a que la construcción de un resumen va un paso más allá de la comprensión textual a partir de preguntas, estrategia que se evalúa en el nivel 1. Para construir el texto resumen el lector de un texto fuente debe captar bien las ideas principales: actores, procesos, agentes afectados (hipótesis Iiia) que le permita hacer una selección jerarquizada de ideas en base a sus distintos sistemas de conocimientos o saberes. ${ }^{9}$ En otras palabras, decidir qué incluir en base al contenido semántico y pragmático del texto fuente. El lector que se obnubila con las formas del texto fuente no puede remontar al nivel semánticodiscursivo (hipótesis Iiib), al que sólo podrá llegar, como ya se ha dicho (Cf. Capítulo 2) si es capaz de realizar tanto un procesamiento local como global del texto.

El texto fuente elegido es un artículo periodístico de tema deportivo del Buenos Aires Herald de aproximadamente 245 palabras, publicado el 17 de mayo de 2003 y titulado “Men's and Women's Sports Completely Separated". Los alumnos reciben el artículo con la siguiente consigna que figura a continuación del mismo:

\section{Summarize the text above in Spanish}

El resumen debe completarse en aproximadamente 1 hora y 15 minutos y los alumnos pueden trabajar con diccionarios bilingües. No se especifica número de palabras pero se espera que los alumnos apliquen los conceptos teóricos desarrollados en los cursos de Capacitación en Inglés-Niveles 1 y 2. En Capacitación en Inglés-Nivel 1, además de los conceptos teóricos de la Lingüística Sistémica de texto como unidad de significado, elementos de cohesión, coherencia y textura (Eggins, 1994; Halliday, 1985; Halliday and Hasan,1976), se trabajan estructuras léxico-gramaticales consideradas fundamentales para

\footnotetext{
${ }^{9}$ Tomamos el concepto de saberes de la tipología textual de Heinemann y Vieweger (1991).
} 
una buena comprensión textual. En Capacitación en Inglés-Nivel 2 se refuerzan dichos conocimientos por considerarlos el punto de partida para la efectiva construcción semántico-discursiva y genérica, y teniendo como foco la construcción del resumen.

Por lo tanto, el motivo de la selección de este texto fuente está estrechamente ligado a nuestras hipótesis de investigación: la importancia de la comprensión de ciertas estructuras léxico-gramaticales para la comprensión global de los significados textuales (hipótesis Ii y IIi). Es decir, cómo resuena el nivel léxico-gramatical en el semántico-discursivo y eventualmente a nivel de género (hipótesis liib y IIi). Nuestra hipótesis Ii) menciona que, para nuestro estudio, nos interesa analizar el procesamiento que nuestros lectores hacen de la voz pasiva. El artículo periodístico que los alumnos deben resumir se caracteriza por la presencia de la voz pasiva en varias de sus cláusulas. Además de las cuatro cláusulas del primer párrafo, tres de ellas en el resto del texto describen los hechos utilizando voz pasiva. El artículo en cuestión, de este modo, constituyó un buen punto de partida para intentar comprobar una de nuestras hipótesis.

Del total de aproximadamente cincuenta textos correspondientes a distintas instancias de evaluación de la materia durante los años 2003/2004/2005 se seleccionaron diez textos. La puntuación que obtuvieron los resúmenes va de 2 (dos) a 10 (diez) Se optó, finalmente, por seleccionar los cinco más efectivos y los cinco menos efectivos según nuestro criterio y se excluyeron aquellos textos cuyas notas finales hubieran sido 4 (cuatro), 5 (cinco), 6 (seis) y 7 (siete). 


\subsection{LA METODOLOGÍA DE ANÁLISIS}

En primer lugar, se segmentaron los textos del corpus en oraciones ortográficas. Al ser textos escritos, ésta se consideró una segmentación inicial conveniente en razón de que la oración ortográfica realiza grafológicamente el complejo clausal, cuyo caso límite es la oración simple (constituida por una única cláusula). (Halliday, 2004: 371).

Esa segmentación inicial, seguida de un análisis en extremo detallado en el que se intentó definir las funciones de todas y cada una de las palabras y estructuras en los tres Sistemas, no nos permitía llegar a lo que estrictamente estábamos buscando que era analizar la adecuada o inadecuada interpretación de la relación participante-proceso (Sistema de Transitividad) en el texto fuente en L2, su efecto en los Sistemas de Modo/Temple y Tema/Rema y eventualmente en la producción del texto meta en L1.

Finalmente, se adaptó el análisis de modo que nos permitiera encontrar respuestas más relevantes a nuestras hipótesis de investigación. Entonces, nos centramos en los participantes y procesos para el Sistema de Transitividad y en la relación Sujeto+Finito+Predicador para el Sistema de Modo/Temple. Para el Sistema de Tema/Rema no fue necesario implementar cambios con respecto a los de la etapa inicial de análisis. 


\subsubsection{La segmentación y el análisis cualitativo de los textos}

El método de análisis utilizado permitió estudiar los textos del corpus desde una perspectiva léxico-gramatical por un lado y, al mismo tiempo, evaluar su efectividad desde una perspectiva genérica.

Siguiendo la propuesta de la Lingüística Sistémico-Funcional, se seleccionó la cláusula como unidad gramatical de análisis y se procedió a llevar a cabo un análisis tripartito. Sin embargo, como ya se ha explicado, dentro del análisis clausular nos concentramos en participantes y procesos. El propósito del análisis en los tres Sistemas léxico-gramaticales en los textos-meta nos permitió: 1) observar el comportamiento de las sucesión de oraciones que constituían los textos en tanto unidades semánticas; 2) determinar la influencia de la apropiada o inapropiada interpretación de la relación participante-proceso en los Sistemas de Modo/Temple y Tema/Rema y a partir de allí en los tres haces de significados: experienciales, interpersonales y textuales del nivel semántico-discursivo; 3 ) determinar la incidencia de la apropiada o inapropiada interpretación de la relación participante-proceso a nivel de registro y género.

De este modo, en una primera etapa, analizamos los textos del corpus utilizando tablas que reproducían todos los complejos clausales ${ }^{10}$ en cada uno de los tres Sistemas. Sin embargo, como ya se ha explicado, en una segunda instancia decidimos restringir nuestro criterio de análisis para el Sistema de Transitividad y concentrarnos en la relación participanteproceso por ser esa relación para nosotros la relevante y la que afectaba los otros dos

\footnotetext{
${ }^{10}$ En inglés, "clause complex". En este trabajo, el sustantivo "clause", utilizado como adjetivo en el complejo "clause complex" se tradujo como "clausal" en español.
} 
Sistemas. Del mismo modo, abandonamos el análisis detallado del Sistema de Modo/Temple de una primera etapa y nos centramos en la relación $\mathrm{S}+\mathrm{F}+$ Predicador por considerar este bloque como el relevante para la construcción de los significados que estábamos estudiando, al tiempo que mantuvimos el criterio de la etapa inicial para nuestro análisis de Tema/Rema.

Veamos entonces, tomando como ejemplo la primera cláusula del Texto 6 (Ver Apéndice 2), cómo varió nuestro criterio de análisis de los sistemas léxico-gramaticales de Transitividad y de Modo/Temple entre esa primera etapa y la segunda etapa, en la que nuestro análisis se enfocó más en lo que necesitábamos encontrar:

Análisis del Sistema de Transitividad en primera (a) y segunda (b) etapas:

a)

\begin{tabular}{|l|l|l|l|l|}
\hline Entrenadores & ayer & fueron & de entrenar & en una profunda \\
& & prohibidos & atletas & y conservadora \\
& & femeninas y & yrovincia de \\
& & & deportes de & Pakistán \\
& & & equipos & \\
\hline Meta & Cir. (Tiempo) & Proceso Material & Circ. (?) & Circ.(lugar) \\
\hline
\end{tabular}


b)

\begin{tabular}{|l|l|ll|l|}
\hline ACTOR/META & $\begin{array}{l}\text { PROCESOS } \\
\text { MATERIALES }\end{array}$ & PROCESOS DE & PROCESOS \\
& $\begin{array}{l}\text { PROYECCIÓN } \\
\text { Conducta }\end{array}$ & Mentales/Verbales & Relacionales/Existenciales \\
\hline Entrenadores & fueron prohibidos & & \\
\hline
\end{tabular}

Podemos observar cómo, en nuestra segunda etapa de análisis (b), nos circunscribimos a la relación participante-proceso porque era la apropiada o inapropiada interpretación de esta relación la que nos conduciría a un análisis relevante a nivel semántico-discursivo. Por otro lado, para concentrarnos en la relación participante-proceso, en esta segunda etapa nuestra tabla distingue entre tres categorías principales de procesos con dos subcategorías cada una: Procesos Materiales con sus subcategorías Materiales y de Conducta; Procesos de Proyección con sus subcategorías Mentales y Verbales; Procesos Relacionales con sus subcategorías Relacionales y Existenciales.

Por último, y como explicación de nuestras decisiones para clasificar procesos, quisiéramos referirnos al hecho de que el mismo Halliday plantea lo poco nítido de los límites entre las categorías en algunos casos. De acuerdo con su criterio, algunos procesos tales como implican, indican, muestran, demuestran, significan, sugieren, en particular cuando el participante no es en realidad "quien dice" pueden ser analizados como verbales (del decir) o relacionales (como signo de) (1985: 154). Para el autor, si el Sujeto es un ser consciente o si es parte de una cláusula de proyección es verbal; de lo contrario es relacional. Según este criterio, mark en el texto fuente fue clasificado como proceso relacional; lo mismo se hizo con las versiones más o menos equivalentes en los resúmenes en español (e.g. marcar, afectar). 
Otra de las dificultades con respecto a la clasificación de procesos que menciona Halliday es la coexistencia (blending) de lo mental, verbal y material en un mismo proceso. En su análisis del verbo insultar (Halliday, 1994:141) el autor comenta que el proceso con su participante asociado están más cerca del tipo de estructura Actor + Meta del proceso material. Siguiendo este criterio, todas las instancias de prohibir y sus significados asociados tanto en el texto fuente como en los resúmenes en español fueron clasificadas como procesos materiales. En los casos de coexistencia mental y material en un mismo proceso como por ejemplo cuando el verbo decidir acompaña un proceso material (e.g. decidió encontrarse), se optó por priorizar el aspecto material puesto que, en ambos casos, el contexto indica que las acciones se realizaron. De este modo, la acumulación de significados a nivel semántico-discursivo muestra que los escritores de los resúmenes, tanto de los más como de los menos efectivos, optan por contar los hechos utilizando procesos materiales. En este sentido, no varía demasiado la selección de procesos con respecto a los procesos seleccionados en el texto fuente.

Análisis del Sistema de Modo/Temple en primera (a) y segunda (b) etapas:

También para el Sistema de Modo/Temple, entonces, variamos nuestro criterio de análisis entre una primera (a) y una segunda etapa (b). Mientras en la primera etapa realizamos un análisis completo de cada uno de los complejos clausales (Bloque Modo+Residuo), en una segunda etapa nos concentramos en los constituyentes funcionales $\mathrm{S}+\mathrm{F}+$ Predicador ya que eran estos constituyentes los que nos mostraban el comportamiento de la relación participante-proceso (Sistema de Transitividad) en el Sistema de Modo/Temple, comportamiento que necesitábamos corroborar según una de nuestras hipótesis de investigación (hipótesis Iiii).

Veamos nuevamente el texto 6, para ejemplificar cómo varío nuestro criterio de análisis entre las dos etapas, esta vez, en el Sistema de Modo/Temple. Observemos, una vez más, su primera cláusula: 
a)

\begin{tabular}{|c|l|l|l|l|l|}
\hline Entrenadores & ayer & fueron & prohibidos & $\begin{array}{l}\text { de entrenar atletas } \\
\text { femeninos } \\
\text { deportes de equipos }\end{array}$ & $\begin{array}{l}\text { en una profunda y } \\
\text { conservadora } \\
\text { provincia de } \\
\text { Pakistán }\end{array}$ \\
\hline Sujeto & Adjunto:circ. & Finito & Predicador & Complemento & Adjunto:circ. \\
\hline Modo/T. & Residuo & Modo/T. & \multicolumn{3}{|c|}{ Residuo } \\
\hline
\end{tabular}

b)

\begin{tabular}{|l|l|l|}
\hline \multicolumn{2}{|c|}{ BLOQUE MODO/TEMPLE } & RESIDUO \\
SUJETO & FINITO & PREDICADOR \\
\hline Entrenadores & fueron & prohibidos \\
\hline
\end{tabular}

Podemos ver que, en una segunda etapa, dejamos de lado el análisis detallado del Residuo de la primera etapa para concentrarnos en la léxico-gramática del bloque Modo/Temple + Predicador. La acumulación de los significados interpersonales en los diferentes textos nos permitió observar que cuanto mayor era el apego a los tiempos verbales del texto fuente, menos efectivos resultaban los significados del texto en su conjunto. Así, el Texto 6 (Ver Apéndice 4) replica exactamente los tiempos verbales y, sin embargo, resultó uno de los menos efectivos. Por otro lado, la interpretación de la Modalidad, el tipo de proceso y la voz en la frase verbal ( $F+$ Predicador) representaron una dificultad que los escritores de los resúmenes menos efectivos, en general, no pudieron resolver (Ver Apéndice 4- Textos menos efectivos) 
En cuanto al análisis del Sistema de Tema /Rema, no varió entre nuestra primera (a) y segunda (b) etapa de análisis, ya que en ambas instancias consideramos:

Análisis del Sistema de Tema/Rema en primera (a) y segunda (b) etapas:

a) y b)

\begin{tabular}{|l|l|l|l|l|}
\hline \multicolumn{3}{|c|}{ TEMA } & \multicolumn{2}{|c|}{ REMA } \\
\hline \multirow{2}{*}{ Textual } & Interpersonal & $\begin{array}{l}\text { Marcado } \\
\text { Tópico }\end{array}$ & No marcado & \multicolumn{2}{|c|}{ Tópico } & \\
\hline & & Entrenadores & $\begin{array}{l}\text { ayer fueron prohibidos de entrenar atletas } \\
\text { femeninos y deportes de equipos en una } \\
\text { profunda y conservadora provincia de } \\
\text { Pakistán }\end{array}$ \\
\hline
\end{tabular}

Optamos por incluir la distinción entre Tema marcado tópico y no marcado tópico porque entendimos que, al ser el Sistema de Tema/Rema el ordenador de los significados experienciales e interpersonales, las selecciones en los distintos resúmenes entre un tipo de Tema tópico y el otro podría arrojar resultados adicionales.

Nuestro criterio para la distinción Tema marcado tópico/Tema no marcado tópico en español corresponde a criterios seguidos para el español que incluyen como Tema no marcado tópico, además del Sujeto gramatical, verbos conjugados y clíticos con sus verbos asociados cuando estos tres tipos de elementos están en posición inicial. (cf. MontemayorBorsinger 2009: 99). El análisis del Sistema de Tema/Rema para nuestro corpus muestra una tendencia a la integración de los hechos contados en Rema 1 y en ocasiones R1 y R2 en los textos más efectivos. También se observa, en general, mayor número de Temas textuales en estos textos que en los menos efectivos. Entendemos que la interpretación de la relación participante-proceso en los textos de nuestro corpus incide en el más o menos 
efectivo fluir de la información, es decir en el Sistema de Tema y los significados textuales.

\subsubsection{El análisis tripartito y sus resultados}

Nuestro análisis de la segunda etapa (Apéndices 3, 4 y 5) nos permitió observar la construcción de la variable CAMPO del Contexto de Situación a partir de las selecciones léxicas para realizar significados experienciales, básicamente a partir de las relaciones participante-proceso. Comparamos las opciones en los resúmenes más efectivos con selecciones de participantes y procesos en los resúmenes menos efectivos. Analizamos, entonces, el Sistema de Transitividad, es decir la elección del tipo de proceso asociada a determinados participantes y configuraciones: el mundo de las acciones, relaciones, participantes y circunstancias.

A nivel TENOR, analizamos el Sistema de Modo/Temple en los resúmenes más efectivos y luego las compararemos con las realizaciones de patrones de Modo/Temple en los resúmenes menos efectivos. Consideramos también el Subsistema de Modalidad a partir del cual la lengua nos permite atenuar la interacción expresando distintos grados de probabilidad/frecuencia u obligación/tendencia. De este modo, observamos cómo se estructura la cláusula para construir los significados interpersonales. Nos interesó ver cómo los resúmenes más efectivos respetan la actitud del escritor del texto fuente hacia el tema del texto y, contrariamente, cómo dificulta la comprensión a los escritores de los resúmenes menos efectivos la presencia de estructuras verbales pasivas cuando, además, están modalizadas. 
A nivel MODO/MEDIO, comparamos los patrones de Tema/Rema de los textos más efectivos con los de los textos menos efectivos. Observamos los significados textuales a partir de la comparación de las selecciones temáticas y de la incidencia de ellas en las opciones remáticas, fundamentalmente en el grupo verbal. Por ejemplo, en Halliday 2004:349, voz deriva de la metafunción textual. Observamos los métodos de desarrollo de las ideas en los resúmenes más efectivos y en los menos efectivos para poder dar respuesta a en qué medida la selección de contenido experiencial afecta el método de desarrollo del texto.

De este modo, nuestro análisis nos condujo desde el nivel léxico-gramatical al semánticodiscursivo. Y puesto que, tanto el registro como el género se realizan a través de la lengua las palabras y las estructuras que se usan-, el método de análisis utilizado permitió estudiar los textos de nuestro corpus desde una perspectiva léxico-gramatical por un lado y, al mismo tiempo, evaluar su efectividad desde una perspectiva genérica; es decir, como resúmenes del texto fuente, con el fin de establecer la incidencia de las relaciones participante-proceso en la efectividad de los textos.

\subsubsection{La evaluación de los informantes}

La selección de los cinco resúmenes más efectivos y los cinco menos efectivos se realizó siguiendo un criterio estrictamente personal en base a la puntuación que los resúmenes habían obtenido en instancia de examen final y al posterior análisis tripartito. Sin embargo, además, se solicitó la evaluación de un pequeño grupo de informantes, profesores de inglés egresados de la Facultad de Humanidades y Ciencias de la Educación de la Universidad Nacional de La Plata. Dicha evaluación se cotejó con nuestra clasificación. De haber 
surgido diferencias importantes se hubiera requerido al/ los informante/s justificar dicha evaluación para, de ser necesario, revisar la propia.

Los informantes recibieron la siguiente consigna de trabajo junto con los textos:

Estimado/a Profesor/a:

Por favor, lea los siguientes resúmenes $\mathrm{A}$ a $\mathrm{J}$ correspondientes al artículo periodístico adjunto y marque con $\sqrt{ }$ los que considere más efectivos y con $x$ los que considere menos efectivos.

Gracias por su colaboración

Se aclaraba a los informantes que la evaluación con $\sqrt{ }$ correspondía básicamente a los resúmenes en los que la información fluía en forma coherente sin traicionar el texto fuente, aún cuando el texto pudiera necesitar algo de edición. Además, se les explicó que estarían evaluando resúmenes de alumnos de las carreras de Licenciatura y Profesorado de Educación Física de la Facultad de Humanidades y Ciencias de la Educación, Universidad Nacional de la Plata escritos en una instancia de examen final en condición de libres y a quienes no se les exigía utilizar un número de palabras determinado; sólo se esperaba de ellos que aplicaran las estrategias trabajadas en el Curso de Capacitación en Inglés- Nivel 2 para poder cumplir satisfactoriamente con la consigna.

No se solicitó a los informantes que dieran una puntuación específica a los textos sino que simplemente juzgaran cuáles creían más efectivos y cuáles menos efectivos. Todos los informantes coincidieron en que los textos A, E, F, G y J (correspondientes a los Textos 6, 7,10, 8 y 9 del Apéndice 2 respectivamente) eran los menos efectivos. Sin embargo, algunos de los informantes incluyeron comentarios personales a partir de los cuales pudimos observar que los Textos 6 y 8 (Apéndice 2) fueron evaluados como los menos efectivos y los Textos 2 y 4 (Apéndice 2) como los más efectivos. Por lo tanto, si bien para 
la clasificación de los textos en más efectivos y menos efectivos seguimos un criterio estrictamente personal, la opinión de nuestros informantes dio mayor sustento a nuestras decisiones. Sus opiniones, además, nos ayudaron a seleccionar los textos 2 y 8 como ejemplos de resumen más y menos efectivo respectivamente; es decir, ejemplos que muestran cómo la interpretación apropiada o inapropiada de la relación participanteproceso repercute a nivel de Registro y de Género (hipótesis IIi).

En este capítulo se presentó la descripción del corpus seleccionado para el estudio, la metodología empleada en el análisis del mismo, los sucesivos pasos de la investigación y la colaboración de los informantes. A continuación, en el Capítulo 4, se presentará la discusión de los resultados partiendo del análisis de Transitividad, luego del Sistema de Modo/Temple y finalmente del Sistema de Tema/Rema. En cada caso, comenzaremos con los textos más efectivos y al concluir el análisis de los diez textos en cada uno de los Sistemas realizaremos comparaciones entre los textos más y menos efectivos. Si bien nos centraremos en los primeros párrafos de los textos meta, en los casos en que ayude a reforzar nuestras hipótesis, analizaremos ejemplos de otras secciones de los resúmenes. 


\section{Capítulo 4}

\section{RESULTADOS Y DISCUSIÓN}

A continuación presentamos el análisis que corresponde a la segunda etapa de estudio de los textos en la que nos centramos en la relación participante-proceso para el Sistema de Transitividad, la relación $\mathrm{S}+\mathrm{F}+$ Predicador para el Sistema de Modo/Temple y la relación Tema (con la distinción Tema textual-interpersonal-marcado tópico y no marcado tópico) y Rema. El análisis completo de los textos se incluye en los Apéndices 3 (Sistema de Transitividad), 4 (Sistema de Modo/Temple) y 5 (Sistema de Tema/Rema).

Realizaremos un análisis tripartito de los datos de nuestro corpus que nos permita observar las diferencias en los sistemas de elección gramatical entre los escritos más efectivos y los menos efectivos. En un sistema gramatical, cada elección se realiza no como determinadas palabras en particular sino según el orden de los roles gramaticales que las palabras cumplen. Es decir, las elecciones se realizan en estructuras. (Eggins, 1994:20) Analizaremos, entonces, qué estructuras construyen los contextos más y menos efectivos.

Como se ha señalado previamente (Cf Capítulo 2), el lenguaje es un sistema en el que

podemos distinguir tres niveles: dos niveles de contenido que construyen significado 
(discursivo-semántico y léxico-gramatical) y un nivel de expresión que corresponde a fonología/grafología. Es el nivel intermedio léxico-gramatical el que resulta particularmente importante para entender cómo el lenguaje realiza tres vetas de significados en forma simultánea. En él nos centraremos.

Las tres áreas de significado que recorren el texto se construyen básicamente a través de las cláusulas que lo componen. Por eso, explica Halliday, la descripción gramatical es esencial para el análisis textual:

Se pretende a veces que (el análisis de discurso o "lingüística textual") se puede llevar a cabo sin recurrir a la gramática -o incluso a veces que es una alternativa de la gramática. Pero esto es un engaño. Un análisis de discurso que no se basa en la gramática no es de ningún modo un análisis, más bien es simplemente un comentario de un texto. (Halliday, 1985: xvii). (Traducción propia)

En el enfoque sistémico-funcional nos interesa describir dos dimensiones del uso del lenguaje. En primer lugar, cuáles son las elecciones posibles que la gente puede hacer; es decir, cuáles son los posibles significados que pueden construir. Para ello, describimos el sistema lingüístico. En segundo lugar, cuál es la función de la elección que hacen, es decir, por qué eligieron construir ese significado. Para ello, describimos cómo se usa el lenguaje en distintos contextos sociales para alcanzar diversos objetivos culturales.

El análisis léxico-gramatical de las cláusulas nos permite llegar a los significados (nivel semántico-discursivo) del texto. Es decir, si queremos describir los significados en el texto, debemos concentrarnos en la estructura de la cláusula. Los patrones léxico-gramaticales, por otra parte, representan las elecciones realizadas. Cada elección se realiza de manera 
particular y las elecciones se organizan en sistemas. El enfoque sistémico-funcional prioriza las relaciones paradigmáticas: los sistémicos toman la noción de elección como fundamental para entender cómo la lengua construye significados. Estas elecciones paradigmáticas son captadas a través de sistemas. El producto de las elecciones son las estructuras, capturadas en enunciados de realización.

Pero los sistemas nos permiten analizar no sólo las elecciones hechas sino también las posibles. Los sistemas capturan el potencial de significado del que los hablantes disponen. Este enfoque orientado a las elecciones reales y las posibles permite comparar alternativas y considerar lo apropiado de una determinada elección. En lugar de hablar de elecciones “correctas" o "incorrectas", hablaremos de elecciones "apropiadas" o "inapropiadas".

En esta sección, analizaremos los textos más efectivos y los menos efectivos para evaluar qué patrones de realización en los textos más efectivos derivan en significados más apropiados y qué patrones lingüísticos en los textos menos efectivos resultan en significados inapropiados. Nos centraremos fundamentalmente en la forma en cómo los escritores procesan el primer párrafo. 


\subsection{SISTEMA DE TRANSITIVIDAD}

El Sistema de Transitividad realiza los significados experienciales que están condicionados por la variable CAMPO del Contexto de Situación (Cf Capítulo 2). El estudio de los patrones de Transitividad se centra en la selección de procesos (verbos), y sus participantes (sustantivos) y circunstancias asociadas (frases preposicionales de tiempo, modo, lugar, etcétera). Estos patrones gramaticales expresan lo que los sistémicos distinguen como el “Quién está haciendo qué cosa, a quién, cuándo, dónde, por qué y cómo”.

En el caso del resumen, al que ya se ha hecho mención como texto de segundo grado, si las relaciones entre procesos, participantes y circunstancias del texto fuente no son interpretadas apropiadamente, el resultado será un texto cuyo contenido probablemente no refleje el contenido del original, por un lado, y/o que resulte en un texto incoherente, por otro. Por lo tanto, al describir la gramática de la cláusula como representación, no sólo se deben describir apropiadamente las diferencias entre los tipos de procesos, sino también las diferencias asociadas en los roles de los participantes, su interacción con otros participantes y la posible selección de circunstancias.

A continuación se analizarán ciertos patrones de Transitividad en los textos más efectivos y en los menos efectivos. Luego se compararán los resultados con el objetivo de ver qué hicieron los escritores de los textos más efectivos que pueda ayudar a los escritores de los textos menos efectivos a mejorar su producto. Con el propósito de facilitar esta parte del análisis, utilizaremos cursiva para una mejor visualización de participantes y procesos. (El análisis completo de participantes-procesos se incluye en el Apéndice 3) 


\subsubsection{Textos Más Efectivos}

\subsubsection{Texto 1}

El escritor no sólo reconoce apropiadamente participantes y procesos sino que también los integra entre sí y las circunstancias en que se realizan. Así:

Texto fuente

PESHAWAR, Pakistan-Male coaches were banned yesterday from training female athletes and sports teams in a deeply conservative province in Pakistan. Male spectators also will be barred from watching sports events were female athletes compete, and male journalists are forbidden from covering them
Texto meta

En Peshawar, una provincia del Noroeste de Pakistán, prohibieron a entrenadores, espectadores y periodistas varones el participar de cualquier manera en deportes de mujeres.

Como lo muestra el ejemplo anterior, el escritor evita repetir el proceso para cada uno de los agentes afectados y mediante una estrategia de reconstrucción semántica (Van Dijk, (1996[1983]: 58 y sig.) integra la información del primer párrafo en una primera cláusula. En resumen, el escritor construye una realidad coherente que replica los hechos contados en el texto fuente sólo que evitando la redundancia a lo que lo conduciría repetir el proceso para cada uno de los participantes afectados.

El núcleo informativo ${ }^{11}$ de su primer párrafo lo completa con el siguiente segundo complejo clausal:

\footnotetext{
${ }^{11}$ Llamaré núcleo informativo a la información de mayor jerarquía y que en el caso del artículo de diario es la que se concentra al comienzo del mismo.
} 
Texto fuente

The new measures, decided at a provincial Cabinet meeting yesterday, mark the latest attempt by the six-party religious alliance to impose a strict version of Islam. The decision will affect thousands of girls and women in the province who compete in sports such as tennis, table tennis and field hockey. Several retired athletes were expected to lose their jobs at girls'schools because of the rules.
Texto meta

Estas medidas, tomadas por el Gabinete provincial, fueron impulsadas por una alianza religiosa islámica y afectarán a muchas mujeres que practican deportes y a atletas retirados que trabajan en escuelas de mujeres.

Aquí también el escritor integra información. Aplica una macrorregla de construcción y se aleja de las formas del texto fuente dando prioridad al significado. De modo que en los dos primeros complejos clausales el escritor construye apropiadamente el Contexto de Situación identificando el proceso principal de prohibir, el responsable, los participantes sobre quienes recae la decisión y hasta las consecuencias futuras de dichas medidas.

Un recorrido por el resto del texto, permite ver que el escritor no sólo reconoce apropiadamente los participantes, procesos y circunstancias más importantes y sus relaciones sino también las causas del evento principal que dio origen a la noticia y otras medidas tomadas en la misma dirección. Veamos los siguientes ejemplos:

Texto fuente

The new measures...mark the latest attempt by the six-party religious alliance to impose a strict version of Islam

The province elected a hard-line Islamic government in last October's national elections. Hard-liners also share power in neighbouring Baluchistan province.

\section{Texto meta}

La prohibición de que los hombres se involucren en deportes de mujeres fue orientada a promover un estilo tradicional de deportes islámicos

La provincia eligió en octubre un gobierno islámico de línea dura que comparte el poder también en la provincia vecina de Baluchistán 
Authorities in North West Frontier Province already have banned all music on public buses and ordered billboards featuring images of women advertising movies or products to be torn down
Autoridades de la provincia de Peshawar prohibieron también la música en los colectivos públicos y ordenaron quitar toda la publicidad con imágenes de mujeres

\subsubsection{Texto 2}

Una vez más, el escritor reconoce apropiadamente al actor responsable del evento principal que da origen a la noticia: un gobierno muy conservador y muy estricto en Pakistán. También reconoce el proceso principal de prohibir y el contexto de dicho gobierno. Además, como en casi todos los casos de resúmenes más efectivos construye una cláusula que no se apega a las formas léxico-gramaticales de las cláusulas iniciales del texto fuente. Opta por comenzar su resumen a partir de la relación el texto trata, lo que le permite referirse a información del contexto global; así, identifica el actor responsable del proceso para referirse luego a las medidas en forma específica.

Comparemos los comienzos del texto fuente y el texto meta:

Texto fuente

PESHAWAR, Pakistan-Male coaches were banned yesterday from training female athletes and sports teams in a deeply conservative province in Pakistan. Male spectators also will be barred from watching sports events were female athletes compete, and male journalists are forbidden from covering them, Asif Iqbal Daudzai, information minister of the North West Frontier province, told a news briefing. (Par. 1)

The province elected a hard-line Islamic government in last October's national elections. Hard-liners also share power in neighbouring Baluchistan province. Both

\section{Texto meta}

El texto trata sobre las decisiones tomadas por un gobierno muy conservador y muy estricto en Pakistán, más específicamente en la provincia de la Frontera Noroeste ubicada junto a la frontera con Afganistán. Esta línea de gobierno asumió en las últimas elecciones nacionales y ya estaba en otra provincia, Baluchistán.

Las nuevas medidas indican que las mujeres ya no podrán ser entrenadas a nivel deportivo por los hombres; tampoco podrán ser vistas 
provinces border Afghanistan. (Par.5)

por espectadores del sexo masculino ni los periodistas hombres podrán cubrir los eventos en los cuales participen mujeres.

Se puede ver que el escritor identifica el núcleo informativo pero reorganiza información de modo de comenzar con el contexto global en el que actúa uno de los actores principales: un gobierno muy conservador y muy estricto en Pakistán. También reconoce las consecuencias de la acción principal sobre los agentes afectados y otras medidas tomadas en la misma dirección. Ya no es posible en este resumen identificar tan fácilmente una correlación léxica uno a uno precisamente porque el escritor construye a partir de las cláusulas del texto fuente sin apegarse a las formas ni al ordenamiento del texto fuente. Además, realiza apropiadamente las relaciones lógicas que el texto que construye requiere. Otros ejemplos en el mismo sentido en el texto que nos ocupa son:

Texto fuente

The decision will affect thousands of girls and women in the province who compete in sports such as tennis, table tennis and field hockey. Several retired athletes were expected to lose their jobs at girls'schools because of the rules.

Authorities in North West Frontier Province already have banned all music on public buses and ordered billboards featuring images of women advertising movies or products to be torn down.
Texto meta

Esta decisión afectará a miles de mujeres y adolescentes que participan en varios deportes a nivel internacional; por otra parte, también puede afectar a varones que dan clases en escuelas para mujeres, ocasionando esto la pérdida de trabajos.

Esta línea de gobierno islámica anteriormente habia prohibido que se escuche música en micros públicos y ordenaron derribar carteles publicitarios con imágenes de mujeres.

\subsubsection{Texto 3}

El escritor reconoce apropiadamente al participante actor, instrumento específico del proceso (la alianza religiosa El partido de los seis) como así también el proceso (decidió separar). Al mismo tiempo, integra la información relativa a los agentes afectados (sobre 
quienes recae el proceso). Es decir, en términos de LSF reconoce “¿Quién hace qué cosa a quién?" De este modo:

Texto fuente

PESHAWAR, Pakistan-Male coaches were banned yesterday from training female athletes and sports teams in a deeply conservative province in Pakistan. Male spectators also will be barred from watching sports events were female athletes compete, and male journalists are forbidden from covering them, Asif Iqbal Daudzai, information minister of the North West Frontier province, told a news briefing.//The new measures ...mark the latest attempt by the six-party religious alliance to impose a strict version of Islam.
Texto meta

La alianza religiosa "El partido de los seis", a través de su vocero Asif Iqbal Daudzai, Ministro de Información de la provincia de Peshawar, Pakistán, en un intento de imponer una estricta versión del Islam decidió separar de los eventos deportivos femeninos toda actividad desarrollada por hombres (entrenadores, profesores, periodistas que cubren dichos eventos).

La oración tópico, entonces, construye un contexto que respeta los significados del texto fuente sin apego a las formas de superficie de los procesos, integra información y no incurre en incoherencias o vaguedades. El escritor también procesa apropiadamente aquellas cláusulas que refieren a algunas de las posibles consecuencias de las medidas tomadas como:

Texto fuente

Several retired athletes were expected to lose their jobs at girls'schools because of the rules.

\section{Texto meta}

Muchos atletas retirados, los cuales trabajan en escuelas de niñas como entrenadores, temen perder su trabajo.

"Dicha medida tiene por objeto promover el tradicional estilo del deporte islámico," agregó Daudzai.

$$
\text { agrego Daudzai. }
$$

The new measures...mark the latest attempt by the six-party religious alliance to impose a strict version of Islam.

Nuevamente el escritor se despega de las formas de superficie como lo indica la reformulación Several retired athletes were expected to lose their jobs como Muchos 
atletas retirados...temen perder su trabajo o el ejemplo The new measures...mark the latest attempt ...to impose... como Dicha medida tiene por objeto promover...

\subsubsection{Texto 4}

El escritor del texto reconoce como tales a los agentes afectados; también identifica al responsable del proceso de prohibir aunque lo incluye en una circunstancia, es decir, en forma indirecta: en una provincia pakistaní. Así:

Texto fuente

PESHAWAR, Pakistán-Male coaches were banned yesterday from training female athletes and sports teams in a deeply conservative province in Pakistan. Male spectators also will be barred from watching sports events were female athletes compete, and male journalists are forbidden from covering them, Asif Iqbal Daudzai, information minister of the North West Frontier province, told a news briefing.
Texto meta

Se prohibió a entrenadores hombres (entrenar deportistas mujeres en una provincia pakistaní) (Lo mismo) les ocurrió a periodistas y entrenadores masculinos.

A partir de este procesamiento inicial, el escritor reconoce consecuencias de la decisión, el contexto en que el actor principal toma su decisión y otras medidas implementadas en la misma dirección.

Texto fuente

The decision will affect thousands of girls and women in the province who compete in sports such as tennis, table tennis and field hockey.

\section{Texto meta}

La decisión afecta a todas las deportistas femeninas de deportes como tenis, tenis de mesa y hockey sobre césped.
Several retired athletes were expected to lose their jobs at girls' schools because of the
Atletas nacionales retirados podrían quedar sin trabajo por esta nueva regla. 
rules.

Authorities in North West Frontier Province have already banned all music on public buses and ordered billboards featuring images of ...se prohibió música en autobuses públicos y se ordenó demoler toda cartelera y anuncio women advertising movies or products to be publicitario con imágenes femeninas.

torn down.

De este modo, el escritor del Texto 4 demuestra su comprensión del núcleo informativo textual y del proceso más importante que recorre el texto fuente: el de prohibir, asociado a los participantes y circunstancias pertinentes.

\subsubsection{Texto 5}

Si bien el escritor de este texto no integra ni reduce información, reconoce apropiadamente los agentes afectados por el proceso principal. No se apega a los equivalentes en español de las formas léxicas del texto fuente y resuelve la estructura del proceso principal de la noticia con la forma pasiva con se en español. Comparemos el comienzo del texto fuente con el del texto meta:

Texto fuente

PESHAWAR, Pakistan-Male coaches were banned yesterday from training female athletes and sports teams in a deeply conservative province in Pakistan. Male spectators also will be barred from watching sports events were female athletes compete, and male journalists are forbidden from covering them.

\section{Texto meta}

El texto se refiere (a que) se le ha prohibido a entrenadores masculinos (entrenar atletas femeninas y equipos integrados por mujeres en una provincia conservadora de Pakistán). También se prohíbe a los espectadores (concurrir a eventos disputados por mujeres), así como también se prohibe a los periodistas masculinos (cubrir dichos eventos). 
De este modo, y a partir de un circunstancial de lugar (...en una provincia conservadora de Pakistán), el escritor refiere indirectamente a los responsables de la acción de prohibir. Más adelante, el escritor identifica también el organismo que da origen al proceso (Estas nuevas medidas, decididas en una reunión de gabinete), las consecuencias de la acción tomada y el contexto en el que se inscribe el actor responsable (gobierno de Pakistán). En este sentido, el escritor incluye otras medidas tomadas en la misma dirección. Así:

Texto fuente

Authorities in North West Frontier Province have already banned all music on public buses and ordered billboards featuring images of women advertising movies or products to be torn down.
Texto meta

Las autoridades fronterizas de la provincia del Noroeste también prohibieron toda la música en ómnibus públicos y ordenaron sacar carteleras con imágenes de mujeres publicitando películas o productos.

Acabamos de ver cómo los escritores de los textos más efectivos interpretan y resuelven los patrones de Transitividad en sus producciones. A continuación, pasaremos a ver qué interpretación realizan los escritores de los textos menos efectivos para que sus producciones se alejen de los significados del texto fuente.

\subsubsection{Textos Menos Efectivos} 4.1.2.1 Texto 6

Este texto muestra un desarrollo de patrones de Transitividad que intenta replicar las formas de superficie del texto fuente. Una comparación de las formas léxico-gramaticales entre el texto fuente y el Texto 6, nos permite especular con que el escritor buscó los equivalentes en español de los términos para participantes y procesos en inglés y repitió estructura sintáctica. Por ese apego a las formas del texto fuente, el Texto 6 repite en el mismo orden que el artículo periodístico prácticamente la totalidad de los participantes y procesos. Como resultado, en lugar de ser un resumen del texto fuente (245 palabras), el Texto 6 (251 palabras) resulta más largo. De modo que, además de la oscuridad de 
significados que deriva del apego a las formas del texto fuente, nada hay de reducción de información.

Observemos las representaciones de participantes y procesos en el primer párrafo del Texto 6:

Texto fuente

PESHAWAR, Pakistan - Male coaches were banned yesterday from training female athletes and sports teams in a deeply conservative province in Pakistan. Male spectators also will be barred from watching sports events where female athletes compete, and male journalists are forbidden from covering them.

\section{Texto meta}

Entrenadores ayer fueron prohibidos de entrenar atletas femeninos y deportes de equipos en una profunda y conservadora provincia de Pakistán. Los espectadores hombres serán enrejados de mirar eventos deportivos en donde compiten atletas femeninas y los periodistas se olvidan de cubrir a ellas.

Este texto, además de no omitir información, tampoco logra integrarla y algunas de sus cláusulas se apartan notoriamente del significado del texto fuente: se observa que el escritor de este resumen no es capaz de establecer relaciones entre las tres cláusulas; su reconocimiento del proceso de prohibir ( aunque no optando por la pasiva con "se" de uso extendido en español) en la primera cláusula no le sirve de punto de apoyo para optar en el proceso 'barred' de la segunda cláusula por la opción 'prohibir'. En el ejemplo: Male spectators also will be barred que es reformulado como Los espectadores hombres serán enrejados, es muy probable que el escritor busque el término bar en su diccionario bilingüe y obtenga el equivalente español reja, tal vez como primera acepción. Dicha opción debe conformarlo aún cuando no se trata de la entrada verbo del término. En este caso, en que el escritor parece tener en claro la estructura de la forma pasiva (verbo ser + participio pasado), su versión se ajusta exclusivamente a lo que pudo resolver con ayuda del diccionario y a lo que conoce de la sintaxis del inglés; transforma el will be en serán y la forma barred en enrejados. Tampoco su reconocimiento de prohibir en la primera cláusula lo ayuda para resolver are forbidden como prohibición; muy probablemente lo interpreta como forgotten y opta por la versión se olvidan en español y además de cambiar significado 
cambia voz: transforma Voz Pasiva en Voz Activa. Este cambio podría deberse a que la forma los periodistas son olvidados de cubrir le resulte demasiado extraña comparada con la forma más usual los periodistas se olvidan de cubrir.

Otros ejemplos de apego a las formas del texto fuente que aparecen en el Texto 6 son:

Texto fuente

Asif Iqbal Daudzai told...

The decision will affect...

The Government will establish...

The province elected...

Hard liners (also) share...
Texto meta

Asif Iqbal Daudzai dijo...

La decisión afectará...

El gobierno establecerá...

La provincia eligió...

Línea dura repartió...

En cuanto al último ejemplo, que nuevamente incluye un error conceptual, el escritor parece optar por el proceso repartir como el equivalente en español de share (compartir). Una vez más, el escritor demuestra su poca sensibilidad al contexto del texto fuente.

Nos interesa analizar un último ejemplo que, si bien no se encuentra al comienzo del texto, entendemos está estrechamente ligado a las ideas del primer párrafo. Nuestra hipótesis es que nuevamente se trataría de un error de tipo conceptual que surge como consecuencia del apego a las formas y al procesamiento término por término:

Texto fuente

Several retired athletes were expected to lose (their jobs).
Texto meta

Varios atletas nacionales retirados fueron anticipados a perder (sus trabajos). 
Si el escritor busca en el diccionario bilingüe el equivalente de expect probablemente encuentre esperar, anticipar. Pudo haber intentado entonces una forma pasiva que, manejada desde lo estructural lo conduce a transformar were expected en fueron anticipados y a to lose en a perder. Elige esta opción en detrimento de la forma to be expected to...que como unidad estructural verbal de traducción correspondería a se supone que/se presume que en español. El resultado es una cláusula en la que la relación participante-proceso resulta poco efectiva ya que de ella no emergen significados coherentes.

\subsubsection{Texto 7}

El escritor de este texto reconoce participantes pero muestra limitaciones para reconocer procesos y circunstancias apropiadamente. Además, tiene dificultades para ubicar los hechos en el tiempo (Ver 4.2.2.2). Entiende que los participantes actores de la primera cláusula son profesores, lo que parece indicar o bien que piensa que son profesores los que entrenan a los atletas, o que no tiene una acabada comprensión de la situación que el texto recrea. Así, resuelve la primera cláusula:

Texto fuente

Male coaches were banned...
Texto meta

Los profesores estaban prohibidos...

Más interesante resulta, sin embargo, la forma en la que el escritor de este texto resuelve la segunda cláusula, no por su reconocimiento de los participantes (que es apropiado) sino por la resolución léxica del proceso:

Texto fuente

Texto meta 
Male spectators (also) will be barred from Los espectadores tienen el deseo de estar watching... mirando...

No es fácil intentar entender por qué reformula male spectators also will be barred from watching del modo en que lo hace. Pero lo cierto es que cambia la relación participanteproceso. La razón podría ser que la búsqueda bar no arrojó ningún resultado que le resultara coherente y su conocimiento de mundo ${ }^{12}$ le indica que los espectadores son quienes tienen el deseo de mirar; a esto podría agregarse que no haya reconocido will como auxiliar sino como sustantivo cuyo significado es deseo en español y a partir de allí haya construído su particular significado. Cualquiera haya sido el motivo para resolver de esta manera la cláusula, el resultado es un primer párrafo en el que no quedan integrados todos los participantes en el proceso principal que dio origen a la noticia; es decir: la prohibición como ejemplo del actuar de un gobierno autoritario.

Queremos detenernos, una vez más, en el siguiente ejemplo que, aunque no pertenece al primer párrafo, causó muchos problemas a los escritores de los resúmenes menos efectivos:

Texto fuente

Several retired athletes were expected to lose their jobs.
Texto meta

Varios atletas nacionales retirados estaban expectantes a perder sus beneficios.

La relación participante-proceso no es interpretada apropiadamente por el escritor del Texto 7 y esto lo lleva a generar formas en español que no construyen significados coherentes. Entendemos que, como en el caso del Texto 6, el problema más difícil de resolver se le

12 Ha habido varios intentos para explicar representaciones convencionalizadas y estereotípicas de "conocimiento de mundo" como base para la interpretación del discurso. Se puede consultar Brown, G. and Yule, G. (1983:236 y sig.) 
presenta a nivel de frase verbal que no puede interpretar como unidad significativa de traducción. (Cf. 4.2.2.2)

La poco efectiva interpretación de muchos de los significados en el texto sea tal vez la razón por la que el escritor resuelve del modo en que lo hace el siguiente complejo clausal hacia el final del texto:

Texto fuente

Texto meta

Police often douse (gasoline on piles of video cassettes and compact discs seized during "anti-obsenity campaigns").

La policía compraba (durante campañas en contra a la obscenidad videocasetes y compact discs).

Si el escritor hubiera entendido el sentido de las relaciones entre participantes y procesos en el primer párrafo es poco probable que pensara que la policía de un gobierno autoritario comprara elementos que pretende quitar por la fuerza a quienes los tengan o consuman. Sin duda, un bajo umbral en el reconocimiento de las estructuras léxico-gramaticales afecta las relaciones en el Sistema de Transitividad, en particular, la interpretación de los procesos.

\subsubsection{Texto 8}

Nuestra hipótesis con respecto a la resolución de este texto es que el escritor, debido a limitaciones en su umbral lingüístico, reconoce algunos participantes y algunos procesos pero no los relaciona apropiadamente. Así, por ejemplo, en su primera cláusula expresa: $E l$ gobierno de Pakistán no permite...Es decir, identifica participante y le atribuye su proceso correspondiente. Más aún, expresa la relación participante actor+proceso de modo adecuado y hasta se aparta de las formas del texto fuente que evitan mencionar el actor en estructura de voz pasiva. 
Sin embargo, luego reformula Male spectators will be barred from watching sports events como ...(que) mujeres ingresen (a los estadios). En esta segunda claúsula, el escritor atribuye el proceso al participante incorrecto. Se trata, por otra parte, de uno de los participantes centrales de la realidad narrada. El escritor, entonces, comienza a construir un núcleo textual que se aparta del tema del texto fuente debido a sus limitaciones a nivel léxico-gramatical. No reconoce participantes afectados por la acción central del texto (la prohibición) y selecciona una tercera cláusula que indica que tampoco interpreta las circunstancias del cuándo y el dónde:

Texto fuente

(The new measures,) decided at a provincial Cabinet meeting (yesterday, mark the latest attempt)
Texto meta

Esto fue decidido en Cabinet.

De este modo, el escritor transforma en proceso lo que es especificación de participante en el texto fuente y omite el proceso más importante de la cláusula (mark) que anuncia el estado de situación: las medidas como parte de un gobierno de línea dura. La selección de Cabinet en su forma original es otro indicio del bajo umbral lingüístico del autor de este texto.

Nos gustaría detenernos en un curioso ejemplo de la realidad reconstruida por el escritor del texto 8:

Texto fuente

The ban on men's involvement in women's sports was aimed at promoting a traditional style of Islamic sports, Daudzai said, without elaborating.
Texto meta

Las bandas de hombres involucradas en deportes son reelaboradas 
El escritor transforma ban on men's involvement in women's sports en las bandas de hombres involucradas en deportes y a ese participante le atribuye una función de agente afectado mediante el proceso son reelaboradas. Es probable, entonces, que el escritor reconozca una forma pasiva, que en el original es was aimed at promoting pero no el proceso al que pertenece (aim at promoting) y lo que hace es trasladarla al circunstancial de modo que en el original está asociado al proceso verbal said correspondiente al participante Daudzai.

Lo que esta curiosa reconstrucción sugiere es que el escritor no se sensibiliza frente a la selección tan poco coherente de relaciones entre participantes y procesos que él mismo construye. Opta tal vez por la forma bandas porque le parece muy similar a la forma inglesa ban, aún cuando a comienzos del artículo resolvió el proceso banned con el equivalente en español no permite. ${ }^{13}$

Un último ejemplo que confirma que el bajo umbral lingüístico de este escritor le impide relacionar participantes y procesos de modo tal de construir el Campo del texto en forma coherente y sin traicionar los significados del texto fuente aparece hacia el final del texto:

Texto fuente

Authorities in North West Frontier Province already have ordered billboards featuring images of women advertising movies or products to be torn down.
Texto meta

Las autoridades pusieron carteleras de las imágenes de futuras mujeres publicitando películas o productos, que fueron o son arrancadas.

\footnotetext{
${ }^{13}$ Es justo mencionar que el ejemplo en cuestión incluye, además, una metáfora ideacional. El proceso material to ban es representado como participante: ban. Sin duda esta transferencia oscurece los significados. Para información sobre metáforas gramaticales consultar Halliday, 1985: 321
} 
¿Cómo no puede entender el escritor del Texto 8 que es poco probable que las autoridades de un gobierno autoritario como el que describe el artículo pongan carteleras con imágenes de mujeres publicitando películas o productos? ¿Por otra parte, a qué se refiere el escritor cuando habla de futuras mujeres? Finalmente, ¿quiénes arrancan las carteleras?, ¿a quién atribuye el escritor esta acción si las autoridades son los actores del proceso de poner carteleras? Una vez más, en este resumen la interpretación de las relaciones entre participantes y procesos resulta poco efectiva a lo largo de todo el texto y, por lo tanto, el lector del resumen no puede reconstruir la realidad que el texto fuente construye.

\subsubsection{Texto 9}

Si bien el escritor del Texto 9 reconoce una buena parte de los participantes y procesos involucrados apropiadamente, es la estructuración léxica lo que empobrece su producción. Así:

Texto fuente

Texto meta

Male coaches were banned... ...los entrenadores masculinos fueron separados (de las atletas femeninas)...

muestra, como en los ejemplos de los resúmenes anteriores, un apego a las formas del texto fuente que ignora la forma pasiva con se mucho más natural en español.

Por otra parte, la no inclusión de uno de los participantes afectados en el primer párrafo (espectadores masculinos-Ver Apéndice 2) indicaría que el escritor no alcanza a comprender el núcleo informativo central que es la separación total entre hombres y mujeres en el deporte. 
En lo que respecta a la interpretación de las consecuencias de las medidas foco de la información, el ejemplo:

Texto fuente

Several retired athletes were expected to lose (their jobs at girls'schools)
Texto meta

Ex atletas nacionales encaran expectativas (de abrir escuelas)

sugiere que el escritor no reconoce el significado de were expected to lose (their jobs at girls'schools) y que, como en el contexto que construye está presente la idea de separación de deportes femeninos y masculinos entiende que bien puede hacer referencia el texto a la necesidad de escuelas sólo para mujeres deportistas. Lo que no queda claro es qué significado quiere recuperar cuando dice: ex atletas...encaran expectativas de abrir escuelas. En otras palabras, cuál es el significado del proceso encarar expectativas de algo.

\subsubsection{Texto 10}

El Texto 10 es otra muestra de cómo, limitaciones de tipo léxico-gramatical llevan al escritor a reconstruir una realidad en su texto que no es la manera en que el texto fuente la construye. El escritor ignora 2 de los 3 participantes afectados por el proceso central (prohibir) de la noticia y reconstruye, tal vez a partir de términos aislados, su propia realidad. Transforma a los entrenadores hombres en entrenadores de hombres y de agentes afectados en actores de la acción principal. Observemos cómo resuelve la primera cláusula del texto fuente:

Texto fuente

Texto meta 
Male coaches were banned...

Los entrenadores de hombres prohibieron (la enseñanza de atletas femeninos en aquellos deportes considerados femeninos)

En el ejemplo anterior la relación participante-proceso del texto fuente es alterada: son los entrenadores de hombres los que prohibieron la enseñanza de atletas femeninos. No hay mención en este texto de los agentes afectados periodistas y espectadores hombres, ni de la responsabilidad que le cabe al gobierno como actor del proceso principal (Ver Apéndice 2). Probablemente la responsabilidad que atribuye a los entrenadores, sin embargo, lo conduzca a construir una realidad que sólo tiene unos pocos puntos en común con la del texto-fuente. Por otra parte, la acción de prohibir la enseñanza de atletas femeninos en aquellos deportes considerados femeninos no ayuda a la construcción de una relación participante-proceso que sea coherente.

Otro ejemplo interesante que indica la poca comprensión del escritor del Texto 10 y que se refleja en la selección de participantes, procesos y circunstancias y las relaciones entre ellos es el siguiente:

Texto fuente

Texto meta

The new measures...mark the latest attempt by Esta última noticia es (el último intento por the six-party religious alliance to impose a imponerse al Islam). strict version of Islam.

Nos preguntamos a qué ultima noticia se refiere el escritor y de quién parte el intento por imponerse al Islam. El escritor elige un proceso relacional para describir un contexto que no comprende y así construye una realidad poco coherente en la que una última noticia resulta ser un intento por imponerse al Islam. La falta de conocimiento de mundo, creemos, también influye aquí en las estructuras resultantes. 
En esta sección, presentamos ejemplos de cómo construyeron los escritores de los resúmenes de nuestro corpus la relación participante-proceso. En la siguiente sección, compararemos los textos más efectivos con los menos efectivos para establecer algunas conclusiones preliminares.

\subsubsection{Comparaciones en el Sistema de Transitividad}

A partir de los patrones de Transitividad podemos interpretar el contenido del discurso: los procesos, los participantes y sus actividades relacionadas. Podemos ver cómo se construye la realidad del texto. En los resúmenes que nos ocupan, observamos que, al igual que en el texto fuente, los procesos materiales dominan los significados experienciales. Esta es una característica compartida por los diez textos. De modo que, no se podría concluir que la mayor o menor efectividad de los resúmenes sea consecuencia de que la selección del tipo de procesos no coincide con las del texto fuente.

Por otra parte, en general, observamos que los escritores identifican a los participantes del evento relatado. Sin embargo, es en la identificación de los roles y las relaciones entre los participantes en que los textos menos efectivos difieren de los más efectivos. Incluso, los escritores de los textos menos efectivos confunden las circunstancias que rodean las acciones de los participantes. Entonces, optan por reconstruir la realidad como la imaginan. Eligen una forma en español muy similar a la forma léxica del inglés sin prestar atención al significado.

En los textos menos efectivos, la decodificación lingüística es del tipo uno a uno. Más aún, muchas veces los escritores eligen la primera acepción que entrega el diccionario bilingüe. 
Otras veces, optan por lo que llamamos falsos amigos ${ }^{14}$. Los escritores buscan la palabra en el diccionario y copian en su texto el equivalente en español. Seleccionan la primera entrada aún cuando claramente se aleja del contexto del texto y se muestran insensibles a la falta de coherencia. Ya mencionamos, en este sentido, la elección, en el Texto 6 de serán enrejados de mirar como equivalente del inglés will be barred from watching.

Una variable más a considerar en relación a las soluciones más o menos efectivas a los cambios de código lingüístico es el diccionario bilingüe que los escritores, en este caso de los resúmenes de nuestro corpus, utilicen. Los diccionarios con enfoques discursivos, que no sólo proveen los equivalentes en L2 de términos aislados sino también de frases y colocaciones del término en cuestión, suelen ser de mucha ayuda. Pero ocurre muchas veces que el estudiante cree que con encontrar una forma equivalente en español al término en inglés soluciona el problema del significado. Se contenta con el cambio de código uno a uno y da por concluida su tarea cuando logra que cada término en L2 tenga su “equivalente" en L1.

El significado fundamental de los procesos materiales es que una entidad hace algo, lleva a cabo una acción (Eggins, 1994: 230). La identificación del actor responsable de los procesos descriptos es un aspecto muy importante del análisis. El actor no necesariamente tiene que estar mencionado pero el significado no debe perderse. Un problema que parecen no poder resolver los escritores de los textos menos efectivos es la recuperación del agente de la acción. Al no poder reconocer la relación entre el proceso central de la cláusula y los agentes afectados, no pueden reformular esas relaciones en un nuevo texto que mantenga equivalencia informativa con el texto fuente. En consecuencia, optan por soluciones que resultan poco efectivas.

\footnotetext{
${ }^{14}$ En lingüística, llamamos falsos amigos a aquellos términos de parecida o idéntica grafía que en un idioma significan una cosa y en otro tienen un significado diferente. Constituyen una grave interferencia lingüística en la traducción, ya que originan graves errores de significado e ininteligibilidad.
} 
Es justo mencionar que el texto fuente posterga hasta el segundo párrafo la mención del actor del proceso central relatado y, por otra parte, lo menciona a partir de una frase preposicional de complemento agente. Lo que hace el escritor del artículo periodístico es retomar el proceso central del núcleo informativo desplegado en las cláusulas del primer párrafo (prohibir) con una frase nominal y atribuir el hecho en cuestión al verdadero responsable: The new measures, decided (...) by the six-party religious alliance. Esta manera indirecta de hacer referencia al actor sin duda representa un problema adicional que no todos los escritores de los resúmenes pueden resolver apropiadamente.

En los textos más efectivos, como ya indicáramos, los procesos seleccionados son en su mayoría materiales. Los escritores identifican actores y agentes afectados. Sin embargo, no replican las formas del texto fuente. No parten de la forma sino del significado. Así, por ejemplo, several retired athletes were expected to lose their jobs at girls'schools because of the rules queda resuelto en el Texto 2: estas medidas...afectarán...a atletas retirados que trabajan en escuelas de mujeres.

Además, los escritores de los textos más efectivos eligen opciones que muestran una interpretación y elaboración más adecuada de los significados. Integran información y hasta reacomodan el orden de los procesos. Ya vimos cómo, en el Texto 3, el escritor reelabora la información de los párrafos 1 (las medidas tomadas a partir de la mención de cada uno de los agentes afectados) y 2 (el organismo de decisión) del texto fuente y produce: La alianza religiosa el partido de los seis...en un intento de imponer una estricta versión del Islam, decidió separar de los eventos deportivos femeninos toda actividad desarrollada por hombres (entrenadores, profesores, periodistas que cubren dichos eventos). El reconocimiento de participantes y procesos de manera apropiada le permite al escritor no 
traicionar la representación del texto fuente. Más aún, le permite respetar los significados del texto original de forma que los textos apegados a la forma no logran hacer.

Los escritores de los textos menos efectivos no parecen reconocer que "el propósito fundamental para el que la lengua ha evolucionado es el de permitirnos transmitir significados. En otras palabras, los usuarios de la lengua no interactúan para intercambiar sonidos, palabras u oraciones. La gente interactúa para construir significados en forma conjunta: para derivar significados del mundo que los rodea y de aquellos con quienes interactúa." (Eggins, 1994:11) En los textos menos efectivos, encontrar un mensaje que fluya claramente es casi imposible. La identificación poco apropiada de la relación entre participantes y procesos del primer párrafo afecta la interpretación de los significados del resto del texto. Por lo tanto, estos resúmenes no constituyen en sentido estricto un "texto". (Eggins, 1994: pág. 81 y sig.)

Quisimos en esta sección comparar la construcción de los significados experienciales en los textos más efectivos con la construcción de significados experienciales en los textos menos efectivos. A continuación, pasaremos a analizar nuestro corpus desde el Sistema de Modo/Temple.

\subsection{SISTEMA DE MODO/TEMPLE}

A través de los patrones léxico-gramaticales del Sistema de Modo/Temple se realizan los significados interpersonales que construyen la variable situacional Tenor del texto. Esta relación involucra, entre otras, la selección de Voz y Modalidad en el grupo verbal. En nuestro corpus, las reformulaciones en español de algunos grupos verbales ofrecieron a 
algunos de los escritores de los resúmenes dificultades de interpretación. Las realizaciones en los textos meta de la relación $\mathrm{S}+\mathrm{F}+$ Predicador nos remite a en qué medida la interpretación participante-proceso afecta el Sistema de Modo/Temple.

Es de esperar que los escritores del resumen del artículo periodístico a través de las selecciones de Sujeto/Verbo Finito respeten los significados del texto fuente. El Sujeto ${ }^{15}$ es el elemento en referencia al cual la proposición puede ser negada o afirmada, el elemento sobre el cual se predica algo. El Operador Finito Temporal cumple la función de circunscribir la proposición en tiempo y espacio e indicar polaridad (positiva o negativa) mientras que el Operador Finito Modal realiza elecciones intermedias entre los dos polos de esa polaridad. El Sujeto y el Operador Finito constituyen el componente Modo/Temple de la cláusula.

En los casos en que el Operador Finito marca el tiempo en relación al hablante/escritor, y no se expresa ningún otro tipo de Modalidad, el hablante/escritor está señalando una posición definida con respecto a lo que dice, argumenta acerca de si algo ES o NO ES. Pero estos dos polos de polaridad no son la única posibilidad. Entre los dos extremos hay una variedad de opciones de grados de certeza o frecuencia (modalización) y de obligatoriedad, necesidad y deseo (modulación) (Eggins, 1994:166, Butt, D. y otros, (2003[1994]:113 y sig.). Modalidad es el término general que indica la postura del hablante/escritor frente a la cláusula y es a menudo un área que ocasiona dificultades para la interpretación apropiada de los significados.

Los significados interpersonales que se generan a partir del TENOR del contexto señalan el tipo de intercambio que el hablante/escritor construye con su oyente/lector. "El sujeto y la

\footnotetext{
${ }^{15}$ Sujeto Gramatical (Halliday, 1985: 32)
} 
conjugación elegidos en la interacción con otros indican relaciones de poder o de solidaridad, distintos grados de intimidad, actitudes y opiniones. Por ello se dice en la LSF que, para los significados interpersonales, la relación crucial está en las relaciones gramaticales del sujeto y del verbo conjugado" (Montemayor-Borsinger, 2005:28). Dentro del procesamiento del verbo conjugado no sólo la polaridad sino también la Modalidad deben ser reconocidas apropiadamente. Cuando esto no ocurre se alteran sensiblemente los significados.

El resto de la estructura constituye el Residuo, que consiste en elementos funcionales de tres tipos: Predicador, Complemento y Adjunto. El Predicador es el elemento no-finito de la estructura verbal y especifica el proceso (acción, evento, proceso verbal, relación) que se predica del Sujeto (Halliday, 2004:122). El Complemento es un elemento en el Residuo que tiene potencial para ser Sujeto pero que no lo es. Comúnmente está realizado en una frase nominal. El Adjunto es un elemento que no tiene potencial para ser Sujeto y que típicamente se realiza en una frase preposicional o grupo adverbial.

En nuestro corpus, analizaremos las elecciones en los textos más efectivos para poder reconocer aquellos significados que no traicionan la idea que el escritor del texto fuente se propuso transmitir. Seguidamente, las compararemos con las de los resúmenes menos efectivos. Estas elecciones, en la mayoría de los casos, resultan en textos poco coherentes $\mathrm{y}$, por lo tanto, de difícil interpretación para el lector. Veremos entonces qué tipo de estructura verbal resulta más problemática a los escritores de los resúmenes menos efectivos.

Nos concentraremos en el componente Modo/Temple de la claúsula; es decir, en las elecciones de Sujeto+Finito. Sin embargo, puesto que los escritores de los textos menos 
efectivos no pueden resolver problemas ligados a la interpretación de la voz, el aspecto y la modalidad, también consideraremos la interpretación de Predicadores, particularmente ejemplos de Predicador complejo, cuando notemos que dicha forma representó un escollo para la comprensión del texto fuente y resultó en significados poco efectivos. Una vez más, para facilitar esta parte del análisis, utilizaremos cursiva para destacar $\mathrm{S}+\mathrm{F}+$ Predicador (El análisis completo de los textos se incluye en el Apéndice 4).

\subsubsection{Textos Más Efectivos}

\subsubsection{Texto 1}

El escritor de este texto reconoce apropiadamente los constituyentes del Bloque Modo/Temple como se desprende de las selecciones léxico-gramaticales de las dos primeras cláusulas de su resumen:

Texto fuente

PESHAWAR, Pakistán-Male coaches were banned yesterday from training female athletes and sports teams in a deeply conservative province in Pakistan. Male spectators also will be barred from watching sports events were female athletes compete, and male journalists are forbidden from covering them (...) The new measures, decided at a provincial Cabinet meeting yesterday, mark the latest attempt by the sixparty religious alliance to impose a strict version of Islam. The decision will affect thousands of girls and women in the province who compete in sports such as tennis, table tennis and field jockey

\section{Texto meta}

En Peshawar, una provincia del Noroeste de Pakistán, prohibieron a entrenadores, espectadores y periodistas varones (el participar de cualquier manera en deportes de mujeres). Estas medidas, tomadas por el Gabinete provincial, fueron impulsadas por una alianza religiosa islámica y afectarán a muchas mujeres que practican deportes y a atletas retirados que trabajan en escuelas de mujeres.

Si bien el Sujeto activo correspondiente a la forma verbal prohibieron no aparece explicitado en la primera cláusula, la elección de estructura pasiva de la segunda cláusula: (estas medidas) fueron impulsadas asociada al Adjunto Circunstancial por una alianza religiosa islámica completa lo que podría considerarse el núcleo informativo central de la 
noticia. Queda claro que el escritor construye a partir de los significados del texto fuente sin apego a las formas de superficie.

También construye apropiadamente la cláusula que describe el motivo de las medidas tomadas como lo muestra el siguiente ejemplo:

Texto fuente

Texto meta

The ban on men's involvement in women's sports was aimed (at promoting a traditional style of Islamic sports)

La prohibición de que los hombres se involucren en deportes de mujeres fue orientada (a promover un estilo tradicional de deportes islámicos)

El escritor reconoce apropiadamente Finito temporal y Predicador (was aimed at promoting) en el texto fuente al igual que su Sujeto gramatical.

En las cláusulas de expansión del tópico del resto del texto el escritor construye adecuadamente las estructuras de Modo/Temple: Sujetos + Finitos (y Predicadores). Observemos algunos ejemplos:

Texto fuente

The Government will establish...

The province elected

Authorities in the North West Frontier province have banned..., ordered...

Police often douse gasoline...videocasettes and compact discs seized...
Texto meta

El gobierno establecerá...

La provincia eligió...

Autoridades de la provincia de Peshawar prohibieron..., ordenaron...

...y fueron incendiados compact discs $y$ videocasetes secuestrados 


\subsubsection{Texto 2}

El escritor de este texto elige como comienzo de su resumen la opción El texto trata...Esta primera selección de Sujeto+Operador Finito+Predicador le permite introducir un Adjunto de Tema en el que precisamente incluye una parte importante de la información que motivó la noticia: sobre las decisiones tomadas por un gobierno muy conservador y muy estricto en Pakistán... Se puede comprobar desde las elecciones de la primera cláusula que el escritor interpretó apropiadamente los significados del texto fuente. El escritor hace referencia, en primer lugar, al contexto (¿Quién? Un gobierno muy conservador y muy estricto; ¿Dónde? En Pakistán, más especificamente en la provincia de la Frontera Noroeste ubicada junto a la frontera con Afganistán...) y a la noticia que originó el artículo después. Comparemos los comienzos del texto fuente y el texto meta:

Texto fuente

PESHAWAR, Pakistan-Male coaches were banned yesterday from training female athletes and sports teams in a deeply conservative province in Pakistan. Male spectators also will be barred from watching sports events were female athletes compete, and male journalists are forbidden from covering them
Texto meta

(El texto trata sobre) las decisiones tomadas por un gobierno muy conservador y muy estricto en Pakistán, más específicamente en la provincia de la Frontera Noroeste ubicada junto a la frontera con Afganistán...

Las nuevas medidas indican que las mujeres ya no podrán ser entrenadas a nivel deportivo por los hombres; tampoco podrán ser vistas por espectadores de sexo masculino ni los periodistas hombres podrán cubrir los eventos en los cuales participen mujeres

Para este escritor, que identifica apropiadamente participantes, procesos y circunstancias asociadas desde el comienzo del texto, la expansión sobre los detalles del hecho contado no ofrece dificultades (Ver apéndices). 


\subsubsection{Texto 3}

El escritor de este texto realiza selecciones léxico-gramaticales en el sistema de Modo/Temple para su cláusula introductoria que denotan una acabada comprensión del núcleo informativo textual.

Texto fuente

PESHAWAR, Pakistan-Male coaches were banned yesterday from training female athletes and sports teams in a deeply conservative province in Pakistan. Male spectators also will be barred from watching sports events were female athletes compete, and male journalists are forbidden from covering them (...) The new measures, decided at a provincial Cabinet meeting yesterday, mark the latest attempt by the sixparty religious alliance to impose a strict version of Islam
Texto meta

La alianza religiosa "El partido de los seis" (...), en un intento de imponer una estricta versión del Islam, decidió separar de los eventos deportivos femeninos toda actividad desarrollada por hombres (entrenadores, profesores, periodistas que cubren dichos eventos).

La combinación Sujeto (La alianza religiosa "El partido de los seis")+Operador Finito temporal (decidió) +Predicador (separar) +Complemento y Adjunto Circunstancial respeta los significados interpersonales del texto fuente aunque no se ajuste a las formas del mismo y aparece como apropiada para concentrar el núcleo informativo del texto. Por tratarse de la primera cláusula del resumen es, además, una selección exitosa como punto de partida para incorporar los detalles de la información.

Observamos cómo el escritor identifica al actor principal de los hechos, que en el texto fuente aparece en el segundo párrafo y lo convierte en sujeto activo (la alianza religiosa “El partido de los seis”) y le atribuye el Operador Finito + Predicador Complejo: decidió 
separar. La cláusula se completa con los significados interpersonales que el texto fuente realiza: ...de los eventos deportivos femeninos (adjunto) toda actividad desarrollada por hombres (entrenadores, profesores, periodistas que cubren dichos eventos) (complemento). Por último, integra en un intento por imponer una estricta versión del Islam a modo de adjunto circunstancial; información que en el texto fuente aparece recién en el segundo párrafo y como cláusula principal: The new measures...mark the latest attempt by the sixparty religious alliance to impose a strict version of Islam.

Asimismo, el escritor resuelve la clásula: Several retired national athletes were expected to lose (their jobs) de manera tal que refleja comprensión de significados; no se apega a la forma del texto fuente y construye a partir de los significados: Muchos atletas retirados temen perder (su trabajo). Rescata la idea de modalidad (modalización: probabilidad) en el Predicador compejo (Several retired national athletes) were expected to lose y opta por la forma (Muchos atletas retirados) temen perder que, si bien cambia la temporalidad del original sigue siendo apropiada en el contexto del texto.

El escritor enriquece el contexto específico de la noticia en cuestión con la selección del Bloque Modo/Temple: La provincia ha elegido (una línea islámica bastante dura en las últimas elecciones), como interpretación de The province elected (a hard-line Islamic government in last October's elections), estructura que le permite construir el escenario explicativo de otras medidas en la misma dirección del hecho principal que originó la noticia (Ver Apéndice 4). 


\subsubsection{Texto 4}

Por alguna razón, tal vez sea el apego a las formas, los escritores de los textos menos efectivos ignoran la forma pasiva con $s e^{16}$ como la más natural en español. El autor de este texto, por el contrario, elige comenzar: se prohibió; es decir, el escritor reconoce apropiadamente temporalidad y ausencia de Modalidad. Así, la selección apropiada de Operador Finito y Predicador, le permite respetar los significados del texto fuente:

Texto fuente

PESHAWAR, Pakistan-Male coaches were banned yesterday from training female athletes and sports teams in a deeply conservative province in Pakistan
Texto meta

Se prohibió a entrenadores hombres entrenar deportistas mujeres en una provincia pakistaní.

Completa el núcleo informativo optando por la forma verbal: ocurrió (lo mismo), que completa con el resto de los complementos: a periodistas y espectadores masculinos como interpretación de Male spectators also will be barred from watching sports events were female athletes compete, and male journalists are forbidden from covering them Se trata en este caso de un escritor que realiza transformaciones de forma, producto de una mayor elaboración. Este mejor trabajo de interpretación de significados queda también demostrado con los siguientes ejemplos que resultaron particularmente difíciles de resolver a los escritores de los resúmenes menos efectivos:

Texto fuente

The new measures, decided at a provincial Cabinet meeting yesterday, mark the latest attempt by the six-party religious alliance to impose a strict version of Islam.
Texto meta

Las medidas, decididas en Gabinete provincial, fueron tomadas por la alianza religiosa del Islam.

\footnotetext{
16 Consultar interpretación ergativa: para cláusulas efectivas receptivas no agentivas en inglés, Halliday (2004: 288-9) y para información sobre cláusulas efectivas receptivas no agentivas en español, Ghio y Fernández (2008: 120)
} 
Several retired national athletes were expected to lose their jobs.
Atletas nacionales retirados podrían quedar sin trabajo.

El primer ejemplo selecciona apropiadamente: Las medidas, (decididas en Gabinete provincial,) fueron tomadas (por la alianza religiosa del Islam); Sujeto (Las medidas) +Finito temporal (fueron) +Predicador (tomadas) realizan los significados del texto fuente aunque las formas no coincidan en su totalidad. El segundo ejemplo: Atletas nacionales retirados podrían quedar (sin trabajo) es la resolución en español de los significados del texto fuente: Several retired athletes were expected to lose their jobs. La combinación Operador Finito+Predicador Complejo were expected to lose es una estructura pasiva que, si se traduce textualmente resulta incoherente. El escritor aquí capta el significado del Predicador complejo modalizado del texto fuente: "posibilidad de que algo suceda". Una vez que interpreta el significado elige la combinación Operador Modalizado (podrían)+Predicador (quedar) para realizar el significado en español. 


\subsubsection{Texto 5}

Una vez más el escritor recurre a la cláusula con Sujeto El texto + Finito temporal+Predicador se refiere para introducir la información que dio origen a la noticia periodística; es decir, la prohibición a entrenadores, espectadores y periodistas hombres. Sin embargo, opta por las formas pasivas con se: se ha prohibido, se prohíbe, se prohíbe para circunscribir la proposición en el tiempo. La ubicación espacial la construye a partir del Adjunto Circunstancial: en una provincia conservadora de Pakistán que completa la información que constituye el núcleo textual. Así:

Texto fuente

PESHAWAR, Pakistan-Male coaches were banned yesterday from training female athletes and sports teams in a deeply conservative province in Pakistan. Male spectators also will be barred from watching sports events where female athletes compete, and male journalists are forbidden from covering them.
Texto meta

El texto se refiere a que se le ha prohibido a entrenadores masculinos entrenar a atletas femeninas y equipos integrados por mujeres en una provincia conservadora de Pakistán. También se prohibe a los espectadores concurrir a eventos disputados por mujeres, así como también se prohíbe a los periodistas masculinos cubrir dichos eventos.

Nos interesa mencionar un ejemplo que si bien no pertenece al primer párrafo lo hemos analizado en distintos resúmenes por las dificultades que ha causado su interpretación. Veamos cómo lo resuelve el escritor de este resumen:

Texto fuente

Several retired athletes were expected to lose their jobs.
Texto meta

Muchos atletas retirados se quedarán ( $\sin$ trabajo). 
En realidad la cláusula en español no respeta exactamente el significado del texto fuente; el escritor del resumen debió elegir, para no traicionar el texto original: Muchos atletas retirados se quedarían/podrían quedarse (sin trabajo). La estructura verbal modalizada del texto fuente incluye la opinión del escritor de la noticia periodística acerca de la posibilidad de los atletas retirados de perder sus trabajos ${ }^{17}$. La idea de posibilidad se pierde en la estructura verbal del resumen: se quedarán, donde no hay modalidad sino polaridad. Sin embargo, dicha elección no contradice el contexto que se va construyendo ni expresa ideas incoherentes. No obstante, una vez más la forma pasiva "were expected to lose" no le permite al escritor del resumen recuperar todos los significados.

Hemos mostrado ejemplos de cómo los escritores de los resúmenes más efectivos interpretan y construyen los patrones de Modo/Temple del texto fuente. A continuación, incluiremos ejemplos de construcción de patrones de $\mathrm{S}+\mathrm{F}+$ Predicador en los resúmenes menos efectivos.

\subsubsection{Textos Menos Efectivos}

\subsubsection{Texto 6}

Tanto las selecciones de Sujeto como las de Finito y Predicador que realiza el escritor intentan ser (aunque no siempre con éxito) los equivalentes léxicos en español de las formas finitas y Predicadores en inglés. Así:

Texto fuente

Male coaches were banned

Male spectators will be barred

Asif Iqbal Daudzai, information minister of the North West Frontier province told
Texto meta

Entrenadores fueron prohibidos

Los espectadores hombres serán enrejados

Asif Iqbal Daudzai, ministro de información del Noroeste de la provincia de Frontera dijo

\footnotetext{
${ }^{17}$ Para más información sobre metáforas de modalidad consultar Halliday, 1985: 334-340
} 
Por otra parte, ya explicamos cómo los escritores de los textos menos efectivos ignoran la forma verbal pasiva con se tan útil en español (Cf.4.1.2.1). Tal vez sea ese apego a las formas junto con el no reconocimiento de la cláusula modificadora de participio pasivo lo que lleva al escritor de este texto al siguiente intento de resolución de significados del texto fuente:

Texto fuente

The new measures, decided at a provincial Cabinet meeting yesterday, mark (the latest attempt by the six-party religious alliance to impose a strict version of Islam).
Texto meta

Las noticias tomadas, el gabinete decidió encontrarse ayer, marcan (el último intento de la alianza religiosa por la fiesta-seis para imponer una estricta versión del Islam).

El participio pasivo, particularmente en relativas reducidas, a menudo ocasiona problemas a los alumnos cuyo umbral lingüístico es bajo. Lo interpretan como un finito en pasado y esa manera de resolver la estructura resulta en incoherencias que se reflejan a nivel textual. En el caso que analizamos, el escritor es insensible a la interrupción que provoca la cláusula que transformó en finita en el flujo de la información. Queda claro que está interpretando inadecuadamente la relación participante-proceso: no es "el Gabinete (participante actor) el que decidió encontrarse" (proceso) sino que "las medidas (meta) fueron decididas (proceso) por la Alianza Gobernante (participante actor).

Donde sí el escritor opta por una forma con se en español es en el siguiente ejemplo: male journalists are forbidden from covering them (sports events). Sin embargo, como ya se ha dicho, (Cf 4.1.2.1) la opción que selecciona en español es: Los periodistas se olvidan (de cubrir a ellas). El escritor opta por una forma activa donde el proceso forbidden debe haber 
sido interpretado como forgotten y de ahí que reformule al español se olvidan y no se prohíbe. ${ }^{18}$ En "se" olvidan estamos en presencia del valor cuasi-reflejo del se que acompaña a los verbos pronominales que, según explica Bello (1998[1847]) es de toda persona y constituye con la forma verbal una única unidad sintáctica; en cambio, el se cuasi-reflejo de las construcciones pasivas es siempre de tercera persona y marca la indeterminación del agente o actor de la acción marcada por el verbo. Entonces, aunque el operador finito respete tiempo y polaridad de la versión en inglés, poco contribuye la opción en español a la coherencia global del texto considerando la poco exitosa selección del proceso.

Nos detendremos ahora en otro ejemplo que, si bien no pertenece al primer párrafo, muestra cómo los problemas de interpretación de la relación participante-proceso afectan la relación $\mathrm{S}+\mathrm{F}+$ Predicador por tratarse de una estructura verbal pasiva modalizada. Veamos cómo trata de resolverlo este escritor:

Texto fuente

Several retired athletes were expected to lose their jobs.
Texto meta

Varios atletas nacionales retirados fueron anticipados a perder sus empleos.

El escritor, una vez más, intenta replicar las formas del texto fuente. Cuando decimos replicar las formas nos referimos no sólo a las formas lexicales sino también a la estructura. Ya se ha mencionado (Cf. 4.1.2.1) cómo pensamos que el escritor procede: busca expect en el diccionario y obtiene como una de sus acepciones anticipar. Luego reformula were expected como fueron anticipados y la forma de infinitivo to lose por la forma de infinitivo en español a perder. Insensible a la poca coherencia de Varios atletas nacionales retirados fueron anticipados a perder (sus empleos) no considera ni la forma verbal pasiva con se ni un significado modalizado más apropiado al contexto que el texto fuente construye como podría ser: Se presume que varios atletas nacionales retirados podrían perder sus trabajos.

\footnotetext{
${ }^{18}$ Para información acerca del pronombre se consultar García Negroni, M. Marta (2010:427 y sig.)
} 


\subsubsection{Texto 7}

En este texto, en el que, una vez más, no hay opciones de forma pasiva con se para el español, el mayor problema que parece presentarse al escritor es el de decidir en las formas pasadas finitas entre las opciones de pretérito perfecto absoluto o simple y pretérito imperfecto. Veamos el siguiente ejemplo:

Texto fuente

PESHAWAR, Pakistan-Male coaches were banned yesterday (from training female (de entrenar atletas femeninos)

Texto meta

Los profesores estaban prohibidos desde ayer athletes)

Lo que este ejemplo parece mostrar, más allá de la elección inapropiada de la forma verbal finita, es que el escritor no es sensible a la poca coherencia de la forma por la que opta desde el punto de vista contextual. Con la elección del Adjunto...desde ayer...que representa un significado "puntual" que hace referencia al comienzo de la acción, la forma del imperfecto no es la más apropiada. ${ }^{19}$

Del mismo modo:

Texto fuente

Male spectators also will be barred (from watching ...)
Texto meta

Los espectadores tienen el deseo (de estar mirando...)

Como ya se ha dicho, el escritor parece confundir la función de will al que no reconoce como auxiliar futuro sino como sustantivo con el significado de deseo (Cf. 4.1.2.2). En

\footnotetext{
19 "En los tiempos imperfectos, la atención del que habla se fija en el transcurso o continuidad de la acción, sin que le interesen el comienzo o el fin de la misma. En los perfectos se resalta la delimitación temporal." Para una explicación más detallada sobre la expresión del tiempo en español se puede consultar Gili y Gaya, Samuel (1960) y García Negroni, M. Marta (2010)
} 
cuanto a be barred from watching, el escritor lo reformula como de estar mirando. El resultado de esta resolución de frase verbal cambia de forma sustancial el significado del componente verbal del texto fuente. Por un lado, el proceso de prohibir no se recupera en la versión en español y, por otro, ya no son los espectadores quienes sufren el efecto de la prohibición (que, por otra parte, es el hecho que dio origen a la noticia) sino sujetos sobre los que se cuenta un hecho de la voluntad.

Volvamos a uno de los ejemplos que, aunque no aparece en el primer párrafo, más problemas causó a los escritores de los textos menos efectivos:

Texto fuente

Several retired athletes were expected to lose their jobs
Texto meta

Varios atletas nacionales retirados estaban expectantes a perder sus beneficios

Ya hablamos del problema que esta estructura verbal representa por tratarse de una estructura pasiva modalizada. El escritor debe reconocer el hecho relatado en referencia a su contexto temporal en cuanto a evento de habla (Tiempo Primario) y en referencia al juicio del hablante/escritor (Modalidad). Este doble reconocimiento en el elemento temporal representa un problema de difícil resolución cuando existen limitaciones de tipo léxico-gramatical. El escritor del Texto 7 (Cf. 4.1.2.2) parece partir de la búsqueda en el diccionario de expected. Entonces, bien puede interpretar la forma were expected como pretérito del verbo to be+ adjetivo. Opta por la opción de pretérito imperfecto + adjetivo estaban expectantes y completa su idea con infinitivo a perder equivalente a to lose en inglés. 
Hacia el final del texto, con la selección La policía...compraba (videocasetes y compact discs) como reformulación de Police often douse (gasolina on piles of videocassettes and compact discs) nuevamente refleja los problemas que el texto le presenta a nivel de Operador Finito. Es probable que Police often douse gasoline on piles of video cassettes and compact discs seized during anti-obsenity campaigns, evento contado en presente (douse) pero que incluye un no-finito con apariencia de pasado (seized) lo conduzca a la selección poco exitosa por la que opta.

\subsubsection{Texto 8}

La relación Sujeto/Finito de la primera cláusula del complejo clausal inicial del resumen nos permite deducir que el escritor reconoce los significados de los procesos pasivos ban, bar y forbid del texto fuente que luego integra en la cláusula en español:

Texto fuente

PESHAWAR, Pakistan-Male coaches were banned (yesterday from training female athletes and sports teams in a deeply conservative province in Pakistan). Male spectators also will be barred (from watching sports events where female athletes compete), and male journalists are forbidden (from covering them).
Texto meta

El gobierno de Pakistán no permite (que mujeres ingresen como espectadoras de eventos deportivos).

Sin embargo, en la proyección del verbo permitir elige como Sujeto de ingresen el sustantivo mujeres. De modo que, aunque la interpretación de la forma pasiva se realiza apropiadamente, la combinación de $\mathrm{S}+\mathrm{F}$ en la proyección de la oración tópico traiciona el núcleo informativo de la noticia. Son, para este escritor, las mujeres quienes tienen la entrada prohibida a los estadios. Por otra parte, nada dice el escritor acerca de la situación de entrenadores y periodistas hombres. 
También en este resumen el escritor parece no reconocer el participio pasado no-finito decided como tal y lo interpreta como verbo finito. De modo que, una estructura que en el texto fuente es modificadora del núcleo del Sujeto The new measures se transforma en este resumen en Predicador de la estructura verbal fue decidido. Veamos el ejemplo en cuestión:

Texto fuente

The new measures, decided at a provincial Cabinet meeting yesterday, mark the latest attempt by the six-party religious alliance to impose a strict version of Islam.
Texto meta

Esto fue decidido en Cabinet.

Así, su segunda cláusula omite la identificación del responsable directo de la acción, que en el texto fuente está introducido en el Bloque $\mathrm{S}+\mathrm{F}+$ Predicador The new measures...mark (the latest attempt attempt by the six-party religious alliance to impose a strict version of Islam) y construye en cambio el Bloque $\mathrm{S}+\mathrm{F}+$ Predicador: Esto fue decidido que completa con el Adjunto en Cabinet que poco o nada aporta a los significados del texto que construye.

Si bien nos propusimos concentrarnos en el primer párrafo, nos interesa referirnos una vez más a un ejemplo que no pertenece al comienzo de la noticia pero que parece indicar cómo, ciertas limitaciones léxico-gramaticales desorientan al lector de un texto en L2 y dificultan la interpretación del mismo:

Texto fuente

The ban on men's involvement in women's sports was aimed at promoting a traditional style of Islamic sports, Daudzai said, without elaborating.
Texto meta

Las bandas de hombres involucradas en deportes son reelaboradas. 
Ya explicamos cómo esta construcción repercute en la relación participantes/procesos (Cf. 4.2.1.3). Desde los significados interpersonales, el escritor atribuye al Sujeto bandas de hombres involucradas en deportes el Finito son y el Predicador reelaboradas. Es decir, el autor construye un Sujeto que, desde la forma, se asemeja al Sujeto del texto fuente: The ban on men's involvement in women's sports pero que no captura los significados del mismo. A ese Sujeto lo predica con la forma son reelaboradas (Finito +Predicador) que parece trasladar del Adjunto: without elaborating de la clásusula: Daudzai said, without elaborating. ${ }^{20}$ Nuestra hipótesis es que, una vez más, la forma verbal pasiva (was aimed at promoting) contribuye a dificultar la comprensión y por lo tanto, el escritor, la ignora. Sin embargo, entiende que la frase nominal que crea "las bandas de hombres involucradas en el deporte" necesita un verbo finito para completar su idea y por eso "transforma" el no finito elaborating en finito pasivo son reelaboradas.

\subsubsection{Texto 9}

Las selecciones de S + Operador Finito + Predicador denotan poca comprensión por parte del escritor del Texto 9. En el primer párrafo, opta por las formas de pretérito perfecto absoluto o simple en:

Texto fuente

Male coaches were banned from training... Male journalists are forbidden from covering them

\section{Texto meta}

Los entrenadores masculinos fueron separados... ...se les pusieron prohibiciones a los periodistas,

En este sentido, resuelve dos de las estructuras verbales pasivas del primer párrafo en forma apropiada. Sin embargo, no es capaz de integrar la idea de deportes entre hombres y

\footnotetext{
${ }^{20}$ Ya mencionamos cómo la presencia de una metáfora gramatical en esta sección del texto fuente dificulta la interpretación de significados
} 
mujeres "completamente separados" ya que nada dice de los espectadores hombres. Esto bien podría deberse a su incapacidad para captar la forma verbal "will be barred".

Finalmente, en la última cláusula del primer párrafo del texto fuente, el escritor no reconoce la forma de pretérito perfecto simple y reformula la cláusula correspondiente a la fuente de la que proviene la información del siguiente modo:

Texto fuente

Texto meta

Asif Iqbal Daudzai, information minister of Eso era lo que informaba el Ministerio the North West Frontier province, told a news briefing

En este caso la cláusula por la que opta contiene un Sujeto cuyo significado no resulta demasiado claro (eso, para referirse a los eventos que originaron la noticia) y una forma verbal finita de pretérito imperfecto y no de pretérito perfecto absoluto o simple como debió seleccionar ( Eso lo informó...)

Ya hablamos de la dificultad que tienen los lectores cuya lengua materna es el español para reconocer Operadores Finitos, particularmente la diferencia entre cláusulas modalizadas y no modalizadas en inglés. En otras palabras, la dificultad que tienen para la interpretación apropiada de la frase verbal cuando deben reconocer al mismo tiempo el hecho relatado en referencia a su contexto temporal en cuanto a evento de habla y en referencia al juicio del hablante/escritor con respecto a lo que dice/escribe.

A modo de ejemplo, nos detendremos una vez más en dos cláusulas del texto fuente que resultaron de difícil resolución para los escritores de los resúmenes menos efectivos y 
veremos cómo las resuelve el escritor del Texto 9. Nos concentraremos en la resolución de Finito-Predicador:

Texto fuente

The ban on men's involvement in women's sports was aimed at promoting (a traditional style of Islamic sports...)

Several retired athletes were expected to lose their jobs at girls' schools
Texto meta

La separación de los hombres de los deportes femeninos puede llegar a promover (el tradicional estilo de los deportes de la Islam...)

Ex atletas nacionales encaran expectativas de abrir? escuelas para mujeres.

En el primer caso, el escritor resuelve una cláusula no modalizada en pasado y en voz pasiva con una cláusula activa modalizada en presente. Si bien no es nuestra idea centrarnos en la interpretación apropiada o inapropiada de la modalización, el ejemplo nos permite especular acerca del hecho de que, al estar la cláusula en voz pasiva, la difícultad aumenta. El escritor construye entonces un significado modalizado de posibilidad cuando el texto original presenta la información como un hecho consumado y de polaridad positiva.

Al segundo ejemplo, ya se ha hecho mención en el análisis de Transitividad (Cf. 4.2.1.4). El escritor parece partir de "expect" y transforma la expresión "were expected to lose their jobs at girls" schools" en "encaran expectativas de abrir escuelas para mujeres". Se trata, una vez más, de un escritor que no puede reconocer la frase verbal pasiva modalizada como unidad de significado y construye un significado ¿idiosincrático? para su expresión.

\subsubsection{Texto 10}

El escritor realiza una elección inapropiada en la primera cláusula del resumen que lo lleva a cambiar el significado del núcleo informativo central: 
Texto fuente

PESHAWAR, Pakistan-Male coaches were banned yesterday (from training female athletes)
Texto meta

Los entrenadores de hombres prohibieron (la enseñanza de atletas femeninos)

El ejemplo demuestra que el escritor no reconoce el marco de referencia (Widdowson, 2007: 29) del texto. Este hecho sumado a la dificultad que parece presentarle la interpretación apropiada de la voz pasiva lo conduce a transformar en Sujeto activo (es decir, agente para la función experiencial) un constituyente que debió ser Sujeto pasivo (es decir, paciente para la función experiencial) del Bloque Modo/Temple. Si tenemos en cuenta que esta es la primera cláusula del resumen, la que podría considerarse proposición temática, la interpretación inapropiada arroja consecuencias que afectan muchos de los significados del texto original.

Por otra parte, como cláusula con función temática, su versión es incompleta puesto que no menciona ni a periodistas ni a espectadores hombres. Este comienzo de resumen, entonces, modifica considerablemente los significados del texto fuente. Por un lado, ubica apropiadamente el evento en pasado como hace el original pero por otro sólo toma algunos Sujetos y los transforma en activos cuando el texto fuente los presenta como Sujetos pasivos.

Más aún, no siempre el escritor reconoce apropiadamente el Finito temporal como lo demuestra el siguiente ejemplo:

Texto fuente

The ban on men's involvement in women's sports was aimed at promoting (a traditional style of Islamic sports)
Texto meta

La prohibición de hombres con mujeres en los deportes está apuntando a promover (el estilo deportivo tradicional de ese país) 
El ejemplo anterior muestra que el escritor del resumen no reconoce en este caso el Finito temporal ni probablemente la forma compleja del Predicador (que construye junto con su Finito una forma pasiva). Como equivalente del was aimed opta por la forma presente está apuntando. También, como en el caso de la proposición temática Los entrenadores de hombres prohibieron, el escritor del resumen transforma una forma pasiva en forma activa con el agravante de que en este último ejemplo no sólo cambia la voz de la frase verbal sino también el tiempo (pasado en texto fuente y presente en su resumen).

De este modo, completamos el análisis del Sistema de Modo/Temple en los textos de nuestro corpus. A continuación, compararemos los textos más efectivos con los menos efectivos para poder elaborar algunas conclusiones preliminares.

\subsubsection{Comparaciones en el Sistema de Modo/Temple:}

Estamos en condiciones de comentar algunas características a nivel de los significados interpersonales que diferencian los resúmenes más efectivos de los menos efectivos.

En general, el análisis de patrones léxico-gramaticales en el Sistema de Modo/Temple nos

permite observar que los escritores de los resúmenes menos efectivos tienen más dificultades para la interpretación de finitos y predicadores complejos. Cuando se trata del Operador Finito temporal los escritores no siempre realizan la selección de tiempo apropiada en el texto en español. Ya vimos cómo en el Texto 7 el escritor opta por la opción de pretérito imperfecto cuando debía optar por el pretérito perfecto absoluto o simple. En su resumen: Male coaches were banned ES FORMULADO COMO Los profesores estaban prohibidos. 
Por otra parte, la Modalidad representa, para los escritores de los resúmenes menos efectivos, un problema adicional a resolver en el constituyente verbal. Esto motiva que en ocasiones se modalicen estructuras en español que no realizan significados modalizados en inglés. Si a esto sumamos la dificultad del no reconocimiento apropiado de la voz del mensaje en los principales predicadores del texto, el resultado es significados interpersonales en estos resúmenes que se alejan de los significados interpersonales del texto fuente. En este sentido, ya observamos la dificultad que la siguiente cláusula presentó a los escritores de los resúmenes menos efectivos:

Texto fuente

Several retired nacional athletes were expected to lose (their jobs)
Texto meta

Varios atletas nacionales retirados fueron anticipados a perder (sus trabajos) (Texto 6)

Varios atletas nacionales retirados estaban expectantes a perder (sus beneficios) (Texto 7)

Ex atletas nacionales encaran expectativas de abrir (escuelas) (Texto 9).

Los escritores deberían comprender el significado modal del grupo y desprenderse de la forma pasiva para lograr una versión adecuada en español. Por ejemplo, uno de los textos más efectivos propone la siguiente versión: Muchos atletas retirados, los cuales trabajan en escuelas de niñas como entrenadores, temen perder su trabajo. En cambio, las versiones en la tabla anterior, como sugerimos oportunamente (Cf. análisis de Sistema de Modo/Temple en Textos 6, 7 y 9) surgen posiblemente de la consulta al diccionario o por la analogía formal con un vocablo en español.

La dificultad que parece presentarse a todos los escritores para interpretar la frase verbal were expected to lose en esta cláusula tiene que ver con la atomización, como consecuencia probablemente de un umbral lingüístico bajo (Cf. Hipótesis Ii) y Iiii)). Los tres ejemplos 
muestran que los escritores de los textos meta parten de expect que, en el caso del Texto 6 se transforma en participio pasado pasivo en la frase fueron anticipados; en el caso del Texto 7 se transforma en adjetivo y se reformula como expectantes; y, en el caso del Texto 9 en sustantivo en la frase encaran expectativas. En suma, ninguno de los tres es capaz de reconocer la Modalidad en la frase verbal were expected to lose.

Por último, los escritores de los resúmenes menos efectivos tienen dificultad para reconocer la estructura Finito+Predicador que corresponde a los patrones de voz pasiva. Es básicamente el predicador el que especifica la voz (Halliday, 1985: 79) y los escritores de los resúmenes menos efectivos tienen dificultad para resolver estos significados. Un claro ejemplo de esta dificultad es la cláusula: Male coaches were banned yesterday from training female athletes FORMULADA COMO Los entrenadores de hombres prohibieron (la enseñanza de atletas femeninos...) en el Texto 10. La transformación del Sujeto pasivo en Sujeto activo representa un cambio de significados de $180^{\circ}$.

En los textos más efectivos, en cambio, los escritores interpretan apropiadamente las formas verbales, lo que se traduce en resúmenes más coherentes y respetuosos de los significados del texto fuente. Los significados de los Operadores Finitos, Operadores Modales y Predicadores Complejos del texto fuente no son traicionados, sin importar las formas que dichos significados adopten en español (Cf. Hipótesis Iiib)). Este no es un dato menor si tenemos en cuenta que, por tratarse de un texto narrativo, la interpretación apropiada del constituyente verbal resulta fundamental para la construcción de un texto coherente.

Hemos comparado los patrones gramaticales en el Sistema de Modo/Temple entre los textos más efectivos y los menos efectivos de nuestro corpus. A continuación, pasaremos a analizar los patrones de Tema/Rema. 


\subsection{SISTEMA DE TEMA/REMA}

Desde una perspectiva sistémico-funcional, Halliday define Tema como la manifestación léxico-gramatical de la metafunción textual que organiza los significados experienciales (metafunción de representación de "contenidos") y significados interpersonales (metafunción de intercambio de estos "contenidos") para formar textos. Es el punto de partida del mensaje aunque no constituye necesariamente el elemento conocido. Como punto de partida, el Tema debe incluir un elemento de la metafunción experiencial. (Montemayor-Borsinger, 2009:95)

Desde este punto de vista posicional, la sucesión de Temas elegidos a medida que se va desarrollando el texto forma su andamiaje (Cf. Capítulo 2) y lo organiza para que el propósito mismo del discurso sea entendible. Así, el Tema se constituye en un elemento clave para entender la organización del discurso. Por lo tanto, los significados textuales no agregan una nueva realidad ni alteran las dimensiones interpersonales de la cláusula sino que constituyen el potencial para organizar los constituyentes de modo tal que se logre el propósito deseado. La elección del Tema en la cláusula en inglés contribuye en gran medida al efecto comunicativo del mensaje. (Eggins, 1994:273)

El Sistema de Tema organiza la cláusula a partir de dos componentes funcionales: Tema, que consideramos junto con Halliday como el punto de partida del mensaje y la información que sigue. La organización temática contribuye al desarrollo cohesivo y, por lo tanto, a la coherencia del texto; por eso Halliday (1974:95) se refiere a la función textual como la función "habilitadora".

Hablar de la función textual como habilitadora de las otras dos no significa que sea menos importante. Por el contrario, dicha función permite que los significados interpersonales y experienciales queden organizados de tal manera que la información pueda ser compartida por hablante/escritor - oyente/lector. En su artículo: "THEME as an enabling resource in ideational 'knowledge' construction" C. Matthiessen (1995:29) expresa: "La metafunción 
textual (...) permite que las personas no sólo intercambien significados ideacionales (experienciales) sino que los organicen de tal manera que puedan ser reconstruidos y contenidos en sistemas -que puedan ser "aprendidos" y "recordados".

Por otra parte, Martin (1984:26-27) ha sugerido que el rol del lenguaje en la interacción puede verse como describiendo dos tipos de distancia en la relación entre el lenguaje y la situación: a) distancia espacial/interpersonal, que va desde la de respuesta inmediata y contacto cara a cara hasta la lectura de un texto escrito siglos atrás; b) distancia experiencial, que comprende distintas situaciones a partir de la distancia que existe entre el lenguaje y el proceso social involucrado. En este continuo se dan, desde situaciones como jugar a las cartas en que el lenguaje acompaña la actividad de quienes interactúan y donde la lengua es uno de los medios que se utilizan para llevar a cabo la acción hasta la escritura de un texto de ficción en que la lengua constituye la totalidad del proceso social involucrado, la lengua es el proceso social.

En la clase de textos que nos ocupa, por un lado, la distancia espacial/interpersonal de Modo/Medio es máxima ya que los escritores de los resúmenes no tienen ningún contacto directo con su audiencia y, por lo tanto, no tienen posibilidad de clarificar; por otro lado, la distancia experiencial, es decir la que existe entre el lenguaje y el proceso social es también máxima; el proceso social que se construye depende exclusivamente del lenguaje. Por lo tanto, los escritores deben ser muy cuidadosos de las selecciones léxico-gramaticales que realizan, tarea que no siempre resulta exitosa cuando no se reconocen apropiadamente determinadas estructuras. Si a esta limitación se agrega el hecho de que, como para todo procesamiento textual, la tarea de resumir depende del conocimiento que se tenga del tema del texto fuente (que, en nuestro contexto en particular fue construido no por el escritor del resumen sino de un escritor desconocido para él), se podrá entender aún más por qué algunos de los textos de nuestro corpus no resultan tan efectivos.

En este tramo de nuestro trabajo, analizaremos las selecciones léxico-gramaticales en el Sistema de Tema/Rema en los textos más efectivos y los compararemos con las selecciones 
de los escritores de los textos menos efectivos. Observaremos qué hacen los escritores de los textos más apropiados para conseguir una instanciación ${ }^{21}$ más exitosa. (Apéndice 5)

En este caso, para facilitar el análisis, utilizaremos negrita para transcribir el Tema tópico no marcado, subrayado para el Tema tópico marcado, cursiva para el Tema textual y fuente normal para el Tema interpersonal.

\subsubsection{Textos Más Efectivos}

\subsubsection{Texto 1}

En este texto, en primer lugar, el escritor decide comenzar la primera cláusula con un Tema marcado que dé cuenta de ¿dónde? (transcurre la acción) aún cuando en el texto fuente el primer párrafo está constituido por cláusulas cuyos Temas son no marcados . En cuanto al Rema de la primera cláusula, el escritor hace lo que ninguno de los otros hizo: integrar apropiadamente lo que es "newsworthy", es decir lo que motivó la noticia. Además, sus patrones de selección remática permiten identificar a los agentes afectados como tales. Entonces:

Texto fuente

PESHAWAR, Pakistán-Male coaches (T1) |were banned (yesterday from training female athletes and sports teams in a deeply conservative province in Pakistan).(R1) Male spectators (T2) |also will be barred (from watching sports events were female athletes compete), (R2) and male journalists (T3) are forbidden (from covering them),(R3) Asif

Iqbal Daudzai, information minister of the North West Frontier province,(T4) | told a news briefing. (R4)

\section{Texto meta}

En Peshawar, una provincia del Noroeste de Pakistán (T1)|prohibieron a entrenadores, espectadores y periodistas varones el participar de cualquier manera en deportes de mujeres. (R1)

\footnotetext{
${ }^{21}$ El término instanciación es utilizado por Matthiessen (1995:22) y definido, desde el punto de vista del hablante, como el sistema de selecciones que debe hacer para producir textos; y, desde el punto de vista del oyente, como el sistema que éste puede crear a partir de la interpretación del texto que despliega.
} 
Vemos cómo el escritor se aparta de las formas pasivas del texto fuente pero no de los significados. Elige comenzar con el Tema marcado circunstancial que ubica el evento en lugar, (incluso especificando un dato que aparece al final del párrafo inicial: "the North West Frontier province"- "una provincia del Noroeste de Pakistán") menciona los agentes afectados y si bien no especifica el actor, los despliega en el Rema 2 donde prácticamente se completa el núcleo informativo textual.

El Rema de la cláusula 1 se transforma en Tema de la cláusula 2, cuyo Rema, como ya especificáramos, construye el participante actor de la acción principal. Así:

Texto fuente

The new measures, decided at a provincial Cabinet meeting yesterday, $(\mathrm{T}) \mid$ mark the latest attempt by the six-party religious alliance to impose a strict version of Islam (R).
Texto meta

Estas medidas (las expresadas en R1), tomadas por el Gabinete provincial, (T2) | fueron impulsadas por una alianza religiosa islámica $(\mathrm{R} 2)$.

El escritor del resumen, a través de la selección que hace de patrones lingüísticos de T-R demuestra que jerarquiza el ¿dónde? ¿quién? ¿a quiénes? como núcleo informativo textual. También muestra que la identificación de la información le es posible por el reconocimiento correcto que hace de la voz pasiva, aunque no se apega a ella. Ese reconocimiento de formas pasivas lo muestra no sólo en la manera en que resuelve las formas finitas sino en el apropiado reconocimiento de la forma no finita: ...decided at a provincial cabinet meeting yesterday... que expresa en español:...tomadas por el Gabinete provincial...

El escritor elige continuar con las consecuencias de las medidas integrando los agentes afectados en una misma cláusula: 
Texto fuente

The decision (T1) $\mid$ will affect thousands of girls and women in the province who compete in sports such as tennis, table tennis and field jockey (R1). Several retired national athletes (T2) | were expected to lose their jobs at girls'schools because of the rules (R2).
Texto meta

Estas medidas, (tomadas por el Gabinete provincial) (T2) fueron impulsadas por una alianza religiosa islámica (R2) y afectarán (T3) a muchas mujeres que practican deportes y a atletas retirados que trabajan en escuelas de mujeres (R3).

El escritor reduce información. Integra en un mismo complejo clausal Estas medidas...fueron impulsadas ...y afectarán a muchas mujeres que practican deportes y a atletas retirados que trabajan en escuelas para mujeres, información que en el texto fuente se despliega en tres complejos clausales. (Ver Apéndice 1) Vemos cómo, una vez más, se ocupa de respetar los significados más que las formas (Estas medidas afectarán...a atletas retirados que trabajan en escuelas de mujeres).

La presencia de Temas textuales contribuye a dar mayor cohesión a este texto. Además del Tema textual $y$ en el complejo clausal (Estas medidas...) fueron impulsadas y afectarán ya mencionado, otros ejemplos de este tipo de construcción son:

Texto fuente

The Hard-liners $(\mathrm{T})$ also share power in neighbouring Baluchistan province $(\mathrm{R})$.

Authorities in the North West Frontier province $(\mathrm{T})$ | have banned all music on public buses (R) and ordered $(\mathrm{T}) \mid$ billboards featuring images of women advertising movies or products to be torn down (R).

Police (T) $\mid$ often douse gasoline on piles of videocassettes and compact discs seized during "anti-obsenity campaigns"( $\mathrm{R}) \mid$ and set $(T)$ them ablaze $(R)$.
Texto meta

La provincia $(\mathrm{T})$ | eligió en octubre un gobierno islámico de línea dura $(\mathrm{R})$ que comparte $(\mathrm{T})$ el poder también en la provincia vecina de Baluchistán $(\mathrm{R})$.

\section{Autoridades de la provincia de Peshawar} (T) | prohibieron también la música en los colectivos públicos (R) y ordenaron (T) | quitar toda la publicidad con imágenes de mujeres (R).

También fueron incendiados $(\mathrm{T}) \mid$ por la policía compact discs y video cassettes secuestrados en campañas anti-obsenidad (R). 


\subsubsection{Texto 2}

El escritor de este resumen integra y reorganiza información de modo que poco tiene que ver con el patrón de T-R del texto fuente. De tal modo que en las cláusulas 1,2 y 3 hace referencia al actor responsable de la medida aún cuando incluye datos en sus cláusulas 2 y 3 que corresponden a información que aparece hacia el final en el texto fuente :

Texto fuente

The province $(\mathrm{T}) \mid$ elected a hard-line Islamic government in last October's national election (R). Hard-liners (T) $\mid$ also share power in neighbouring Baluchistan province.(R) Both provinces (T) |border Afganistán (R).
Texto meta

El texto (T1) trata sobre las decisiones tomadas por un gobierno muy conservador y muy estricto en Pakistán, más específicamente en la provincia de la Frontera Noroeste ubicada junto a la frontera con Afganistán (R1). Esta línea de gobierno (T2) | asumió en las últimas elecciones nacionales (R2) y ya (T3) | estaba en otra provincia, Baluchistán (R3).

En las cláusulas 4, 5 y 6 incluye la información que tiene que ver con los agentes afectados y que en el texto fuente aparece en el primer párrafo. Los temas textuales en las clásulas 5 y 6 contribuyen a la cohesión, y por lo tanto a la coherencia, del texto:

Texto fuente

PESHAWAR, Pakistan-Male coaches (T1)|were banned yesterday from training female athletes and sports teams in a deeply conservative province in Pakistan. (R1) Male spectators (T2) $\mid$ also will be barred from watching sports events were female athletes compete, (R2) and male journalists (T3) are forbidden from covering them) (R3).
Texto meta

Las nuevas medidas (T4) $\mid$ indican que las mujeres ya no podrán ser entrenadas a nivel deportivo por los hombres (R4) tampoco podrán ser vistas (T5) | por espectadores del sexo masculino (R5) $n i$ los periodistas hombres (T6) | podrán cubrir los eventos en los cuales participen mujeres (R6). 
$\mathrm{Su}$ método de desarrollo temático demuestra que el escritor elige apropiadamente contar al lector ¿quién hace qué cosa a quién en qué circunstancias? En las primeras cláusulas, el escritor concentra el núcleo informativo mientras que las combinaciones de T-R hacia el final del texto agregan detalles acerca de qué consecuencias tendrán las medidas para mujeres y adolescentes que practican deportes a nivel internacional y varones que dan clases en escuelas para mujeres. Como otra característica de este resumen se puede indicar que el escritor incluye 7 Temas textuales que contribuyen a darle mayor cohesión a su texto (Ver apéndice 5).

\subsubsection{Texto 3}

También el escritor de este resumen construye, a partir de su interpretación del texto fuente, patrones de T-R que no intentan replicar el método de desarrollo temático del texto fuente. El Tema tópico no marcado de la primera cláusula identifica el quién (La alianza religiosa "El partido de los seis", que en el texto fuente aparece recién en el Rema de la cuarta cláusula) y el R1 integra el resto de la información que constituye el núcleo textual: qué hace, a quién y por qué. De modo que, la información que en el texto fuente aparece desplegada en 5 cláusulas se construye en este resumen en la primera cláusula. El contenido experiencial en T1 identifica al participante actor y el proceso en R1 describe la acción principal, la que motivó la noticia.

Texto fuente

PESHAWAR, Pakistan-Male coaches (T1) |were banned yesterday from training female athletes and sports teams in a deeply conservative province in Pakistan.(R1) Male spectators (T2) $\mid$ also will be barred from watching sports events were female athletes compete,(R2) and male journalists (T3) $\mid$ are forbidden from covering them, (R3) Asif Iqbal Daudzai, information minister of the North West Frontier province,(T4) $\mid$ told a
Texto meta

La alianza religiosa "El partido de los seis"(T1) a través de su vocero Asif Iqbal Daudzai, Ministro de Información de la provincia de Peshawar, Pakistán, en un intento de imponer una estricta versión del Islam, decidió separar de los eventos deportivos femeninos toda actividad desarrollada por hombres (entrenadores, profesores, periodistas que cubren dichos eventos) (R1). 
news briefing. (R4) //The new measures, decided at a provincial Cabinet meeting (T5) | yesterday, mark the latest attempt by the six-party religious alliance to impose a strict version of Islam (R5).

Esta integración de información le resulta posible al escritor del Texto 3 debido al uso que hace de adjuntos circunstanciales que representan relaciones lógicas en Rema (...a través de su vocero..., en un intento de imponer una versión una estricta versión del Islam) y de la selección del grupo verbal decidió separar que le permite integrar los significados en inglés: were banned, will be barred y are forbidden.

Además, el escritor de este resumen evita la repetición de Temas no marcados referidos al mismo actor, que obligan a desplegar la información en varias cláusulas como ocurre en el texto fuente (The Government (will establish a separate sports group for women), The province (elected a hard-line Islamic government), Hard-liners (share power in neighbouring Baluchistan province), Authorities in North West Frontier Province (have already banned... and ordered...), Police (often douse gasoline...) y a partir de un solo Tema tópico no marcado La provincia y dos Temas textuales (que, también) integra información para agregar otras medidas tomadas en el mismo sentido (Ver apéndice 5).

\subsubsection{Texto 4}

En este texto el T1 explicita el proceso central de la noticia: Se prohibió, mientras que, el R1, T2 y R2 completan el núcleo informativo acerca de quiénes son los agentes afectados. Por último, en lo que sería T4 y R4 (sin descuidar la fuente: afirmó (T3) un vocero pakistaní (R3)) se identifica apropiadamente al responsable de la acción. De modo que, en T-R de las cuatro primeras cláusulas se incluye quiénes hacen a quiénes. La información que dio origen a la noticia:

Texto fuente

PESHAWAR, Pakistan-Male coaches (T1)|
Texto meta

Se prohibió (T1)| a entrenadores hombres 
were banned (yesterday from training female athletes and sports teams in a deeply conservative province in Pakistan) (R1).

Male spectators (T2) | also will be barred (from watching sports events were female athletes compete),(R2) and male journalists (T3) $\mid$ are forbidden (from covering them) (R3).

The new measures, decided at a provincial Cabinet meeting $(\mathrm{T}) \mid$ yesterday, mark the latest attempt by the six-party religious alliance to impose a strict version of Islam (R). entrenar deportistas mujeres en una provincia pakistaní (R1).

Lo mismo les ocurrió (T2 )|a periodistas y espectadores masculinos que quisieran ver deportes femeninos... (R2)

Las medidas, decididas en Gabinete provincial, (T4) $\mid$ fueron tomadas por la alianza religiosa del Islam (R4).

Entonces, el punto de partida del mensaje (y también del texto) es el proceso de prohibir lexicalizado con la forma pasiva con se; en R1 y R2 el escritor lexicaliza apropiadamente la información que identifica a los agentes afectados. Y, en R4 a partir de un adjunto circunstancial identifica al responsable de la acción. La selección de Temas de las cuatro primeras cláusulas del resumen, donde se concentra el núcleo informativo textual, no replica los Temas del texto fuente sino que busca capturar significados.

En el resto de las cláusulas se agregan detalles para enriquecer el contexto. Una vez más, las selecciones léxicas temáticas se alejan de las formas del texto fuente. Por ejemplo, hacia el final del texto, donde el escritor del artículo periodístico elige temas que identifican actores como: Authorities in North West Frontier Province, Police(x2), el escritor del Texto 4 elige Temas que son procesos pasivos en dos oportunidades y un proceso relacional en la última cláusula. Veamos cómo lo resuelve:

Texto fuente

Authorities in North West Frontier Province (T) | already have banned all music on public buses $(\mathrm{R})$.

\section{Texto meta}

También se prohibió (T) | música en autobuses públicos $(\mathrm{R})$.

\section{Authorities in North West Frontier}


Province $(\mathrm{T}) \mid$ have ordered billboards featuring images of women advertising movies or products to be torn down (R).

Police (T) $\mid$ often douse gasoline on piles of videocassettes and compact discs seized during "anti-obsenity campaigns"(R). $y$ se ordenó $(\mathrm{T}) \mid$ demoler toda cartelera y anuncio publicitario con imágenes femeninas (R).

Es (T) $\mid$ común ver a la policía quemando discos compactos y cassettes de video en campañas anti-obsenidad (R).

Otro elemento de coherencia y cohesión lo constituye la selección del proceso de prohibir (se prohíbe) en posición temática al comienzo del primero y del último párrafo del resumen (Ver Apéndice 5). De este modo, el escritor logra que la idea principal del texto fuente que es la prohibición emerja como tópico central también en su resumen.

\subsubsection{Texto 5}

Este texto es otro ejemplo de desarrollo en que el escritor se aparta de las formas de superficie del texto fuente y opta fundamentalmente por la forma pasiva con se. Para completar el núcleo informativo utiliza dos Temas textuales:

Texto fuente

PESHAWAR, Pakistan-Male coaches (T1) were banned yesterday from training female athletes and sports teams in a deeply conservative province in Pakistan (R1).

Male spectators (T2) $\mid$ also will be barred from watching sports events where female athletes compete, (R2)

and male journalists (T3) are forbidden from covering them (R3).
Texto meta

El texto (T1) | se refiere a que se le ha prohibido a entrenadores masculinos entrenar atletas femeninas y equipos integrados por mujeres en una provincia conservadora de Pakistán (R1).

También se prohíbe (T2) | a los espectadores concurrir a eventos disputados por mujeres (R2)

...así como también se prohíbe (T3)| a los periodistas masculinos cubrir dichos eventos (R3). 
De este modo, se incluye en el comienzo del texto la información referida al hecho que motivó la noticia (la separación de deportes de hombres y mujeres), dónde transcurre (en una provincia conservadora de Pakistán), quiénes son los afectados (entrenadores masculinos, espectadores, periodistas masculinos) y, aunque no instanciado como Sujeto lógico, de quién emana la decisión (se prohíbe - en una provincia conservadora de Pakistán). El escritor del resumen no sólo realiza una apropiada selección de procesos en Tema sino que también construye en forma efectiva las relaciones lógicas entre los hechos contados.

Tampoco replica el escritor de este resumen el elemento remático verbal del texto fuente para los detalles de la noticia. Veamos, entonces, como los resuelve:

Texto fuente

These new measures $(\mathrm{T}) \mid \ldots$ mark...(R) Several retired national athletes $(T) \mid$ were expected to lose their jobs (R).

The ban on men's involvement in women's La prohibición $(\mathrm{T}) \ldots$... sigue el estilo sports $(\mathrm{T})$ was aimed at promoting a tradicional de los deportes islámicos. (R) traditional style of Islamic sports (R).
Texto meta

Estas nuevas medidas $(\mathrm{T}) \ldots \mid$ son... (R) Muchos atletas retirados $(\mathrm{T}) \mid$ se quedarán sin trabajo. (R)

El resto de los Temas incluyen detalles que enriquecen el contexto. Los cuatro Temas tópico-no marcados restantes (Esta línea dura del gobierno islámico, Esta línea dura de gobierno, Las autoridades..., La policía) hacen referencia a la autoridad de la que emanan otras medidas similares (Ver Apéndice 5).

Hasta aquí hemos mostrado ejemplos de construcciones de patrones temáticos en los cinco textos que fueron evaluados como más efectivos. En 4.3.1 analizaremos ejemplos de patrones temáticos en los textos de nuestro corpus que fueron evaluados como menos efectivos. 


\subsubsection{Textos Menos Efectivos}

\subsubsection{Texto 6}

El escritor de este texto pretende replicar las formas léxico-gramaticales del texto fuente. Elige Temas tópico no-marcados que son los equivalentes léxicos en español de los Temas tópico no-marcados en inglés. Estas selecciones obligan al escritor a replicar también las formas verbales finitas pasivas del inglés. Los ejemplos, entonces, resultan mucho menos naturales que si hubiera optado por la voz pasiva con se. Así:

Texto fuente

PESHAWAR, Pakistan-Male coaches (T1) | were banned yesterday from training female athletes (R1)
Texto meta

Entrenadores (T1) $\mid$ ayer fueron prohibidos de entrenar atletas femeninos (R1)

Este método de desarrollo temático justamente para la primera cláusula del texto en español dificulta el acceso al significado no sólo al lector externo del resumen sino al propio escritor del resumen (y primer lector del mismo). Con esta opción en lugar de la más apropiada Se prohibió ayer a entrenadores (hombres) entrenar atletas femeninas el escritor oscurece los significados y dificulta su propio camino para la comprensión global del texto.

Veamos ahora dos ejemplos, aún más problemáticos, por las selecciones léxicas erróneas a nivel de estructuras verbales:

Texto fuente

Male spectators ( $\mathrm{T}) \mid$ also will be barred from watching...(R)

Several retired national athletes $(T) \mid$ were expected to lose their jobs (R)
Texto meta

Los espectadores hombres $(\mathrm{T}) \mid$ serán enrejados de mirar...(R)

Varios atletas nacionales retirados (T) | fueron anticipados a perder sus empleos (R) 
Vemos entonces que la decisión del escritor de este resumen de replicar las formas Tema/Rema del texto fuente lo conduce a selecciones remáticas poco exitosas cuya coherencia se hace prácticamente nula. Es decir que estas dificultades a nivel de Rema se originan, en la mayoría de los casos, a partir del apego a replicar la relación formal participante-proceso, relación cuya interpretación se distorsiona por la poco efectiva interpretación de la expresión verbal finita. En definitiva, el escritor de este resumen no considera la posibilidad que ofrecen las cláusulas declarativas en español de selección de procesos como tema no marcado.

Existe otra selección poco feliz en este resumen que dificulta la comprensión del lector. El escritor confunde una forma no finita de participio pasado por una finita. Así, la estructura de modificación que es parte del Tema en: (The new measures,) decided at a provincial Cabinet meeting yesterday, se transforma en una cláusula finita en la que decided inicia el Rema :

Texto fuente

(The new measures,) decided at a provincial Cabinet meeting $(\mathrm{T}) \mid$ yesterday mark... (R)
Texto meta

(Las noticias tomadas) ( $\mathrm{T}$ ?), el gabinete $(\mathrm{T}) \mid$ decidió reunirse ayer, (R), marcan...(R?)

De este modo, con su Tema no-marcado: el gabinete y su Rema: decidió reunirse ayer la estructura finita antes mencionada interrumpe el flujo de información de la cláusula: Las noticias tomadas $(\mathrm{T} ?) \mid$ (el gabinete $(\mathrm{T}) \mid$ decidió reunirse ayer $(\mathrm{R}) \mid$ marcan el último intento de la alianza religiosa...(R?) Esta resolución poco efectiva de la cláusula subordinada decided at a provincial Cabinet meeting yesterday oscurece aún más los significados.

El apego al método de desarrollo del texto fuente, tratando de replicar participantesprocesos en Tema/Rema desde la forma aún a expensas de los significados lleva al escritor 
del Texto 6 a no intentar reorganizar ni reducir ningún tipo de información (Ver apéndice $5)$.

\subsubsection{Texto 7}

En este texto también observamos cambios de significados, básicamente, en los elementos remáticos. El escritor selecciona Temas que entiende replican los significados del texto fuente sin darse cuenta que una cosa son las formas y otra, muy distinta, los significados; por eso, no todas las selecciones resultan efectivas. En principio, ignora la modificación male, central para la comprensión del núcleo informativo textual: la separación de los deportes entre hombres y mujeres; además, no selecciona entrenadores como opción en español de coaches, con lo cual contribuye a distorsionar significados. Comparemos los comienzos del texto fuente y el Texto 7:

Texto fuente

PESHAWAR, Pakistan-Male coaches (T1) | were banned yesterday from training female athletes...(R1)
Texto meta

Los profesores (T1)| estaban prohibidos desde ayer de entrenar atletas femeninos (R1)

En el ejemplo anterior, el escritor no selecciona el Tema más apropiado. Sin embargo, es a nivel de Rema donde el texto presenta más cambios de significados en relación al texto fuente. Ahora bien, Eggins explica: “(El textual) es el nivel de organización de la cláusula que hace posible que la cláusula quede empaquetada de forma tal que sea efectiva teniendo en cuenta su propósito y su contexto" (Eggins, 1994: 273).

La forma en la que el escritor del Texto 7 organiza la información en las cláusulas de su resumen no las hace efectivas para permitir al lector llegar a delimitar claramente el contexto (un gobierno islámico de línea dura de Pakistán como actor de la prohibición) o el propósito (la separación total de hombres y mujeres en los deportes). Veamos algunos ejemplos que muestran esta poca efectividad: 
Texto fuente

Male spectators ( $\mathrm{T})$ also will be barred from watching sports events where female athletes compete (R).

Asif Iqbal Daudzai, information minister of the North West Frontier province (T) $\mid$ told a news briefing $(\mathrm{R})$.

Several retired national athletes $(\mathrm{T}) \mid$ were expected to lose their jobs (R)

The province $(\mathrm{T}) \mid$ elected a hard-line Islamic government in last October's national elections (R)

The police ( $\mathrm{T})$ often douse gasoline on piles of video cassettes and compact discs seized during "anti-obsenity campaigns" (R)
Texto meta

Los espectadores $(\mathrm{T})$ |tienen el deseo de estar mirando deportes donde compitan mujeres (R).

Asif Iqbal Daudzai, Ministro de Información del Noroeste de la Provincia de Pakistán (T) $\mid$ contaba una historia concisa (R).

Varios atletas nacionales retirados $(T) \mid$ estaban expectantes a perder sus beneficios (R).

La provincia $(\mathrm{T})$ | estableció una dura raya con el gobierno para alcanzar las elecciones nacionales en octubre $(\mathrm{R})$.

La policía $(\mathrm{T})$ | durante campañas en contra a la obscenidad compraba video casetes y compact discs (R).

Un recorrido por el método de desarrollo de este resumen nos permite concluir que el escritor cambia sistemáticamente los significados a nivel de Rema. Tampoco hay intención de reorganizar información. El escritor simplemente opta por eliminar cláusulas; no estamos en condiciones de afirmar si las elimina porque las considera de menor jerarquía (a su entender, simplemente cláusulas de expansión) o si simplemente incluye en su texto aquellas estructuras léxico-gramaticales que percibe como menos problemáticas. Lo cierto es que, nuevamente, estamos en presencia de un escritor que intenta replicar formas en la relación participante-proceso a partir, creemos, de la búsqueda léxica uno a uno en el diccionario bilingüe (insensible al contexto específico de los términos que busca) y que no logra, entonces, construir significados textuales coherentes. Por otra parte, llama la atención la ausencia de elementos de cohesión; el escritor no incluye ni siquiera un solo Tema textual. 


\subsubsection{Texto 8}

El autor de este resumen parece haber logrado, a comienzos del texto, algún tipo de comprensión adecuada que lo lleva a seleccionar El gobierno de Pakistan como Tema de la primera claúsula. Decide, de alguna manera, que el texto trata del gobierno de Pakistán. Sin embargo, ya a partir del primer Rema tergiversa información central. Habla de prohibición a mujeres y no integra ni a periodistas ni a entrenadores a la prohibición. Comparemos el comienzo del texto fuente con el del Texto 8:

Texto fuente

PESAWAR, Pakistan-Male coaches (T1)|were banned yesterday from training female athletes and sports teams in a deeply conservative province in Pakistan (R1). Male spectators (T2) | also will be barred from watching sports events where female athletes compete, (R2) and male journalists (T3) | are forbidden from covering them (R3).
Texto meta

El gobierno de Pakistán (T1) $\mid$ no permite que mujeres ingresen como espectadoras de eventos deportivos (R1).

Así instancia el escritor del Texto 8 su segunda cláusula: Esto (la prohibición a mujeres de ingreso a eventos deportivos) (T2)| fue decidido en Cabinet (R2).

Esta selección en Rema 2 nos indica que el escritor de este texto no logra distinguir en la cláusula en inglés lo que constituye la frase verbal finita de lo que es estructura no-finita de modificación y por eso, en: The new measures, decided at a provincial Cabinet meeting yesterday, mark the latest attempt by the six-party religious alliance to impose a strict version of Islam transforma decided (forma no-finita de modificación dentro del Tema) en forma finita (Rema de su versión en español). De este modo, convierte una idea subordinada en idea principal. Más aún, no demuestra acabada comprensión de elementos léxicos en Rema y por eso selecciona Cabinet en lugar de Gabinete.

Por otra parte, esta selección lo lleva a eliminar lo que sí representa una idea principal en cuanto a que (Las medidas=Esto) $\mid$ marcan el último intento de imponer una estricta versión del Islam. Es decir que la selección remática del escritor del Texto 8 (fue decidido 
en Cabinet) para el Tema: Esto conduce a una importante pérdida de significado del texto fuente, en particular porque se trata de la segunda cláusula del resumen en la que se trabaja con significados de la parte inicial del texto fuente.

Ya se ha mencionado (Cf. 4.1.2.3- 4.2.2.3) la particular interpretación de la cláusula: The ban on men's involvement in women's sports (Tema) | was aimed at promoting a traditional style of Islamic sports (Rema) por parte del escritor del Texto 8. Vemos que en este ejemplo, el Tema en la cláusula del texto fuente es una reformulación de la información central de la noticia periodística que fue desplegada en las primeras cláusulas del artículo (la separación de hombres y mujeres en los deportes) y que el Rema anuncia las causas de la medida (promover el estilo tradicional del deporte islámico).

Sin embargo, el escritor, que parece desconocer el significado de ban opta por la forma en español bandas y construye su Tema como Las bandas de hombres involucradas en el deporte; el Rema de la clásula del texto fuente se realiza en la forma pasiva: was aimed at promoting a traditional style of Islamic sports. El escritor elige omitir esta información y lo que parece hacer es tomar la forma without elaborating, Rema del Tema: Daudzai de la cláusula siguiente y transformarla en Rema de su Tema Las bandas de hombres involucradas en el deporte. Finalmente construye: Las bandas de hombres involucradas en el deporte son reelaboradas, cláusula que no sólo no aporta al núcleo informativo textual sino que resulta incoherente en el contexto. En este caso, tanto el contenido experiencial en Tema como en Rema refleja una interpretación poco efectiva por parte del escritor del Texto 8 .

Veamos otro ejemplo que muestra una poco efectiva construcción remática:

Texto fuente

(Authorities in North West Frontier (Las autoridades) (T) $\mid$ pusieron carteleras Province) (T) $\mid$...have ordered billboards de las imágenes de futuras mujeres featuring images of women advertising publicitando películas o productos, que fueron 
movies or products to be torn away(R).

o son arrancadas $(\mathrm{R})$.

El ejemplo demuestra, una vez más, que el escritor encuentra dificultades a nivel de Rema y que, aunque selecciona Temas que replican las selecciones del texto fuente, no puede resolver cómo desarrollar esos Temas, por consiguiente, la información nueva que despliega es diferente a la del texto fuente y/o incoherente. No son Las autoridades las que pusieron las carteleras de (futuras?) mujeres y, por otra parte, ¿por quiénes fueron o son arrancadas?

Los significados textuales se realizan con las selecciones en el Sistema de Tema/Rema. Sin embargo, las selecciones de Tema/Rema por sí solas no constituyen texto. El escritor debe organizar el contenido experiencial del texto apropiadamente para luego desplegarlo en forma coherente. Son esos contenidos, particularmente a nivel de Rema, los que el escritor del resumen parece no poder interpretar de modo apropiado para compartir información con su lector. Halliday y Martin (1993) explican que son los Remas los que elaboran el Campo en la construcción de la experiencia; podemos concluir, entonces, que el producto de este resumen será un texto carente de coherencia y cohesión.

\subsubsection{Texto 9}

El análisis temático de este texto demuestra que el escritor intenta reorganizar información. En principio, con la selección de Tema marcado: En Pakistán que elige para su primera cláusula demuestra sensibilidad para ubicar los hechos en el espacio, información de suma importancia para el lector de un texto que cuenta un evento de la realidad. Así:

Texto fuente

PESHAWAR, Pakistan-Male coaches (T1) were banned yesterday from training female athletes...(R1)
Texto meta

En Pakistán (T1) los entrenadores masculinos fueron separados de las atletas femeninas... (R1); también se les pusieron (T2) | prohibiciones (R2)...; eso (T3) | era lo 
que informaba...(R3)

El Tema textual: también, de su segunda cláusula: también se les pusieron| prohibiciones a los periodistas de cubrir dichos eventos demuestra sensibilidad para integrar información y dar cohesión al texto. La misma intención de cohesión se ve en la selección que hace de su tercer Tema tópico no marcado: eso, que remite a los Remas de sus dos primeras cláusulas: los entrenadores masculinos fueron separados de las atletas femeninas por la profunda conservadora provincia de Pakistán (Rema 1) y prohibiciones a los periodistas de cubrir dichos eventos (Rema 2).

Sin embargo, también en este texto, los problemas se presentan básicamente a nivel de Rema y más específicamente en el reconocimiento apropiado de la frase verbal. Ejemplos de esto son:

Texto fuente

(Several retired nacional athletes) $(\mathrm{T}) \mid$ were expected to lose their jobs at girls' schools (R)
Texto meta

(Ex atletas nacionales) (T) $\mid$ encaran expectativas de abrir escuelas para mujeres (R)

(The ban on men's involvement in women's sports) (T) $\mid$ was aimed at promoting a traditional style of of Islamic sports $(\mathrm{R})$

\begin{abstract}
(La separación de los hombres de los deportes femeninos) $(\mathrm{T}) \mid$ puede llegar a promover el tradicional estilo de deportes de la Islam (R)
\end{abstract}

La poco efectiva interpretación de las formas verbales finitas en los Remas del texto fuente resulta clave para la coherencia del texto. Entonces, como los contenidos de los Remas del texto meta se alejan de los contenidos de los Remas del texto fuente, en primer lugar el propio escritor del resumen y luego el lector externo no llegan a comprender el núcleo informativo textual de la noticia periodística. Ya que, aunque los Temas, en su mayoría nomarcados (sólo un Tema marcado en la primera cláusula) identifican los actores de los 
eventos, los Remas transmiten información que se aleja de los hechos contados en el texto de primer grado.

\subsubsection{Texto 10}

En general, lo que hace el escritor de este resumen es aplicar la estrategia que Brown y Day (1983) han denominado "copy-delete" (suprimir-copiar) que consiste en construir resúmenes analizando el texto en forma lineal, oración por oración, eliminando aquellos aspectos que no son considerados importantes por su valor en sí mismo (o, bien podría ser éste el caso, eliminando lo que le resulta al escritor imposible de decodificar), y copiando literalmente aquellos que sí lo parecen (o lo que puede decodificar) (Kaufman y Perelman, 2000).

Aunque Brown y Day (1983) se refieren a estrategias usadas por niños de escuela primaria en resúmenes en L1, en cierta forma el lector de un texto en L2 cuyo nivel de lengua extranjera es escaso o nulo enfrenta algunos de los problemas que debe resolver el lector con dificultades de comprensión lectora en L1. Probablemente a los dos les cueste reconocer los constituyentes de la oración: al niño, por la falta de familiaridad con la organización textual del texto escrito y al estudiante de una lengua extranjera con escaso o nulo nivel de L2 por desconocimiento léxico-gramatical. En el caso particular del resumen que nos ocupa, el escritor elige algunos de los Temas del texto fuente e intenta reproducirlos en español, aunque no sabemos con qué criterios selecciona Temas. Pero, una vez más, los cambios de significados se observan a nivel de Rema. Algunos ejemplos son:

Texto fuente

PESHAWAR, Pakistan-Male coaches (T1)| were banned yesterday from training female athletes...(R1)

\section{Texto meta}

Los entrenadores de hombres (T1)|
prohibieron la enseñanza de atletas
femeninos... (R1)

Asif Iqbal Daudzai, information minister of La información $(\mathrm{T}) \mid$ fue dada por el the North West Frontier Province, $(\mathrm{T}) \mid$ told ministro de la frontera del noroeste de a news briefing $(\mathrm{R})$
Pakistán (R) 
Es precisamente el Rema de la primera cláusula del Texto 10 el que introduce el cambio de significado más importante. En este caso también, es la estructura Finito temporal +Predicador la que no es reconocida apropiadamente. Es decir, el escritor no reconoce la voz pasiva. En consecuencia, los entrenadores (a quienes, además, el escritor del resumen interpreta como entrenadores de hombres y no entrenadores hombres) son los que prohíben y no los afectados por la acción.

Pareciera que el escritor de este resumen evita las cláusulas cuyos verbos finitos están en voz pasiva. Por ejemplo, selecciona sólo la primera claúsula del primer párrafo cuyo Rema resuelve de manera poco efectiva. No incluye las cláusulas referidas a espectadores hombres (Male spectators | also will be barred from watching sports events where female athletes compete) ni a periodistas hombres (...male journalists| are forbidden from covering them). Tampoco incluye ningún tipo de información sobre la cláusula Several retired national athletes | were expected to lose their jobs... y sólo intenta dar cuenta, de forma no muy efectiva, de:

Texto fuente

The ban on men's involvement in women's sports $(\mathrm{T}) \mid$ was aimed at promoting a traditional style of Islamic sports $(\mathrm{R})$
Texto meta

La prohibición de hombres con mujeres en los deportes $(\mathrm{T})$ | está apuntando a promover el estilo deportivo tradicional de ese país $(\mathrm{R})$

En general, es a nivel de Rema donde los escritores de los textos menos efectivos encuentran más dificultades. En este sentido, nos gustaría referirnos a una cita de Margaret Berry: cuando habla de Tematización informacional, cita las ventajas que ve Martin (1986) en este tipo de Tematización. Martin explica, dice Berry, que la Tematización informacional permite la producción de un texto: "que está bien orientado para un lector que busca información. El texto resultante permite una lectura de recorrido superficial 
rápido, guía bien al lector y es fácil para resumir o tomar notas. Simplemente con la lectura o el recorrido de los Temas...luego de una lectura inicial, alcanza...” (Berry, 1995: 59)

Nuestros ejemplos de textos menos efectivos no parecen mostrar que sea suficiente con una buena selección de Temas para orientar bien a un lector que busca información y menos aún para construir un texto que se deje resumir fácilmente. Pudimos observar cómo, los textos analizados mostraban incoherencias a nivel de Rema que, o bien volvían todo el texto incoherente, o provocaban errores conceptuales o ambas cosas.

El interés particular que tiene Halliday en el Tema se debe a que la sucesión de los Temas a nivel del discurso indica la manera en que se eligió desarrollar un texto, constituye su "esqueleto", su "andamiaje", o, para usar otra metáfora explicativa, su "soporte" (Mendehall, 1990:77), su método de desarrollo, como lo llamó Peter Fries (Martin, 1995: 241). Para la Lingüística Sistémico-Funcional la selección del Tema es esencial para la cohesión de un texto. Ahora bien, nos preguntamos, ¿es suficiente? Nuestros textos menos efectivos parecen conducir a una respuesta negativa.

Por eso, nos apoyamos adicionalmente en los conceptos de la Perspectiva Funcional de la Oración, enfoque para el cual el Tema constituye el elemento de base menos dinámico...Sin embargo, se entiende el Rema como el elemento más dinámico, el "aporte" (Mendenhall, 1990:77) que hace culminar la información. Como ya dijimos, (Cf.2.1.6) en palabras de Firbas: "una de las raisons d'etre más significativas de la oración” (Firbas, 1995:214).

Entonces, nos interesa la idea de Firbas acerca de la relevancia del Rema como elemento que completa el desarrollo comunicativo, que cumple con el propósito comunicativo de la oración (Cf. Introducción). Nuestros textos menos efectivos en la mayoría de los casos despliegan selecciones de Tema apropiadas y sin embargo son fundamentalmente las elecciones remáticas las que se apartan de los significados del texto fuente, lo que se traduce en cambio de información, incoherencias, o ambas cosas. 
En esta sección, presentamos ejemplos de cómo construyeron los escritores de los resúmenes de nuestro corpus los patrones temáticos en los cinco textos que fueron evaluados como menos efectivos. En la siguiente sección, compararemos los textos más efectivos con los menos efectivos para establecer algunas conclusiones preliminares.

\subsubsection{Comparaciones en el Sistema de Tema/Rema:}

En general, tanto en los textos más efectivos como en los menos efectivos, los Temas son no marcados. Sin embargo, en los resúmenes más efectivos:

a) se cambia adecuadamente el flujo de la información, no replicando a ciegas el orden de las palabras del texto fuente por lo que los patrones de Tema/Rema difieren de los de la noticia periodística.

Por ejemplo:

Texto fuente

PESHAWAR, Pakistan-Male coaches (T)|were banned yesterday from training female athletes and sports teams in a deeply conservative province of Pakistan. (R ) Male spectators $(\mathrm{T}) \mid$ also will be barred from watching sports events where female athletes compete (R), and male journalists (T) | are forbidden from covering them. (R)
Texto meta

La alianza religiosa "El partido de los seis",(T)| a través de su vocero Asif Iqbal Daudzai, Ministro de Información de la provincia de Peshawar, Pakistán, en un intento de imponer una estricta versión del Islam, decidió separar de los eventos deportivos femeninos toda actividad desarrollada por hombres (entrenadores, profesores, periodistas que cubren dichos eventos).(R) (Texto 3 )

b) se incluyen Temas textuales que contribuyen a dar cohesión al texto Por ejemplo:

Texto fuente

Texto meta 
PESHAWAR, Pakistan-Male coaches (T)|were banned yesterday from training female athletes and sports teams in a deeply conservative province of Pakistan. (R ) Male spectators $(\mathrm{T})$ also will be barred from watching sports events where female athletes compete (R), and male journalists (T) $\mid$ are forbidden from covering them. $(\mathrm{R})$
Las nuevas medidas $(\mathrm{T}) \mid$ indican que las mujeres ya no podrán ser entrenadas a nivel deportivo por los hombres (R); tampoco podrán ser vistas $(\mathrm{T})$ por espectadores del sexo masculino (R) $n i$ los periodistas hombres ( $T$ ) podrán cubrir los eventos en los cuales participen mujeres. (R) (Texto 2)

c) se ubica el texto en el espacio y el Contexto de Situación en las primeras cláusulas sin que necesariamente se trate de las primeras cláusulas del texto fuente. Por ejemplo:

Texto fuente

Male coaches $(\mathrm{T}) \mid$ were banned yesterday from training female athletes and sports teams in a deeply conservative province of Pakistan. (R ) Male spectators ( $\mathrm{T}$ ) |also will be barred from watching sports events where female athletes compete $(\mathrm{R})$, and male journalists $(\mathrm{T}) \mid$ are forbidden from covering them $(\mathrm{R})$...The new measures, decided at a provincial Cabinet meeting yesterday, $(\mathrm{T})$ mark the latest attempt by the six-party religious alliance to impose a strict version of Islam.(R)

Male coaches $(T) \mid$ were banned yesterday from training female athletes and sports teams in a deeply conservative province of Pakistan. (R ) Male spectators (T) $\mid$ also will be barred from watching sports events where female athletes compete (R), and male journalists $(\mathrm{T}) \mid$ are forbidden from covering them $(\mathrm{R})$...The province $(\mathrm{T})$ elected a hardline Islamic government in last October's natinal elections.(R) Hard-liners ( $\mathrm{T}$ ) |also share power in neighbouring Baluchistan province. (R )

d) se integra información. Por ejemplo:

\section{Texto meta}

En Peshawar, una provincia del Noroeste de Pakistán, (T) prohibieron a entrenadores, espectadores y periodistas varones el participar de cualquier manera en deportes de mujeres (R). Estas medidas, tomadas por el Gabinete provincial, $(\mathrm{T})$ | fueron impulsadas por una alianza religiosa islámica. (R) (Texto 1)

El texto (T) | trata sobre las decisiones tomadas por un gobierno muy conservador y muy estricto en Pakistán, más específicamente en la provincia de la Frontera Noroeste ubicada junto a la frontera con Afganistán. (R) Esta línea de gobierno (T) |asumió en las últimas elecciones nacionales (R) y ya $(\mathrm{T})$ estaba en otra provincia, Baluchistán (R) (Texto 2) 
Texto fuente

PESHAWAR, Pakistan-Male coaches (T)|were banned yesterday from training female athletes and sports teams in a deeply conservative province of Pakistan. (R ) Male spectators $(\mathrm{T}) \mid$ also will be barred from watching sports events where female athletes compete (R), and male journalists $(\mathrm{T}) \mid$ are forbidden from covering them $(\mathrm{R})$

PESHAWAR, Pakistan-Male coaches (T) | were banned yesterday from training female athletes and sports teams in a deeply conservative province of Pakistan. (R ) Male spectators $(\mathrm{T}) \mid$ also will be barred from watching sports events where female athletes compete (R), and male journalists $(\mathrm{T}) \mid$ are forbidden from covering them (R )...The new measures, decided at a provincial Cabinet meeting yesterday, $(\mathrm{T})\rceil$ mark the latest attempt by the six-party religious alliance to impose a strict version of Islam.(R)
Texto meta

En Peshawar (T) | prohibieron a entrenadores, espectadores y periodistas varones el participar de cualquier manera en deportes de mujeres (R) (Texto 1)

La alianza religiosa "El partido de los seis", (T) a través de su vocero Asif Iqbal Daudzai, Ministro de Información de la provincia de Peshawar, Pakistán, en un intento de imponer una estricta versión del Islam, decidió separar de los eventos deportivos femeninos toda actividad desarrollada por hombres (entrenadores, profesores, periodistas que cubren dichos eventos). (R) (Texto 3 )

Por el contrario, los escritores de los textos menos efectivos replican las formas de Temas del texto fuente. Esta tendencia combinada con una inapropiada interpretación de patrones verbales da lugar a incoherencias en algunos casos y cambios de información en otros.

Veamos algunos ejemplos de estos resultados poco felices:

Texto fuente

Male spectators (T) $\mid$ also will be barred from watching sports events where female athletes compete (R)

Male spectators $(\mathrm{T}) \mid$ also will be barred from watching sports events where female athletes compete $(\mathrm{R})$
Texto meta

Los espectadores hombres ( $\mathrm{T})$ serán enrejados de mirar eventos deportivos donde compitan atletas femeninas (R) (Texto 6) (incoherencia)

Los espectadores $(\mathrm{T})$ |tienen el deseo de estar mirando eventos donde compitan mujeres (R) (Texto 7) (cambio de información)

The ban on men's involvement in women's Las bandas de hombres involucradas en 
sports $(\mathrm{T}) \mid$ was aimed at promoting a traditional style of of Islamic sports, (R) Daudzai (T) | said, without elaborating (R)

Several retired athletes $(\mathrm{T})$ were expected to lose their jobs at girls'schools (R)

Male coaches (T)|were banned yesterday from training female athletes and sports teams... (R) deportes $(\mathrm{T})$ | son reelaboradas (R) (Texto 8) (incoherencia)
Ex atletas nacionales (T) | encaran expectativas de abrir escuelas (R) (Texto 9) (algo incoherente y cambia información)

\section{Los entrenadores de hombres (T)|prohibieron la enseñanza de atletas femeninos en aquellos deportes que eran considerados femeninos (R) (Texto 10) (cambio de información e incoherente)}

Nuestra hipótesis es que el contenido experiencial en Tema afecta los significados textuales y, por lo tanto, el desarrollo del texto. Aunque nuestros textos representan una muestra acotada, observamos cómo una determinada selección de relaciones entre participantes y procesos afecta el flujo de información y la coherencia del texto (hipótesis IIi). Más aún, vimos cómo las selecciones de contenido experiencial conducen, en los textos menos efectivos, a versiones que hasta superan el número de palabras del texto fuente debido a la poca reorganización e integración de ideas.

Matthiessen subraya que "...la metafunción textual...construye los significados experienciales e interpersonales como información que puede ser compartida por el hablante y el receptor..." (Matthiessen, 1995: 22). Entonces, si es cierto que la función textual impone un orden informacional a los significados experienciales, qué sucede en los resúmenes menos efectivos para que esos significados se aparten de los del texto fuente. Los escritores de estos resúmenes tratan de replicar participantes en Temas no marcados y aún así la información que construyen es muchas veces errónea e incoherente.

El presente análisis comparativo de resúmenes más y menos efectivos en L1 a partir de un texto fuente en L2 sugiere que los escritores que tienen un umbral léxico-gramatical muy bajo no pueden reconocer ciertas estructuras de mucho peso para construir los significados 
del texto fuente (por ejemplo la voz pasiva en el artículo periodístico que nos ocupahipótesis Ii)) y se transforman en "esclavos de la forma"; optan por replicar los Temas del texto fuente a partir, en la mayoría de los casos, de la traducción literal de las frases nominales y cuando llegan a los elementos remáticos, particularmente a la frase verbal, la traducción literal los conduce a significados que se alejan de los del texto fuente.

Más aún, las limitaciones a nivel léxico-gramatical no les permiten a los escritores de los textos menos efectivos reconocer el propósito del texto que deben resumir que es: anunciar las estrictas medidas tomadas por un gobierno de línea dura, en parte porque no pueden reconocer el patrón de progresión temática del género del texto fuente "artículo periodístico". Y en este sentido, acordamos con Fries en su hipótesis sobre que: "hay una correlación entre diferentes patrones de progresión temática y los diferentes géneros, i.e. los patrones de progresión temática no ocurren al azar sino que son sensibles al género" (Fries, 1995: 7).

El género artículo periodístico ha sido analizado extensamente entre otros por van Dijk ${ }^{22}$ y en base a esos estudios estamos en condiciones de argumentar que los escritores de los textos más efectivos despliegan un desarrollo temático que respeta la jerarquía de ideas inherente al género noticia periodística. En sus resúmenes comienzan integrando el contenido correspondiente a ¿quiénes?, ¿dónde? y ¿por qué? del núcleo textual -los hechos que dieron origen a la noticia- para completar sus resúmenes con detalles de las causas y consecuencias del evento relatado. Los escritores de los textos menos efectivos, por su parte, son esclavos de las formas. Parecería que desde ellas quieren llegar a los significados sin comprender que deberían intentar el camino inverso. Volviendo a la pregunta desde la LSF de tratar de responder el ¿quién hace qué cosa a quién en qué circunstancias?, cómo podrían los escritores de nuestros resúmenes menos efectivos identificar el ¿quién? si no pueden reconocer que, por las selecciones en el texto fuente de estructuras pasivas sin agente explícito en el primer párrafo, el ¿quién? o ¿quiénes? debe ser inferido del contexto

\footnotetext{
${ }^{22}$ Consultar van Dijk, Teun [1996 (1983)], La ciencia del texto, Barcelona: Paidós
} 
ya que recién en el segundo párrafo aparece textualizado: La alianza religiosa el partido de los seis. 


\section{Capítulo 5}

\section{CONCLUSIONES}

"On ne comprend bien que ce que l'on est capable de résumer",23

Liliane SPRENGER-CHAROLLES

\subsection{INTRODUCCIÓN}

A través del análisis del presente trabajo se ha procurado mostrar la interpretación de la relación participante-proceso en un texto fuente escrito en L2 y su incidencia en la escritura de resúmenes de dicho texto en L1. Para ello, se realizó un análisis tripartito tanto del texto fuente como de los textos meta con el fin de analizar la relación participante-proceso del Sistema de Transitividad y su incidencia en los Sistemas de Modo/Temple y de Tema/Rema. El objetivo general del trabajo ha sido demostrar cómo determinadas estructuras léxico-gramaticales apropiadamente interpretadas contribuyen a la efectividad de la producción textual. El objetivo aplicado, poder utilizar los resultados de esta

\footnotetext{
23 "Sólo comprendemos bien lo que somos capaces de resumir"
} 
investigación para asistir a nuestros alumnos en una efectiva producción del resumen a través de las estrategias apropiadas.

El análisis léxico-gramatical nos permitió observar la relación entre contexto y texto. Así, las opciones en las relaciones participante-proceso del Sistema de Transitividad, su repercusión en el Sistema de Modo/Temple y el Sistema de Tema/Rema realizaron significados semántico-discursivos que resultaron en contextos con distintos grados de coherencia y, eventualmente, en resúmenes con distintos grado de efectividad. Es decir, la selección de patrones léxico-gramaticales incidió, a partir de los significados que se reconstruyeron, en el Contexto de Situación (Registro) y el Contexto de Cultura (Género) de los textos meta.

Ya se ha mencionado anteriormente (Cf Capítulo 2) que Halliday enfatiza los vínculos sistemáticos entre la organización del lenguaje y la organización del contexto. Las distintas selecciones de significados experienciales, interpersonales y textuales construyen distintos tipos de Campo, Tenor y Modo (Registro). Por otro lado, el procedimiento analítico central en el análisis genérico es relacionar las distintas etapas de estructura esquemática con sus patrones de realización lingüísticos. Los límites entre las distintas etapas y la función de cada una de ellas se expresa precisamente a través de las elecciones lingüísticas específicas de cada texto.

También se ha mencionado que cada una de las etapas del género contribuye a lograr el propósito general que debe conseguirse para que el género tenga éxito y que, cuando describimos la estructura esquemática de un género, lo que describimos es su estructura constitutiva, es decir, de partes: un Comienzo, un Medio y un Final. Pero, si queremos ver cómo las distintas partes de un texto se relacionan entre sí y contribuyen al propósito general del texto dado en una cultura determinada, también se ha dicho, es más conveniente utilizar etiquetajes funcionales y no formales para describir las diferentes etapas. Así, vemos cómo cada parte constitutiva (etapa) y el orden en que se despliega cada una de ellas cumple una función relativa al todo. 
En la siguiente sección, mostraremos cómo funcionan las distintas etapas genéricas en un texto efectivo; y a continuación, veremos si es posible identificar esas etapas en un texto menos efectivo.

\subsection{EL TEXTO MÁS EFECTIVO Y EL TEXTO MENOS EFECTIVO}

En base a nuestra puntuación y a la opinión de nuestros informantes, nos gustaría contrastar el resumen que fue evaluado como ejemplo de texto más efectivo (Texto 2) y contrastarlo con el menos efectivo (Texto 8):

\section{Texto 2}

a)

El texto trata sobre las decisiones tomadas por un gobierno muy conservador y muy estricto en Pakistan, más específicamente en la provincia de la Frontera Noroeste ubicada junto a la frontera con Afganistán. Esta línea de gobierno asumió en las últimas elecciones nacionales y ya estaba en otra provincia, Baluchistan.

b)

Las nuevas medidas indican que las mujeres ya no podrán ser entrenadas a nivel deportivo por los hombres; tampoco podrán ser vistas por espectadores del sexo masculino ni los periodistas hombres podrán cubrir los eventos en los cuales participen mujeres. Esta decisión afectará a miles de mujeres y adolescentes que participan en varios deportes a nivel internacional; por otra parte, también puede afectar a varones que dan clases en escuelas para mujeres, ocasionando esto la pérdida de trabajos.

c)

Esta línea de gobierno islámica anteriormente había prohibido que se escuche música en micros públicos y ordenaron derribar carteles publicitarios con imágenes de mujeres. Además, de vez en cuando, la policía secuestra videocassettes y compact discs y los prenden fuego. Todo esto es parte de una campaña antiobsenidad. 
A nivel de género, se distingue claramente en este texto el propósito de informar para beneficio del lector. Por otra parte, cada una de sus etapas constitutivas puede reconocerse en términos funcionales; su primera etapa (a) define con claridad de qué se trata el texto, lo que motivó la noticia; la segunda etapa (b) proporciona detalles de los hechos e incluye posibles consecuencias; por último, la tercera etapa (c) ubica el contexto específico de la noticia en el contexto de otras medidas tomadas en el mismo sentido, se podría decir que ubica el Contexto específico de Situación dentro del Contexto más general de Cultura. Podemos, entonces, reconocer una estructura esquemática global

A nivel de registro, también se pueden distinguir los haces de significados: experienciales (el texto trata sobre las medidas tomadas por un gobierno conservador en Pakistán); interpersonales (los hechos "se cuentan solos", la información avanza a partir de cláusulas declarativas, hay poca presencia subjetiva y se selecciona apropiadamente la modalización cuando se hace referencia a posibles consecuencias futuras de los hechos contados); textuales (el texto progresa desde la autoridad y desde las medidas tomadas y utiliza elementos de cohesión que dan aún más unidad a los hechos contados). Por lo tanto, el texto es consistente desde la construcción del Campo, Tenor y Modo/Medio aunque no necesariamente replique la relación participante-proceso del texto fuente.

Se trata, entonces, de un texto que ostenta coherencia situacional y genérica, donde cada oración está relacionada con las demás, puede interpretarse a la luz de las mismas y contribuye al propósito general del texto. En otras palabras, hablamos de texto en el sentido de que constituye una unidad de significado y que, como resumen del texto fuente es efectivo puesto que logra informar al lector acerca de los hechos contados por el texto fuente (la noticia periodística: Men's and Women's Sports Completely Separated) sin traicionar sus significados.

Entonces, a partir de una buena interpretación de la relación participante-proceso del primer párrafo, el escritor construye un contexto claro del ¿quién?, ¿qué? y ¿dónde? sobre el que da detalles de la situación y completa los hechos más importantes contados en el texto 
fuente. Es interesante también destacar, que el escritor del Texto 2 no construye desde una decodificación lineal replicando a ciegas la progresión temática del texto fuente. En este resumen, el escritor describe primero el contexto de las medidas para luego detallarlas y, finalmente, ubicarlas en el contexto más amplio de otras medidas en la misma dirección.

Pasemos ahora a analizar el que constituye uno de los ejemplos menos efectivos de resumen:

\section{Texto 8}

El gobierno de Pakistan no permite que mujeres ingresen como espectadoras de eventos deportivos.

Esto fue decidido en Cabinet.

La decisión afecta a miles de mujeres que compitan en tenis, tenis de mesa y jockey sobre césped.

Las bandas de hombres involucradas en deportes son reelaboradas.

El gobierno estableció separar el deporte en equipo para mujeres.

En las elecciones nacionales de octubre la provincia eligió un firme gobierno islámico.

Las autoridades pusieron carteleras de las imágenes de futuras mujeres publicitando películas o productos, que fueron o son arrancadas.

La policía quemó videocasetes y compact discs hechos en campañas anti-obsenidad.

No todas las colecciones de cláusulas en secuencia constituyen texto (Eggins, 1994:112). En el ejemplo que nos ocupa, a nivel de género, no es posible distinguir diferentes etapas de una posible estructura genérica, ni desde lo formal, ya que el texto progresa en complejos clausales que se despliegan uno debajo del otro sin poder distinguir un Comienzo, un Medio y un Final, ni desde lo funcional, ya que no es posible reconocer la función de cada complejo clausal en relación a un propósito global.

A nivel de registro, si bien hay un esbozo de construcción de Campo con la mención de participantes como el gobierno de Pakistán y mujeres y el proceso de prohibición (no permite) las limitaciones a nivel léxico-gramatical no ayudan a la construcción de un Campo coherente, es decir a crear significados experienciales apropiados, fieles al texto fuente. En cuanto a los significados interpersonales, bloques como: Esto fue decidido (en 
Cabinet) o Las bandas de hombres involucradas en deportes son reelaboradas hacen que los argumentos sobre la veracidad o no de los hechos giren en torno a Sujetos que nada tienen que ver con el texto fuente; el Tenor del texto, entonces, resulta poco efectivo. Por último, los significados textuales avanzan a partir de Temas no claramente definidos ni relacionados entre sí. Tampoco hay elementos de cohesión que establezcan relaciones entre las distintas cláusulas. La falta de coherencia situacional es también producto de la poca cohesión interna de una "colección de complejos clausales" en la que cada oración crea su propio contexto, no se relaciona con las demás ni contribuye a la interpretación de las mismas. Por lo tanto, no es fácil explicar de qué se trata el "texto".

Contrariamente a lo que sucede en el Texto 2, el escritor del Texto 8 intenta reproducir algunos participantes, algo que no siempre logra con éxito, y además no puede relacionarlos entre sí para construir un contexto coherente. Los procesos que asocia a esos participantes poco aportan a la construcción de significados coherentes y de ese modo, el texto en su totalidad no sólo tiene poco que ver con el texto fuente sino que, como nuevo "texto", no constituye una unidad de significado.

\subsection{EL TEXTO FUENTE Y SU INTERPRETACIÓN}

Los resultados de nuestro trabajo revelan que una efectiva interpretación de la relación participante-proceso depende de una adecuada interpretación de determinadas estructuras léxico-gramaticales. En particular, en el texto fuente que nos ocupa esa estructura es la voz pasiva. Como se ha señalado en el Capítulo 3, el artículo periodístico que los alumnos deben resumir se caracteriza por la presencia de la voz pasiva en varias de sus cláusulas. Además de las cuatro cláusulas del primer párrafo, tres de ellas en el resto del texto describen los hechos utilizando voz pasiva. Por eso, si bien nos concentramos en el procesamiento del primer párrafo no ignoramos el tratamiento de la estructura participante- 
proceso en el resto de los textos-meta, sobre todo en los casos en que servía para reforzar nuestra hipótesis Ii).

Asociado a cada estrato del lenguaje hay una unidad de análisis diferente. Para nuestro análisis léxico gramatical nos concentramos en la cláusula como unidad y cuando consideramos la acumulación de significados a nivel semántico discursivo estamos considerando el texto como unidad de análisis. Pero más allá del texto, los significados que construimos con el lenguaje están motivados por lo que pasa en el mundo fuera del texto, es decir, el contexto con sus dos niveles: uno general de Cultura y otro inmediato de Situación.

El texto fuente que nos ocupa es una noticia periodística y como tal es un texto cuya principal función es informar, presentar hechos de forma que parezcan objetivos, de modo que es de esperar que haya poca presencia personal subjetiva explícita. Las instancias de voz pasiva en el texto fuente ayudan a objetivizar aún más la información. Existe considerable distancia entre un escritor no fácil de individualizar y el lector. El escritor parece construir una imagen impersonal con poco o nada de margen de negociación de los hechos. Se presenta casi como fuente de información absoluta. El texto se estructura exclusivamente a través de cláusulas declarativas donde el autor se construye como autoridad que posee información "que es" o "no es". La elección de Sujetos parece centrarse en "la autoridad" luego de un comienzo de elección de "participantes afectados".

El Campo del discurso del texto fuente se centra en la autoridad establecida con participantes que "hacen" y "dicen" para asentar esa autoridad. Sin embargo, lo que hace a nuestro texto fuente particularmente difícil de interpretar es que en tres instancias, centrales para la interpretación del tópico ya que aparecen en el párrafo inicial del texto, se presentan participantes animados que "sufren las consecuencias de esas acciones". Esta estructuración lingüística sumada a la presencia de nominalizaciones (Cf. Capítulo 4) para elecciones de participantes como "la prohibición", "la decisión", "las medidas" que, de alguna manera empaquetan las acciones de prohibir, decidir y tomar medidas y la selección de 
participantes que representan instituciones más que individuos bien definidos dificultan la interpretación de los hechos contados $\mathrm{y}$, en consecuencia, la posterior construcción del resumen.

La efectividad de los textos meta parece estar vinculada a la interpretación de la relación participante-proceso a lo largo del texto fuente. En los textos evaluados como más efectivos, los escritores interpretan apropiadamente dicha relación de modo que la acumulación de significados experienciales resulta en una construcción de Campo coherente que no traiciona el texto fuente. Asimismo, como estos escritores interpretan en forma adecuada tanto contenido como voz y modalidad de los procesos, la acumulación de significados interpersonales y, en consecuencia, la construcción del Tenor no se aparta del rol que asume el escritor del texto fuente ni de su actitud frente a los hechos contados. Por último, los escritores que son capaces de interpretar las relaciones participante-proceso tal como el texto fuente las construye organizan los patrones de Modo/Medio que constituyen los significados textuales de modo tal que la reflexión sobre los hechos replica el Contexto de Situación construido por el texto fuente.

En otras palabras, los escritores de los textos más efectivos, a partir de la interpretación adecuada de las relaciones participante-proceso reconstruyen los tres haces de significados del texto fuente en forma coherente. El nuevo texto que construyen respeta: Campo (decisiones de un gobierno autoritario en el campo del deporte), Tenor (los hechos "se cuentan solos", con poca presencia subjetiva por parte del escritor; no obstante, cuando modalizan, los escritores de los textos más efectivos respetan el rol que asume el escritor del texto fuente) y Modo/Medio (los textos más efectivos respetan el propósito fundamental del texto fuente que es impartir información).

Un detalle no menor es que, si bien el Campo es el deporte, el texto fuente que nos ocupa podría encuadrarse dentro del sub-Campo "Deporte y Política". El autor del mismo (¿intencionalmente?) intenta que los hechos se cuenten solos y que los actores de determinadas acciones aparezcan menos nítidos. De ahí la concentración de la voz pasiva en el primer párrafo, selección que oscurece participantes actores y resalta agentes 
afectados. Esta estructura en particular debe ser reconocida apropiadamente para no cambiar significados o incurrir en incoherencias como ocurre en los resúmenes menos efectivos de nuestro corpus. En este sentido, se trata de la interpretación del más abstracto de los niveles del texto: el de Ideología, que también impacta en el resto de los niveles y que, a través de ellos, se realiza en las selecciones lingüísticas (Eggins, 1994: 330).

\subsection{RESPUESTAS A LAS PREGUNTAS QUE GUIARON EL ESTUDIO}

Al comenzar nuestro trabajo, nos planteamos una serie de preguntas que guiaron este estudio. En esta sección, y con el fin de lograr una presentación más clara de las conclusiones de esta investigación, se transcriben y responden dichos interrogantes planteados en la Introducción:

I) i) ¿Cómo influye un umbral bajo de conocimiento lingüístico en L2 en la interpretación de la relación participante-proceso? ii) Qué ocurre en el posterior proceso de escritura en L1 cuando no se interpreta adecuadamente la relación participante-proceso en un texto en L2? iii) ¿Cómo afecta la adecuada interpretación de la relación participante-proceso (Sistema de Transitividad) las relaciones a nivel de los Sistemas de Modo/Temple y Tema/Rema?

Estamos en condiciones de dar una respuesta a nuestra pregunta Ii) acerca de cómo influye un umbral bajo de conocimiento lingüístico en L2 en la interpretación de la relación participante-proceso. En el caso de nuestro estudio, la estructura que nos interesó analizar es la voz pasiva. El hecho de que en el texto fuente que nos ocupa la elección de Tema (sujeto psicológico)-particularmente al comienzo del texto en lo que constituye, si se quiere, el Tema del artículo- no coincida con el actor de la acción (sujeto lógico) sumado a que, en el desarrollo del texto se incluyan sujetos psicológicos que son nominalizaciones de 
acciones encubiertas hace sensiblemente más difícil la interpretación adecuada de la relación participante-proceso.

Entonces, ¿qué ocurre en el proceso de escritura en L1 cuando dicha relación no se interpreta adecuadamente (I ii))? En el origen de todo resumen efectivo se encuentra una comprensión adecuada de la información del texto de partida (Alvarez Angulo, 2005:243/263-Cf. Introducción). Ahora bien, Silvestri subraya que la producción de un nuevo texto a partir de un texto fuente consta de cuatro fases y la primera de ellas es la comprensión (Silvestri, 1998:23). Es razonable suponer entonces que puedan verse rastros de lecto-comprensión en la producción de resúmenes. Nuestro análisis parece mostrar que los escritores de los resúmenes menos efectivos no pueden reconocer determinadas estructuras y por lo tanto esa comprensión poco efectiva resulta en una producción menos satisfactoria en el texto de segundo grado que construyen. Entonces, ¿qué estrategia emplean como consecuencia de esa comprensión poco efectiva? En otras palabras, ¿que ocurre cuando no se interpreta adecuadamente la relación participante-proceso?

Ya dijimos que Mathesius planteó la idea de que el orden de las palabras era un sistema regido por principios que no eran únicamente gramaticales (Cf. Capítulo 2). Acordamos con Mathesius cuando explica que la influencia de los tres principios (gramatical; Perspectiva Funcional de la Oración; enfático) puede variar de un idioma a otro. El no reconocimiento de estas diferencias conduce a los escritores de algunos de nuestros resúmenes a tratar de imitar formas que traicionan los significados del texto fuente (hipótesis Iiib). Nuestro corpus está constituido por textos en español a partir de un texto fuente en inglés y los escritores deben seleccionar patrones lingüísticos que resulten apropiados para la construcción de un texto cohesivo y coherente. Para que este ordenamiento en español sea coherente, y siguiendo las ideas de Mathesius, los escritores deberían tener en cuenta los tres principios que rigen dicho ordenamiento y que "...pueden diferir en su influencia relativa de un idioma a otro" (Mathesisus, 1926) ${ }^{24}$.

\footnotetext{
${ }^{24}$ Citado en Montemayor-Borsinger, 2009. 1926 corresponde al año en que fundó el Círculo de Praga.
} 
Ahora bien, los escritores que no son conscientes de las diferencias que existen entre el inglés y el español con respecto al ordenamiento sintáctico pretenden repetir en sus cláusulas en español el orden de palabras que impone el principio gramatical en inglés. El escritor se apega a la forma de representar la relación participante-proceso en inglés: $\mathrm{S}+\mathrm{V}$ de la estructura pasiva e intenta copiar literalmente la forma. El resultado es un texto cuyos significados difieren del texto original, que resulta incoherente o ambas cosas (hipótesis Iiib). Lo que estos escritores no alcanzan a comprender es que “...a diferencia de las declarativas en inglés, en declarativas en español el Sujeto gramatical puede ser implícito y con ello, abrir la posibilidad de que el Tema no marcado pueda ser tanto el Sujeto gramatical como el verbo, ya que ambos pueden constituir una opción por defecto." (Montemayor-Borsinger, 2009:99) Más aún, en el caso de estructuras verbales pasivas, la elección de la forma pasiva con "se" es en general la más apropiada como punto de partida de mensaje de oración declarativa.

Entonces, y para dar respuesta a nuestra pregunta I)iii), cuando los escritores de los resúmenes interpretan en forma adecuada las relaciones participante-proceso del Sistema de Transitividad, también los patrones de Modo/Temple y Tema/Rema resultan efectivos. Es decir, cuando las elecciones en los textos meta reflejan a los participantes actores como tales y a los participantes sobre quienes las acciones recaen apropiadamente, también los escritores identifican el componente de la cláusula que carga el argumento aunque no sea necesariamente el participante actor e identifican el rol que asume el escritor del texto original ante los hechos contados. Finalmente, estos escritores seleccionan como punto de partida de su cláusula componentes que ayuden a la coherencia textual aunque estos no necesariamente coincidan con los Temas elegidos por el escritor del texto fuente. Y, puesto que las tres metafunciones se despliegan en forma conjunta aunque, al mismo tiempo, cada una avanza y se desarrolla en forma individual, es de esperar, que una determinada interpretación a nivel de una metafunción resuene a nivel de las otras dos metafunciones y, eventualmente, a nivel de registro y género (Ravelli, 1995) 
Por el contrario, en el caso de los resúmenes menos efectivos, estamos en presencia de textos que alteran la relación participante-proceso, lo que repercute en la construcción del Campo del discurso. Al mismo tiempo, la relación Sujeto-Verbo Finito no se corresponde con la del texto fuente y por lo tanto no se construye apropiadamente el Tenor del discurso. Por último, el método de desarrollo seleccionado crea significados textuales que distan de los del texto fuente y a menudo resultan incoherentes. Esto se observa en los textos de nuestro corpus particularmente cuando los escritores llegan a las selecciones remáticas que constituyen el núcleo central del mensaje y proporcionan la información más importante. El Modo/Medio, entonces, también realiza significados textuales que se alejan de los del texto fuente.

Por otra parte, si tenemos en cuenta que la noticia periodística es un tipo de texto orientado ideacionalmente (Matthiessen, 1995 :22), una poco eficaz interpretación de la relación participante-proceso afectará sensiblemente los tres haces de significados. Por un lado, porque el apego a las formas verbales (que instancian los procesos) en detrimento de los significados afecta el Sistema de Modo/Temple y, por otro, porque es a partir del Sistema de Tema/Rema (significados textuales) que se construyen los significados experienciales (participantes-procesos).

En resumen, la lectura es fundamentalmente un proceso lingüístico, aunque este aspecto de la lectura es a menudo minimizado (Graber y Stroller, 2002:19- Cf. Introducción). La falta de conocimiento de determinadas estructuras gramaticales en L2, en nuestro caso la voz pasiva, dificulta la comprensión de la relación participante- proceso (Pregunta I)i). Pero además, los escritores de los textos de nuestro corpus deben resolver dos tipos de problemas; por un lado, los de comprensión (en tanto lectores) y por otro, los de producción (en tanto escritores). Por lo tanto, la inapropiada interpretación de la relación participanteproceso conduce a los escritores de nuestros textos menos efectivos a replicar formas (Pregunta Iii); estas elecciones repercuten en los Sistemas de Modo/Temple y Tema/Rema (Pregunta Iiii) y eventualmente en la construcción de textos incoherentes, alejados de la realidad contada por el texto fuente. 
Veamos ahora, cómo podemos dar respuesta a las siguientes preguntas de nuestra Introducción:

II) i) ¿Qué relación existe entre la inapropiada interpretación de la relación participante-proceso en la interpretación global de los significados del texto fuente y la efectividad del resumen? ii) ¿En qué aspectos textuales debemos poner énfasis como docentes para ayudar a nuestros alumnos a reformular textos efectivos en L1 a partir de un texto fuente en L2.

Con respecto a la pregunta IIi), la relación entre los significados experienciales y la efectividad del resumen puede explicarse, como ya se ha dicho, por el hecho de que los escritores que intentan reproducir las formas, seleccionan para comenzar sus cláusulas, los mismos participantes que selecciona el texto fuente para comenzarlas. Esta selección en Tema, intenta reproducir esas formas incluso en su encadenamiento sintáctico. Pero ocurre que a medida que avanzan en la construcción del Rema los significados se vuelven menos transparentes y los alumnos construyen procesos, en muchos casos, carentes de significados coherentes. Y puesto que, la información expresada al comienzo de una cláusula declarativa es responsable de la construcción del método de desarrollo de un texto (Martin, 1995: 241), la construcción del texto en su totalidad se resiente.

En este sentido, Elija Ventola explica que poco se ha explorado acerca de qué sucede en los procesos de traducción con las estructuras de Tema/Rema. La autora observa que en las traducciones menos efectivas los escritores parecen insensibles a los significados globales que el escritor del texto fuente intentó construir. Más que considerar el método de desarrollo del texto y tratar de ver su efecto en la textualidad, coherencia y cohesión globales, el foco parece ponerse en cada una de las cláusulas y no en la motivación textual y el efecto retórico de los patrones globales de Tema/Rema (Ventola, 1995: 85 y sig.). Esta observación constituye una buena respuesta a nuestra pregunta IIi). 
Lo que algunos lectores hacen es tratar de crear un texto paralelo replicando las formas del texto fuente, con la ayuda del diccionario (ibid.). Estamos en condiciones de afirmar, a partir del análisis de nuestros textos, que así procedieron los escritores de los resúmenes menos efectivos. Entonces, los escritores de los resúmenes menos efectivos, en general y por limitaciones a nivel léxico-gramatical, eligen replicar en Tema las formas correspondientes a los participantes seleccionados en el texto fuente. Es decir, optan por "traducciones literales" de participantes con respecto a la versión en inglés. Y cuando deben resolver el proceso construyen formas que se alejan de los significados del texto fuente o que resultan en significados incoherentes. Como el proceso es el punto en el que el mensaje queda completamente elaborado y, al mismo tiempo, por tener correspondencia el Rema con los objetivos globales del texto (Fries, 1995:11/12) esta decisión de construir un texto paralelo incide sensiblemente en los significados globales del texto meta que construyen.

Al querer traspolar la relación participante-proceso tal como aparece en el texto fuente estos escritores alteran las relaciones que se establecen entre las ideas; muchas veces, construyendo ideas incoherentes. ${ }^{25}$ Por ejemplo, los escritores de los resúmenes menos efectivos no pueden reconocer la voz pasiva $\mathrm{y}$, como de los 5 grupos verbales que les ofrecieron mayores dificultades, tres están en el párrafo introductorio, estos escritores no son capaces de construir un contexto coherente en el cual apoyarse y poder parafrasear los significados del texto fuente. Porque ¿cómo podrán los escritores de los resúmenes menos efectivos identificar el ¿quién hace? si no son capaces de reconocer que los sujetos gramaticales de esos 5 grupos verbales no son sujetos lógicos, es decir que no son agentes sino pacientes.

Sin embargo, como se ha mostrado, es básicamente a nivel de procesos donde los escritores de los resúmenes menos efectivos "pierden la brújula" del texto que construyen. Por eso, al no reconocer la voz pasiva, alteran la relación participante-proceso y esa limitación a nivel

\footnotetext{
${ }^{25}$ Para información sobre la relación entre el orden de las palabras y el orden de las ideas consultar Tema. Una perspectiva funcional de la organización del discurso (Montemayor-Borsinger, 2009)
} 
léxico-gramatical repercute en todos los significados del texto que construyen. En otras palabras, no son capaces de realizar el salto semántico que les permita comprender los significados que ellos mismos están construyendo.

En suma, el texto meta no construye información que pueda ser compartida entre escritor y lector. De hecho, el escritor, primer lector del texto resultante, poco puede comprender del texto que produce. Sin embargo, su apego a las formas del texto fuente no le permite, en muchos casos, reconocer las inexactitudes y/o incoherencias de su texto. Y, más aún, su lector externo, por el modo en que la relación participante-proceso (significados experienciales) se despliega en el texto no puede integrar los significados experienciales en un sistema de instanciación que le permita derivar conocimiento del texto que enfrenta.

Por último, ¿en qué aspectos aspectos textuales debemos poner énfasis como docentes para ayudar a nuestros alumnos a reformular textos efectivos en L1 a partir de un texto fuente en L2?

Los resultados obtenidos del análisis llevado a cabo permiten afirmar, siempre teniendo en cuenta que se ha trabajado en detalle con un corpus acotado, que para interpretar un texto escrito en L2 que debe ser resumido en L1 el reconocimiento de ciertas estructuras léxico gramaticales álgidas es fundamental. Es ese reconocimiento el que permite la apropiada interpretación entre participantes, procesos y sus circunstancias asociadas. De este modo, el lector del texto en L2 no se aferra a las formas para intentar llegar a los significados. Por el contrario, los escritores de los textos menos efectivos de nuestro corpus, por no reconocer determinadas estructuras gramaticales, básicamente la voz pasiva, intentan replicar estructuras sintácticas y orden de información que resulta en una interpretación errónea de los conceptos del texto fuente. Estos escritores, entonces, terminan produciendo significados nuevos, en muchos casos incoherentes. 
Pensamos, como indicáramos al inicio de nuestro trabajo, que la enseñanza de las formas debe pensarse como medio para llegar a los significados ya que, como también ya explicáramos, el aprendizaje de un idioma es esencialmente el aprendizaje de cómo funciona su gramática para realizar los significados (Widdowson, 1990:97) (Cf. Capítulo 1). En palabras de Halliday (1961:275) considerar a la lingüística sólo como un estudio de gramática formal y nada más es como "una idea verde sin color que duerme furiosamente entre las sábanas de la teoría lingüística y no permite que se pueda hacer la cama” ${ }^{\text {26 }}$.

Por eso, y desde una perspectiva pedagógica, entendemos que nuestros resultados nos permiten sugerir que en los cursos de Capacitación en Lengua Extranjera es conveniente enseñar el sistema lingüístico a través de instancias de lengua en uso. El debate entre "lo natural vs lo adquirido" generó, a lo largo del siglo XX argumentos encontrados. Acordamos con F. Christie y B. Derewianka (2010:213) que en realidad no se trata de opuestos sino de "lo natural vía lo adquirido". Nuestros alumnos tienen la capacidad genética del desarrollo lingüístico, en nuestro caso particular de una segunda lengua, pero somos nosotros como docentes quienes debemos ayudarlos a adquirir las estructuras y los patrones de organización típicos de una variedad de géneros. Si podemos guiarlos a detectar más eficientemente las áreas léxico-gramaticales problemáticas, podrán construir contextos de situación y de cultura más apropiados, es decir, textos más cohesivos y coherentes.

Por ejemplo, la información en Rema está casi siempre representada por el reconocimiento de las formas verbales. En este sentido, acordamos con Mendivelzua et al (2008) quienes mencionan entre las estrategias de intervención para la comprensión lectora el reconocimiento del verbo finito. Nuestros ejemplos muestran que cuando los significados que contienen las frases verbales no son identificados en forma apropiada los textos pierden cohesión y coherencia. Lo mismo ocurre cuando un no-finito es interpretado como forma verbal finita.

\footnotetext{
${ }^{26}$ Traducción de la autora
} 
Por supuesto, no es razonable pensar que la efectividad de nuestros resúmenes pueda deberse exclusivamente a la interpretación adecuada de la relación participante-proceso. Si bien nuestros resultados permiten considerar que éste es un aspecto significativo, entendemos que un estudio más abarcador podría echar luz sobre otros aspectos que también incidirían. Por ejemplo, podría ser que las dificultades de nuestros alumnos para construir resúmenes efectivos estuviera, además, relacionada con la habilidad para escribir resúmenes efectivos en español. En este caso, quedaría pendiente mostrar si la Hipótesis de la Interdependencia Lingüística es aplicable a esos casos. También sería pertinente seguir investigando la incidencia de las diferencias a nivel léxico-gramatical entre las dos lenguas. Los resultados de nuestro análisis podrían enriquecerse con un análisis más profundo del principio gramatical y su influencia en el ordenamiento de las palabras en las distintas lenguas. Por último, la aplicación del modelo ergativo de la Transitividad permitiría comparar casos como la interpretación de formas de voz efectiva receptiva y su resolución en pasajes del inglés al español. Es de esperar que futuras investigaciones, en otros contextos y con corpora más extensos, representen importantes aportes al estudio de algunos de los aspectos antes mencionados. 


\section{BIBLIOGRAFÍA}

Alderson, J.C. (1984), "Reading in a Foreign Language: A reading problem or a language problem?, en J.C. Alderson y A.H.Urquhart (eds) (1984) Reading in a Foreign Language. London: Longman.

Alderson, J.C. (2000), Assessing Reading. New York: Cambridge University Press.

Alvarez Angulo, T. (2005), El resumen como estrategia de composición textual y su aplicación didáctica. Tesis Doctoral. Universidad Complutense de Madrid: España. Disponible en: www.ucm.es/BUCM/tesis/19911996/H/3/AH3037801.pdf.

Bajtín, M. (1979), Estética de la Creación Verbal. México: Siglo XXI.

Bello, A. (1988 [1847]), Gramática de la lengua castellana destinada al uso de los americanos. Con las notas de Rufino José de Cuervo, edición crítica de Ramón Trujillo. Madrid: Arco Libros.

Bernhardt, E. y Kamil, M. (1995), "Interpreting relationships between L1 and L2 reading: Consolidating the Linguistic Threshold and the Linguistic Interdependence Hypotheses". Applied Linguistics, 16:1; pp. 15-34.

Berry, M. (1995) “Thematic options and success in writing”, en Ghadessy, M. (ed.) (1995) Thematic Development in English Texts. London: Pinter Publishers; pp.55-84.

Brown, A. L. et Day J. D. (1983), "Macrorules for summarizing texts: The development of expertise" en Journal of Verbal Learning and Verbal Behavior, 22:1; pp.1-14.

Brown, G. And Yule, G. (1983), Discourse Analysis. Cambridge: Cambridge University Press. 
Butt, D. y otros, ([2003] 1994), Using Functional Grammar. An Explorer's Guide. Sydney: MacquarieUniversity.

Charolles, M. (1991ª), "Le résumé de texte scolaire. Fonctions et principes d'elaboration". Pratiques, $\mathrm{N}^{\mathrm{o}} 72 ;$ pp. 7-27.

Christie, F. and Derewianka, B. (2010 [2008]), School Discourse. Learning to write across the years of schooling. London: Continuum International Publishing Group.

Ciapuscio, Guiomar, (1994). Tipos Textuales. Buenos Aires: Facultad de Filosofía y Letras-Universidad de Buenos Aires.

Eggins, SuZanne (1994), An Introduction to Systemic Functional Linguistics. London: Pinter Publishers.

EgGins, S., y Martin, J.R. (1997), "Genres and Registers of discourse" en van Dijk, T. (ed.) (1997) Discourse as Structure and Process, Vol.1, London: Sage; pp.230-256.

Firbas, J. (1964) "On Defining the Theme in Linguistic Sentence Analysis" en Travaux Linguistiques de Prague, 1; pp. 267-280.

Firbas, J. (1992), Functional Sentence Perspective in Written and Spoken Communication. Cambridge: Cambridge University Press.

Firbas, J. (1995), “A contribution on a panel discussion on Theme” en Ghadessy, M.) (ed.) (1995) Thematic Development in English Texts. London: Printer Publishers; pp. 213-222.

Firth, J.R. (1935), "The technique of semantics", Transactions of the Philological Society. Reprinted in J. R. Firth, Papers in Linguistics 1934-1951 ( London: Oxford University Press, 1959).

Firth, J.R. (1957), Papers in Linguistics 1934-1951. London: Oxford University Press. 
Fries, P. (1981), “On the status of Theme in English: arguments from discourse”, Forum Linguisticum, 6; pp.1-38.

Fries, P. (1994), “On Theme, Rheme and discourse goals”, en Coulthard, M. (ed.) (1994) Advances in Written Text Analysis. London: Routledge; pp.229-249.

Fries, P.(1995) “A personal view of Theme” en Ghadessy, M. (comp.) (1995) Thematic Development in English Texts. London: Printer Publishers.

García Negroni, M. M. (2010), Escribir en español. Claves para una corrección de estilo. Buenos Aires: Santiago Arcos editor.

Ghio, E. y Fernández, M.E. (2008), Lingüística Sistémico Funcional. Aplicaciones a la lengua española. Santa Fe: Waldhuter Editores, ediciones UNL.

Gili y Gaya, S. (1960), Curso superior de sintaxis española. Barcelona: Publicaciones y Ediciones Spes, S.A.

Goodman, K. (1996), On Reading. Portsmouth: Heinemann.

Goodman, Y. (1984), “The development of initial literacy”, en H. Goelman, A. Oberg y F. Smith (eds.) (1984) Awakening to Literacy. Exeter: Heinemann Educational Books

Grabe, W. y Stoller, F.L. (2002), Teaching and Researching Reading. London: Pearson Education.

Gutiérrez Ordóñez, S. (2000), Temas, remas, focos, tópicos y comentarios. Cuadernos de Lengua Española. Madrid: Arco/Libros.

Halliday, M.A.K. (1961), “Categories of the theory of grammar”, Word, 13. 3 (Dec.1961); pp. 241-92. 
Halliday, M.A.K. (1974), "Interview with M.A.K. Halliday, en H. Parret (ed.), Discussing Language (Janua Linguarum Series Maior 93). The Hague: Mouton; pp 81-120 (extractos reimpresos en Halliday 1978).

Halliday, M.A.K. and Hasan, R. (1976). Cohesion in English. London: Longman.

Halliday, M.A.K. (1982), El Lenguaje como Semiótica Social (J. Ferreiro Santana Trad). México: FCE.

Halliday, M.A.K. (1985), An Introduction to Functional Grammar. London: Edward Arnold.

Halliday, M.A.K. and Hasan, R. (1990 [ 1985]). Language, context and text: aspects of language in a social-semiotic perspective. Oxford: Oxford University Press.

Halliday, M.A.K. (1993), "The construction of knowledge and value in the grammar of scientific discourse: Charles Darwin's The origin of species, Halliday, M.A.K.Y Martin, J.R. (1993); pp. 86-105.

Halliday, M.A.K. y Martin, J.R. (1993), Writing Science: Literacy and Discursive Power. London: Falmer Press.

Halliday, M.A.K. (1994), An Introduction to Functional Grammar. London: Edward Arnold.

Halliday, M.A.K. y Matthiessen, C.M.I.M. (2004), An Introduction to Funcional Grammar. London: Edward Arnold.

Heinemann, W. y Viehweger, D. (1991), Textlinguistik. Eine Einführung. Tübingen: Niemeyer. 
Kaufman A.M. y F.Perelman (2000) "Resúmenes escritos: reconstrucción de un proceso investigativo", en N.Elichiry (comp.) (2000) Aprendizaje de niños y maestros. Hacia la construcción del sujeto educativo. Buenos Aires: Editorial Manantial.

López Casanova, M., Inza, M. y Peralta, D. (2000), "Los géneros resuntivos en relación con las competencias de lectura y escritura especializadas", en Actas del IV Congreso de Lingüística General, Cádiz 2000, Vol. 3, 2002, ISBN 84-7786-740-2; pp. 1491-1500

Malinowski, B. (1935), Coral Gardens and their Magic, a Stdy of the Methods of Tilling the Soil and of Agricultural Rites in the Trobriand Islands, vol. 2. The Language of Magic and Gardening. London: Allen and Unwin.

Malinowski, B. (1946 [1923]), "The Problem of Meaning in Primitive Languages", Supplement 1 in Charles K. Ogden / Ian A. Richards (eds.) The Meaning of Meaning. New York: Harcourt Brace \& World.

Martin, J.R. (1984) “Language, Register and Genre”, en F. Christie (ed.) (1984), Children's Writing: reader. Geelong, Vic: Deakin University Press; pp. 21-29.

Martin, J.R. (1985b) "Process and Text: Two Aspects of Semiosis", en J.D. Benson y W.S. Greeves (eds.) Systemic Perspectives on Discourse, Volume 1, Norwood, NJ: Ablex Publishing; pp. 248-274.

Martin, J.R. (1986), "Intervening in the process of writing development", en C.Painter y J.R. Martin (eds.), Writing to mean: Teaching Genres across the Curriculum (Occasional Papers Number 9), Applied Linguistics Association of Australia, 11-43.

Martin, J.R. (1989), Factual Writing: Exploring and Challenging Social Reality. London: Oxford University Press.

Martin, J. R. (1992), English Text. Amsterdam: John Benjamins. 
Martin, J.R. (1995) "More then what the message is about: English Theme" en Ghadessy, M.) (ed.) (1995) Thematic Development in English Texts. London: Printer Publishers; pp. $223-258$.

Martin, J. R., Matthiensen, Christian and Painter, Clare (1997), Working with Functional Grammar. London: Arnold.

Martin, J. R. y Rose, D. (2003), Working with Discourse: Meaning beyond the clause, London and New York: Continuum.

Martin, J. R. y Rose, D. (2008), Genre Relations: Mapping Culture, London: Equinox.

Matthiessen, C. (1995), "THEME as an enabling resourse in "ideational" knowledge construction" en Ghadessy, M. (ed.) (1995) Thematic Development in English Texts. London: Printer Publishers; pp. 20-54.

Meldivelzua, A., Sánchez, M., De Lorenzis, M., Fonseca, L., Schmidt, B., Loffredo, M., Manso, M., Sueta, L., Morgan, P., (2008), “Cómo hacer fácil lo difícil: estrategias de intervención para facilitar la comprensión lectora" Revista Aprendizaje Hoy- Año XXVIIIN71, UCA. Disponible en: http://www.uca.edu.ar/uca/common/grupo18/files/Cmo_hacer_f-cil_lo_dif-cil_publicar.pdf

Mendenhall, V. (1990), Une introduction à l'analyse du discours argumentatif. Canada: Les presses de 1'Université d'Ottawa.

Montemayor- Borsinger, A. (2001), Case Studies of Academic Writing in the Sciences: A Focus on the Development of Writing Skills. Tesis Doctoral. Universidad de Glasgow, Escocia. Disponible en: http//www.wagsoft.com/Systemics/Archive/index.html.

Montemayor-Borsinger, A. (2004), “Tema según la LSF y el funcionalismo de Praga, en Hasan y Parra (comp.) (2004) Actas I Conferencia Latinoamericana de Lingüística 
Sistémico-Funcional La Lingüística Sistémico-Funcional, la Lengua y la Educación. Mendoza: UNCuyo.

Montemayor-Borsinger, A. ( 2005), "Una Perspectiva Sistémico-Funcional de Texto e Interacción: las funciones de Sujeto y Tema” en Rasal, Revista de la Sociedad Argentina de Lingüística-N1-2005; pp.25-36.

Montemayor-Borsinger, A. (2009), Tema: Una perspectiva funcional de la organización del discurso. Buenos Aires: Eudeba.

Palincsar, A.S. y Brown, A.L. (1984), "Reciprocal teaching of comprensión-fostering and comprensión-monitoring activities”. Cognition and instruction, 1; pp.117-175.

Preiti, M. (1998), "Resumir es comprender” en Rébola M.C. y Stroppa, M.C. El resumen en el aula. Rosario: Centro de Lingüística Aplicada. Facultad de Humanidades y Artes, Universidad Nacional de Rosario; pp. 167-179.

Ragan, P. (1987) "Meaning in communication of a set of instructions".Ph. D. dissertation, National University of Singapore.

Ravelli L.J.(1995), “A dynamic perspective: implications for metafunctional interaction and understanding of Theme", en R. Hasan y P. Fries (eds). On Subject and Theme: A Discourse Functional Perspective. Amsterdam and Philadelphia: John Benjamins; pp. 185234.

Rébola, M.C. y Stroppa, M.C. (1998), El resumen en el aula. Rosario: Centro de Lingüística Aplicada. Facultad de Humanidades y Artes, Universidad Nacional de Rosario; pp.19-27.

Silvestri, A. (1998), En otras palabras. Las habilidades de reformulación en la producción del texto escrito. Buenos Aires: Cántaro Editores.

Solé, I. (1997[1992]), Estrategias de lectura. Barcelona: Graó. 
ThOMPSON, GeOfF (1997). Introduction to Functional Grammar. London: Arnold.

Van Dijk, T. (1996[1983]), La ciencia del texto (S. Hunzinger Trad). Barcelona: Paidós.

van Dijk, T.A. (1995[1980]), Estructuras y funciones del discurso (M. Gann y M. Mur, Trads). Madrid: Siglo veintiuno de España editores, s .a.

Ventola, E. (1995), “Thematic Development and translation" en Ghadessy, M. (ed.), (1995)

Thematic Development in English Texts. London: Printer Publishers; pp.84-104.

Vygotsky, L. (1962), Thought and language. (Editado y traducido por E. Haufmann, y G. Vakar), Cambridge, Mass., MIT Press. (Idem. 1962. Nueva York, Londres, Wiley; (Idem. 1986. (Editado por A. Kozulin), Cambridge, Mass., MIT Press.

Wallace, C. (2003), Critical Reading in Language Education. London: Palgrave Macmillan.

Widdowson, H. G. (1984), Explorations in Applied Linguistics 2. Oxford: Oxford University Press.

Widdowson, H.G. (1990), Aspects of Language Teaching. Oxford: Oxford University Press.

Widdowson, H.G. (2007), Discourse Analysis. Oxford: Oxford University Press. 
APÉNDICES 


\section{Apéndice 1}

\section{Apéndice}

Men's and women's sports completely separated PESHAWAR, Pakistan - male coaches were banned yesterday from training female athletes and sports teams in a deeply conservative province in Pakistan. Male spectators also will be barred from watching sports events where female athletes compete, and male journalists are forbidden from covering them, Asif Iqbal Daudzai, information minister of the North West Frontier province, told a news briefing.

The new measures, decided at a provincial Cabinet meeting yesterday, mark the latest attempt by the six-party religious alliance to impose a strict version of Islam. The decision will affect thousands of girls and women in the province who compete in sports such as tennis, table tennis and field hockey.

Several retired athletes were expected to lose their jobs at girls' schools because of the rules.

Buenos Aires Herald, 17 de mayo de 2003. 245 palabras
The ban on men's involvement in women's sports was aimed at promoting a traditional style of Islamic sports, Daudzai said, without elaborating. The government will establish a separate sports group for women, he added.

The province elected a hard-line Islamic government in last October's national elections. Hard-liners also share power in neighboring Baluchistan province. Both provinces border Afghanistan.

Authorities in North West Frontier Province already have banned all music on public buses and ordered billboards featuring images of women advertising movies or products to be torn down.

Police often douse gasoline on piles of videocassettes and compact discs seized during "anti-obsenity campaigns" and set them ablaze. 


\section{FIELD}

\begin{tabular}{|c|c|c|c|}
\hline$\underline{\text { ACTOR/GOAL }}$ & $\frac{\text { MATERIAL }}{\text { PROCESSES }}$ & $\begin{array}{l}\frac{\text { PROJECTING }}{\underline{\text { PROCESSES }}} \\
\text { Mental / Verbal }\end{array}$ & 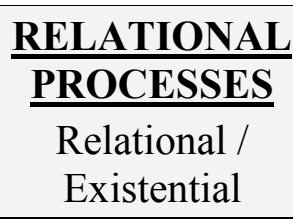 \\
\hline Male coaches & were banned & & \\
\hline Male spectators & will be barred & & \\
\hline Female athletes & compete & & \\
\hline Male journalists & are forbidden & & \\
\hline $\begin{array}{l}\text { Asif Iqbal } \\
\text { Daudzai }\end{array}$ & & told & \\
\hline $\begin{array}{l}\text { The new } \\
\text { measures }\end{array}$ & mark & & \\
\hline The decision & will affect & & \\
\hline $\begin{array}{l}\text { (girls and women } \\
\text { in the province) } \\
\text { who }\end{array}$ & compete & & \\
\hline $\begin{array}{l}\text { Several retired } \\
\text { national athletes }\end{array}$ & & were expected to lose & \\
\hline The ban & $\begin{array}{l}\text { was aimed at } \\
\text { promoting }\end{array}$ & & \\
\hline Daudzai & & said & \\
\hline The government & will establish & & \\
\hline $\mathrm{He}$ & & added & \\
\hline The province & elected & & \\
\hline Hard-liners & share & & \\
\hline Both provinces & border & & \\
\hline $\begin{array}{l}\text { Authorities in } \\
\text { North West } \\
\text { Frontier Province }\end{array}$ & have banned & & \\
\hline $\begin{array}{l}\text { (Authorities in } \\
\text { North West } \\
\text { Frontier } \\
\text { Province) }\end{array}$ & & ordered & \\
\hline Police & douse & & \\
\hline (Police) & set ablaze & & \\
\hline
\end{tabular}




\section{TENOR}

\begin{tabular}{|c|c|c|}
\hline $\begin{array}{l}\text { MOOD BLOCK } \\
\text { SUBJECT }\end{array}$ & FINITE & PREDICATOR \\
\hline Male coaches & were & Banned \\
\hline male spectators & will & be barred \\
\hline female athletes & \multicolumn{2}{|c|}{ Compete } \\
\hline male journalists & are & Forbidden \\
\hline $\begin{array}{l}\text { Asif Iqbal Daudzai, information ministry of the North West } \\
\text { Frontier province }\end{array}$ & \multicolumn{2}{|r|}{ Told } \\
\hline $\begin{array}{l}\text { The new measures, decided at a provincial Cabinet meeting } \\
\text { yesterday }\end{array}$ & \multicolumn{2}{|r|}{ Mark } \\
\hline The decision & will & Affect \\
\hline (girls) who & \multicolumn{2}{|r|}{ Compete } \\
\hline Several retired national athletes & were & expected to lose \\
\hline The ban on men's involvement in women's sports & was & $\begin{array}{l}\text { aimed at } \\
\text { promoting }\end{array}$ \\
\hline Daudzai & \multicolumn{2}{|r|}{ Said } \\
\hline The Government & will & Establish \\
\hline he & \multicolumn{2}{|r|}{ Added } \\
\hline The province & \multicolumn{2}{|r|}{ Elected } \\
\hline Hard-liners & \multicolumn{2}{|r|}{ Share } \\
\hline Both provinces & \multicolumn{2}{|r|}{ Border } \\
\hline Authorities in North West Frontier Province & have & Banned \\
\hline Police & \multicolumn{2}{|r|}{ Douze } \\
\hline (police) & set & Ablaze \\
\hline
\end{tabular}


MODE

\begin{tabular}{|c|c|c|c|c|}
\hline \multicolumn{4}{|c|}{ THEME } & \multirow[b]{2}{*}{ RHEME } \\
\hline Textual & Interpersonal & $\begin{array}{l}\text { Marked } \\
\text { Topical }\end{array}$ & $\begin{array}{l}\text { Unmarked } \\
\text { Topical }\end{array}$ & \\
\hline & & & Male coaches & $\begin{array}{l}\text { were banned yesterday from } \\
\text { training female athletes and } \\
\text { sports teams in a deeply } \\
\text { conservative province in } \\
\text { Pakistan. }\end{array}$ \\
\hline & & & Male spectators & $\begin{array}{l}\text { also will be barred from } \\
\text { watching sports events where } \\
\text { female athletes compete, and }\end{array}$ \\
\hline & & & male journalists & $\begin{array}{l}\text { are forbidden from covering } \\
\text { them, }\end{array}$ \\
\hline & & & $\begin{array}{l}\text { Asif Iqbal Daudzai, } \\
\text { information } \\
\text { minister of the } \\
\text { North West } \\
\text { Frontier province, }\end{array}$ & told a news briefing \\
\hline & & & $\begin{array}{l}\text { The new measures, } \\
\text { decided at a } \\
\text { provincial Cabinet } \\
\text { meeting yesterday, }\end{array}$ & $\begin{array}{l}\text { mark the latest attempt by the } \\
\text { six-party religious alliance to } \\
\text { impose a strict versionof } \\
\text { Islam. }\end{array}$ \\
\hline & & & The decision & $\begin{array}{l}\text { will affect thousands of girls } \\
\text { and women in the province } \\
\text { who compete in sports such as } \\
\text { tennis, table tennis and field } \\
\text { hockey }\end{array}$ \\
\hline & & & $\begin{array}{l}\text { Several retired } \\
\text { national athletes }\end{array}$ & $\begin{array}{l}\text { were expected to lose their } \\
\text { jobs at girls'schools because } \\
\text { of the rules. }\end{array}$ \\
\hline & & & $\begin{array}{l}\text { The ban on men's } \\
\text { involvement in } \\
\text { women's sports }\end{array}$ & $\begin{array}{l}\text { was aimed at promoting a } \\
\text { traditional style of Islamic } \\
\text { sports, }\end{array}$ \\
\hline & & & Daudzai & said, without elaborating. \\
\hline & & & The government & $\begin{array}{l}\text { will establish a separate sports } \\
\text { group for women, }\end{array}$ \\
\hline & & & he & Added \\
\hline & & & The province & $\begin{array}{c}\text { elected a hard-line Islamic } \\
\text { government in last October's } \\
\text { national elections. }\end{array}$ \\
\hline & & & Hard-liners & $\begin{array}{c}\text { also share power in } \\
\text { neighbouring Baluchistan } \\
\text { province. }\end{array}$ \\
\hline & & & Both provinces & border Afghanistan. \\
\hline
\end{tabular}


MODE

\begin{tabular}{|c|c|c|c|c|}
\hline \multicolumn{4}{|c|}{ THEME } & \multirow[b]{2}{*}{ RHEME } \\
\hline Textual & Interpersonal & $\begin{array}{r}\text { Marked } \\
\text { Topical }\end{array}$ & $\begin{array}{c}\text { Unmarked } \\
\text { Topical }\end{array}$ & \\
\hline & & & $\begin{array}{c}\text { Authorities in } \\
\text { North West } \\
\text { Frontier Province }\end{array}$ & $\begin{array}{l}\text { already have banned all music } \\
\text { on public houses and ordered } \\
\text { billboards featuring images of } \\
\text { women advertising movies or } \\
\text { products to be torn down }\end{array}$ \\
\hline & & & Police & $\begin{array}{l}\text { often douse gasoline on piles } \\
\text { of videocassettes and compac } \\
\text { discs seized during "anti- } \\
\text { obsenity campaigns"and set } \\
\text { them ablaze }\end{array}$ \\
\hline
\end{tabular}




\section{Apéndice 2: Resúmenes}

A) A continuación se transcribirán cinco ejemplos de resúmenes bien efectivos. Cada uno de los resúmenes se transcribirá con la división de párrafos, lexis y ordenamiento léxico original.

\section{Texto 1}

En Peshawar, una provincia del Noroeste de Pakistan, prohibieron a entrenadores, espectadores y periodistas varones el participar de cualquier manera en deportes de mujeres. Estas medidas, tomadas por el Gabinete provincial, fueron impulsadas por una alianza religiosa islámica y afectarán a muchas mujeres que practican deportes y a atletas retirados que trabajan en escuelas de mujeres.

La prohibición de que los hombres se involucren en deportes de mujeres fue orientada a promover un estilo tradicional de deportes islámicos. El gobierno establecerá grupos deportivos separados de hombres y mujeres.

La provincia eligió en octubre un gobierno islámico de línea dura que comparte el poder también en la provincia vecina de Baluchistán.

Autoridades de la provincia de Peshawar prohibieron también la música en los colectivos públicos y ordenaron quitar toda la publicidad con imágenes de mujeres.

También fueron incendiados por la policía compact discs y videocassettes secuestrados en campañas anti-obsenidad.

\section{Texto 2}

El texto trata sobre las decisiones tomadas por un gobierno muy conservador y muy estricto en Pakistan, más específicamente en la provincia de la Frontera Noroeste ubicada junto a la frontera con Afganistán. Esta línea de gobierno asumió en las últimas elecciones nacionales y ya estaba en otra provincia, Baluchistan.

Las nuevas medidas indican que las mujeres ya no podrán ser entrenadas a nivel deportivo por los hombres ; tampoco podrán ser vistas por espectadores del sexo masculino ni los periodistas hombres podrán cubrir los eventos en los cuales participen mujeres. Esta decisión afectará a miles de mujeres y adolescentes que participan en varios deportes a nivel internacional; por otra parte, también puede afectar a varones que dan clases en escuelas para nujeres, ocasionando esto la pérdida de trabajos.

Esta línea de gobierno islámica anteriormente había prohibido que se escuche música en micros públicos y ordenaron derribar carteles publicitarios con imágenes de mujeres. Además, de vez en cuando, la policía secuestra videocassettes y compact discs y los prenden fuego. Todo esto es parte de una campaña anti-obsenidad. 


\section{Texto 3}

La alianza religiosa "El partido de los seis", a través de su vocero Asif Iqbal Daudzai, Ministro de Información de la provincia de Peshawar, Pakistán, en un intento de imponer una estricta versión del Islam, decidió separar de los eventos deportivos femeninos toda actividad desarrollada por hombres (entrenadores, profesores, periodistas que cubren dichos eventos). Muchos atletas retirados, los cuales trabajan en escuelas de niñas como entrenadores, temen perder su trabajo.

"Dicha medida tiene como objeto promover el tradicional estilo del deporte islámico," agregó Daudzai.

La provincia ha elegido una línea islámica bastante dura en la últimas elecciones, que además de la anterior medida, ha impulsado una campaña anti-obsenidad, quemando pilas de videocassettes y compact discs. También, ha prohibido la música en autobuses públicos, publicidades de películas o productos con mujeres en ellas.

\section{Texto 4}

Se prohibió a entrenadores hombres entrenar deportistas mujeres en una provincia pakistaní. Lo mismo les ocurrió a periodistas y espectadores masculinos que quisieran ver deportes femeninos, afirmó un vocero pakistaní.

Las medidas, decididas en Gabinete provincial, fueron tomadas por la alianza religiosa del Islam. La decisión afecta a todas las deportistas femeninas de deportes como tenis, tenis de mesa y jockey sobre césped.

Atletas nacionales retirados podrían quedar sin trabajo por esta nueva regla.

"La proscripción a los hombres es para fomentar el tradicional estilo de los deportes islámicos," explicaron.

Esta provincia eligió una política dura del gobierno islámico como su provincia vecina de Baluchistan, ambas fronterizas con Afganistán.

También se prohibió música en autobuses públicos y se ordenó demoler toda cartelera y anuncio publicitario con imágenes femeninas. Es común ver a la policía quemando discos compactos y cassettes de video en campañas anti-obsenidad.

\section{Texto 5}

El texto se refiere a que se le ha prohibido a entrenadores masculinos entrenar atletas femeninas y equipos integrados por mujeres en una provincia conservadora de Pakistán. También se prohíbe a los espectadores concurrir a eventos disputados por mujeres, así como también se prohíbe a los periodistas masculinos cubrir dichos eventos.

Estas nuevas medidas, decididas en una reunión de gabinete, son otras de las que caracterizan esta dura versión del Islam.

Esta decisión afectará a miles de mujeres que practican deportes como el tenis, el ping pong y el jockey sobre césped.

Muchos atletas retirados se quedarán sin trabajo. 
La prohibición que no deja que los hombres se desenvuelvan en deportes femeninos sigue el estilo tradicional de los deportes islámicos, estableciendo así grupos deportivos femeninos separados.

Esta dura línea del gobierno islámico fue elegida en las elecciones que se realizaron en el mes de octubre último. Esta línea dura de gobierno comparte el poder en una provincia vecina que también limita con Afghanistan.

Las autoridades fronterizas de la Provincia del Noroeste también prohibieron toda la música en ómnibus públicos y ordenaron sacar carteleras con imágenes de mujeres publicitando películas o productos.

La policía incautó videos y discos compactos durante campañas anti-obsenidad y los prendieron fuego.

B) A continuación se transcribirán cinco ejemplos de resúmenes menos efectivos. Cada uno de los resúmenes se transcribirá con la división de párrafos, lexis y ordenamiento léxico original.

\section{Texto 6}

Entrenadores ayer fueron prohibidos de entrenar atletas femeninos y deportes de equipos en una profunda y conservadora provincia de Pakistán. Los espectadores hombres serán enrejados de mirar eventos deportivos en donde compiten atletas femeninas y los periodistas se olvidan de cubrir a ellas.

Asif Iqbal Daudzai, Ministro de Información del Noroeste de la provincia de Frontera, dijo a las noticias informativas.

Las noticias tomadas, el gabinete decidió encontrarse ayer, marcan el último intento de la alianza religiosa por la fiesta-seis para imponer una estricta versión del Islam.

La decisión afectará a cientos de chicas y mujeres en la provincia que compiten en deportes tales como tenis, tenis de mesa y jockey sobre césped.

Varios atletas nacionales retirados fueron anticipados a perder sus empleos en escuelas de chicas a causa de las reglas.

La prohibición sobre la participación de hombres en deportes de mujeres fue dirigida a promoción de estilos tradicionales de deportes islámicos, Daudzai dijo sin elaboración.

El gobierno establecerá una separación de deportes grupales para mujeres.

La provincia eligió una línea dura en el gobierno islámico en las últimas elecciones nacionales de octubre. Línea dura también repartió autoridad en la provincia de Neighboring y Baluchistan. Ambas provincias bordean Afganistán.

Autoridades del noroeste de la frontera de la provincia aún han prohibido toda música sobre autobuses públicos y controlan carteleras con aspecto de imágenes de mujeres o productos para ser difamados.

Policía frecuentemente gasolina sobre pilas de videocassettes y compacts durante "campañas de anti-obsenidad" y envía? a ellos en llamas. 


\section{Texto 7}

Los profesores estaban prohibidos desde ayer de entrenar atletas femeninos. Los espectadores tienen el deseo de estar mirando eventos donde compitan mujeres. Los periodistas están prohibidos de cubrirlos. Asif Iqbal Daudzai, Ministro de Información del Noroeste de la Provincia de Pakistan contaba una noticia concisa.

La nueva medida tomada por el Concejo de Ministros marca el último intento de establecer una estricta versión por la sexta religiosa.

Varios atletas nacionales retirados estaban expectantes a perder sus beneficios.

La provincia estableció una dura raya con el gobierno para alcanzar las elecciones nacionales en octubre. discs.

La policía durante campañas en contra a la obscenidad compraba videocasetes y compact

\section{Texto 8} deportivos.

El gobierno de Pakistan no permite que mujeres ingresen como espectadoras de eventos

Esto fue decidido en Cabinet. césped.

La decisión afecta a miles de mujeres que compitan en tenis, tenis de mesa y jockey sobre

Las bandas de hombres involucradas en deportes son reelaboradas.

El gobierno estableció separar el deporte en equipo para mujeres.

En las elecciones nacionales de octubre la provincia eligió un firme gobierno islámico.

Las autoridades pusieron carteleras de las imágenes de futuras mujeres publicitando películas o productos, que fueron o son arrancadas.

La policía quemó videocasetes y compact discs hechos en campañas anti-obsenidad.

\section{Texto 9}

En Pakistan los entrenadores masculinos fueron separados de las atletas femeninas por la profunda conservadora provincia de Pakistan; también se les pusieron prohibiciones a los periodistas de cubrir dichos eventos; eso era lo que informaba el Ministerio del Noroeste de dicha provincia.

Se dice que la decisión podría afectar a miles de varones y mujeres de dicha provincia para competir en diferentes disciplinas. Ex atletas nacionales encaran expectativas de abrir escuelas para mujeres para diferentes deportes. La separación de los hombres de los deportes femeninos puede llegar a promover el tradicional estilo de los deportes de la Islam.

El gobierno estableció la separación de los deportes por grupo.

Las autoridades del Noroeste de la provincia también excluyó música, publicidad, productos e imágenes masculinos. 


\section{Texto 10}

Los entrenadores de hombres prohibieron la enseñanza de atletas femeninos en aquellos deportes que eran considerados femeninos, no tan solo la enseñanza sino la inclusión en los equipos.

La información fue dada por el ministro de la frontera del noroeste de Pakistan.

Esta última noticia es el último intento por imponerse al Islam.

La medida afecta a chicas y mujeres que practican los deportes de tenis, etcétera.

La prohibición de hombres con mujeres en los deportes está apuntando a promover el estilo deportivo tradicional de ese país.

El gobernador establecerá una orden para separar los grupos que pertenecen a los deportes de las mujeres.

La provincia eligió en el pasado octubre (en las elecciones nacionales) un firme representante del Islam.

Las autoridades de la Frontera Noroeste dispusieron la prohibición de música sobre los Micros públicos y pancartas. 


\section{Apéndice 3: Análisis de Transitividad}

\section{A) Textos más efectivos}

\section{Texto 1}

\begin{tabular}{|c|c|c|c|}
\hline ACTOR/OBJETIVO & $\frac{\frac{\text { PROCESOS }}{\text { MATERIALES }}}{\begin{array}{c}\text { Materiales / de } \\
\text { Conducta }\end{array}}$ & $\frac{\text { PROCESOS DE }}{\underline{\text { PROYECCIÓN }}}$ & $\frac{\text { PROCESOS }}{\text { RELACIONALES }}$ \\
\hline $\begin{array}{c}\text { a entrenadores, } \\
\text { espectadores y } \\
\text { periodistas varones }\end{array}$ & prohibieron & & \\
\hline $\begin{array}{c}\text { Estas medidas, } \\
\text { tomadas por el } \\
\text { Gabinete provincial, }\end{array}$ & fueron impulsadas & & \\
\hline (estas medidas) & afectarán & & \\
\hline (muchas mujeres) que & practican & & \\
\hline (atletas retirados) que & trabajan & & \\
\hline $\begin{array}{l}\text { La prohibición de que } \\
\text { los hombres se } \\
\text { involucren en } \\
\text { deportes de mujeres }\end{array}$ & $\begin{array}{l}\text { fue orientada a } \\
\text { promover }\end{array}$ & & \\
\hline El gobierno & establecerá & & \\
\hline La provincia & eligió & & \\
\hline $\begin{array}{l}\text { (un gobierno islámico } \\
\text { de línea dura) que }\end{array}$ & comparte & & \\
\hline $\begin{array}{c}\text { Autoridades de la } \\
\text { provincia de Peshawar }\end{array}$ & prohibieron & & \\
\hline $\begin{array}{c}\text { (Autoridades de la } \\
\text { provincia de } \\
\text { Peshawar) }\end{array}$ & ordenaron & & \\
\hline $\begin{array}{l}\text { Compact discs y } \\
\text { videocassettes }\end{array}$ & fueron incendiados & & \\
\hline
\end{tabular}




\section{Texto 2}

\begin{tabular}{|c|c|c|c|}
\hline ACTOR/OBJETIVO & $\frac{\frac{\text { PROCESOS }}{\text { MATERIALES }}}{\begin{array}{c}\text { Materiales / de } \\
\text { Conducta }\end{array}}$ & $\frac{\text { PROCESOS DE }}{\underline{\text { PROYECCIÓN }}}$ & $\frac{\text { PROCESOS }}{\text { RELACIONALES }}$ \\
\hline El texto & & & trata (sobre) \\
\hline las decisiones & (que fueron) tomadas & & \\
\hline Esta línea de gobierno & & & asumió \\
\hline $\begin{array}{l}\text { (Esta línea de } \\
\text { gobierno) }\end{array}$ & & & estaba \\
\hline Las nuevas medidas & & & indican \\
\hline las mujeres & $\begin{array}{l}\text { (no) podrán ser } \\
\text { entrenadas }\end{array}$ & & \\
\hline (las mujeres) & & (no) podrán ser vistas & \\
\hline $\begin{array}{l}\text { (ni) los periodistas } \\
\text { hombres }\end{array}$ & podrán cubrir & & \\
\hline mujeres & participen & & \\
\hline Esta decisión & afectará & & \\
\hline $\begin{array}{l}\text { (miles de mujeres y } \\
\text { adolescentes) que }\end{array}$ & participan & & \\
\hline (esta decisión) & puede afectar & & \\
\hline (varones) que & dan & & \\
\hline $\begin{array}{c}\text { Esta línea de gobierno } \\
\text { islámica }\end{array}$ & había prohibido & & \\
\hline música & & se escuche & \\
\hline $\begin{array}{l}\text { (Esta línea de gobierno } \\
\text { islámica) }\end{array}$ & ordenaron derribar & & \\
\hline la policía & secuestra & & \\
\hline (la policía) & prende fuego & & \\
\hline Todo esto & & & es \\
\hline
\end{tabular}


Texto 3

\begin{tabular}{|c|c|c|c|}
\hline ACTOR/OBJETIVO & 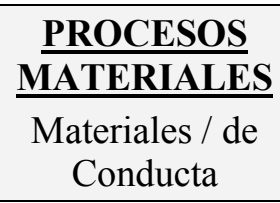 & $\begin{array}{l}\frac{\text { PROCESOS DE }}{\text { PROYECCIÓN }} \\
\text { Mentales / Verbales }\end{array}$ & $\frac{\text { PROCESOS }}{\text { RELACIONALES }}$ \\
\hline $\begin{array}{l}\text { La alianza religiosa } \\
\text { "El partido de los seis" }\end{array}$ & decidió separar & & \\
\hline $\begin{array}{c}\text { Muchos atletas } \\
\text { retirados, los cuales } \\
\text { trabajan en escuelas de } \\
\text { niñas como } \\
\text { entrenadores, }\end{array}$ & temen perder & & \\
\hline $\begin{array}{c}\text { (atletas retirados) los } \\
\text { cuales }\end{array}$ & trabajan & & \\
\hline Dicha medida & $\begin{array}{l}\text { tiene por objeto } \\
\text { promover }\end{array}$ & & \\
\hline Daudzai & & agregó & \\
\hline La provincia & ha elegido & & \\
\hline $\begin{array}{l}\text { (una línea islámica } \\
\text { bastante dura) que }\end{array}$ & ha impulsado & & \\
\hline $\begin{array}{l}\text { (una línea islámica } \\
\text { bastante dura) que }\end{array}$ & ha prohibido & & \\
\hline
\end{tabular}

Texto 4

\begin{tabular}{|c|c|c|c|}
\hline ACTOR/OBJETIVO & $\frac{\text { PROCESOS }}{\text { MATERIALES }}$ & $\begin{array}{l}\frac{\text { PROCESOS DE }}{\text { PROYECCIÓN }} \\
\text { Mentales / Verbales }\end{array}$ & $\frac{\text { PROCESOS }}{\text { RELACIONALES }}$ \\
\hline $\begin{array}{l}\text { a entrenadores } \\
\text { hombres }\end{array}$ & Se prohibió & & \\
\hline $\begin{array}{l}\text { les/a periodistas y } \\
\text { espectadores } \\
\text { masculinos }\end{array}$ & & & ocurrió \\
\hline $\begin{array}{l}\text { (periodistas y } \\
\text { espectadores } \\
\text { masculinos) que }\end{array}$ & & quisieran ver & \\
\hline un vocero pakistaní & & afirmó & \\
\hline $\begin{array}{c}\text { Las medidas, } \\
\text { decididas en Gabinete } \\
\text { provincial, }\end{array}$ & fueron tomadas & & \\
\hline La decisión & afecta & & \\
\hline $\begin{array}{l}\text { Atletas nacionales } \\
\text { retirados }\end{array}$ & & & podrían quedar \\
\hline
\end{tabular}




\begin{tabular}{|c|c|c|c|}
\hline ACTOR/OBJETIVO & $\frac{\text { PROCESOS }}{\text { MATERIALES }}$ & $\frac{\text { PROCESOS DE }}{\underline{\text { PROYECCIÓN }}}$ & $\begin{array}{l}\text { PELOCESOS } \\
\text { Relacionales / } \\
\text { Existenciales }\end{array}$ \\
\hline \multirow[t]{2}{*}{$\begin{array}{c}\text { La proscripción a los } \\
\text { hombres }\end{array}$} & & & es \\
\hline & & explicaron & \\
\hline Esta provincia & elgió & & \\
\hline música & se prohibió & & \\
\hline $\begin{array}{l}\text { toda cartelera y } \\
\text { anuncio publicitario } \\
\text { con imágenes } \\
\text { femeninas }\end{array}$ & se ordenó demoler & & \\
\hline $\begin{array}{c}\text { ver a la policía } \\
\text { quemando discos } \\
\text { compactos y cassettes } \\
\text { de video }\end{array}$ & & & es \\
\hline
\end{tabular}

Texto 5

\begin{tabular}{|c|c|c|c|}
\hline ACTOR/OBJETIVO & $\frac{\text { PROCESOS }}{\text { MATERIALES }}$ & $\frac{\text { PROCESOS DE }}{\underline{\text { PROYECCIÓN }}}$ & $\begin{array}{c}\text { RELACIONALES } \\
\begin{array}{c}\text { PROCESOS } \\
\text { Existenciales }\end{array}\end{array}$ \\
\hline El texto & & & se refiere \\
\hline $\begin{array}{l}\text { le/a entrenadores } \\
\text { masculinos }\end{array}$ & se ha prohibido & & \\
\hline a los espectadores & se prohíbe & & \\
\hline $\begin{array}{l}\text { a los periodistas } \\
\text { masculinos }\end{array}$ & se prohíbe & & \\
\hline $\begin{array}{l}\text { Estas nuevas medidas, } \\
\text { decididas en una } \\
\text { reunión de gabinete }\end{array}$ & & & son \\
\hline Esta decisión & afectará & & \\
\hline (mujeres) que & practican & & \\
\hline $\begin{array}{l}\text { Muchos atletas } \\
\text { retirados }\end{array}$ & & & se quedarán \\
\hline
\end{tabular}




\begin{tabular}{|c|c|c|c|}
\hline ACTOR/OBJETIVO & $\frac{\text { PROCESOS }}{\text { MATERIALES }}$ & $\frac{\text { PROCESOS DE }}{\underline{\text { PROYECCIÓN }}}$ & $\frac{\text { PROCESOS }}{\text { RELACIONALES }}$ \\
\hline $\begin{array}{l}\text { La prohibición que no } \\
\text { deja que los hombres } \\
\text { se desenvuelvan en } \\
\text { deportes femeninos }\end{array}$ & & & sigue \\
\hline (la prohibición) que & & (no) deja & \\
\hline los hombres & se desenvuelvan & & \\
\hline $\begin{array}{l}\text { Esta dura línea del } \\
\text { gobierno islámico }\end{array}$ & fue elegida & & \\
\hline (las elecciones) que & se realizaron & & \\
\hline $\begin{array}{c}\text { Esta línea dura de } \\
\text { gobierno }\end{array}$ & comparte & & \\
\hline $\begin{array}{c}\text { (una provincia vecina) } \\
\text { que }\end{array}$ & & & limita \\
\hline $\begin{array}{l}\text { Las autoridades } \\
\text { fronterizas de la } \\
\text { Provincia del } \\
\text { Noroeste }\end{array}$ & prohibieron & & \\
\hline $\mathrm{y}$ & ordenaron & & \\
\hline La policía & incautó & & \\
\hline los & prendieron fuego & & \\
\hline
\end{tabular}

\section{B) Textos menos efectivos}

Texto 6

\begin{tabular}{|c|c|c|c|}
\hline ACTOR/OBJETIVO & $\begin{array}{c}\text { PROCESOS } \\
\frac{\text { MATERIALES }}{\text { Materiales / de }} \\
\text { Conducta }\end{array}$ & $\begin{array}{c}\frac{\text { PROCESOS DE }}{\text { PROYECCIÓN }} \\
\text { Mentales / Verbales }\end{array}$ & $\begin{array}{c}\frac{\text { PROCESOS }}{\text { RELACIONALES }} \\
\begin{array}{c}\text { Relacionales / } \\
\text { Existenciales }\end{array}\end{array}$ \\
\hline $\begin{array}{c}\text { Entrenadores } \\
\text { hombres }\end{array}$ & fueron prohibidos & & \\
\hline $\begin{array}{c}\text { atletas femeninas } \\
\text { serán enrejados }\end{array}$ & compiten & se olvidan & \\
\hline $\begin{array}{c}\text { Los periodistas } \\
\text { Asif Iqbal daudzai, } \\
\text { Ministro de } \\
\text { Información del }\end{array}$ & & dijo & \\
\hline
\end{tabular}




\begin{tabular}{|c|c|c|c|}
\hline ACTOR/OBJETIVO & $\frac{\text { PROCESOS }}{\text { MATERIALES }}$ & $\begin{array}{l}\frac{\text { PROCESOS DE }}{\text { PROYECCIÓN }} \\
\text { Mentales / Verbales }\end{array}$ & $\begin{array}{c}\text { RELOCESOS } \\
\text { Relacionales / } \\
\text { Existenciales }\end{array}$ \\
\hline \multicolumn{4}{|l|}{$\begin{array}{c}\text { Noroeste de la } \\
\text { provincia de Frontera }\end{array}$} \\
\hline Las noticias tomadas & marcan & & \\
\hline el gabinete & decidió encontrarse & & \\
\hline La decisión & afectará (a) & & \\
\hline $\begin{array}{l}\text { (cientos de chicas y } \\
\text { mujeres) que }\end{array}$ & compiten & & \\
\hline $\begin{array}{c}\text { Varios atletas } \\
\text { nacionales retirados }\end{array}$ & $\begin{array}{l}\text { fueron anticipados a } \\
\text { perder }\end{array}$ & & \\
\hline $\begin{array}{l}\text { La prohibición sobre } \\
\text { la participación de } \\
\text { hombres en deportes } \\
\text { de mujeres }\end{array}$ & fue dirigida & & \\
\hline Daudzai & & dijo & \\
\hline El gobierno & establecerá & & \\
\hline La provincia & eligió & & \\
\hline Línea dura & repartió & & \\
\hline Ambas provincias & & & bordean \\
\hline $\begin{array}{c}\text { Autoridades del } \\
\text { noroeste de la frontera } \\
\text { de la provincia }\end{array}$ & han prohibido & & \\
\hline (autoridades) & controlan & & \\
\hline Policía & gasolina & & \\
\hline (policía) & envía en llamas & & \\
\hline
\end{tabular}

Texto7
\begin{tabular}{|c|c|c|c|}
\hline ACTOR/OBJETIVO & $\frac{\text { PROCESOS }}{\text { MATERIALES }}$ & $\frac{\text { PROCESOS DE }}{\text { PROYECCIÓN }}$ & $\begin{array}{c}\text { PROCESOS } \\
\text { RELACIONALES }\end{array}$ \\
& $\begin{array}{c}\text { Materiales / de } \\
\text { Conducta }\end{array}$ & $\begin{array}{c}\text { Mentales / Verbales } \\
\text { Relacionales / } \\
\text { Existenciales }\end{array}$ \\
\hline Los profesores & estaban prohibidos & & \\
\hline Los espectadores & & tienen el deseo? & \\
\hline mujeres & compitan & & \\
\hline $\begin{array}{c}\text { Los periodistas } \\
\text { Ministro de }\end{array}$ & están prohibidos & contaba & \\
\hline
\end{tabular}




\begin{tabular}{|c|c|c|c|}
\hline ACTOR/OBJETIVO & $\frac{\text { PAOCESOS }}{\text { MATERIALES }}$ & $\frac{\text { PROCESOS DE }}{\underline{\text { PROYECCIÓN }}}$ & $\frac{\underline{\text { PROCESOS }}}{\underline{\text { REACIONALES }}}$ \\
\hline $\begin{array}{c}\text { Información del } \\
\text { Noroeste de la } \\
\text { Provincia de Pakistán }\end{array}$ & & & \\
\hline $\begin{array}{l}\text { La nueva medida } \\
\text { tomada por el Concejo } \\
\text { de Ministros }\end{array}$ & marca & & \\
\hline $\begin{array}{c}\text { Varios atletas } \\
\text { nacionales retirados }\end{array}$ & $\begin{array}{c}\text { estaban expectantes a } \\
\text { perder }\end{array}$ & & \\
\hline La provincia & estableció & & \\
\hline La policía & compraba & & \\
\hline
\end{tabular}

Texto 8

\begin{tabular}{|c|c|c|c|}
\hline ACTOR/OBJETIVO & $\frac{\text { PROCESOS }}{\text { MATERIALES }}$ & $\frac{\text { PROCESOS DE }}{\underline{\text { PROYECCIÓN }}}$ & $\frac{\text { PROCESOS }}{\text { RELACIONALES }}$ \\
\hline $\begin{array}{l}\text { El gobierno de } \\
\text { Pakistan }\end{array}$ & (no) permite & & \\
\hline mujeres & ingresen & & \\
\hline Esto & fue decidido & & \\
\hline La decisión & afecta & & \\
\hline mujeres & compitan & & \\
\hline $\begin{array}{c}\text { Las bandas de } \\
\text { hombres involucradas } \\
\text { en deportes }\end{array}$ & son reelaboradas & & \\
\hline El gobierno & estableció & & \\
\hline La provincia & eligió & & \\
\hline Las autoridades & pusieron & & \\
\hline $\begin{array}{l}\text { (carteleras de las } \\
\text { imágenes de futuras } \\
\text { mujeres publicitando } \\
\text { películas o productos) } \\
\text { que }\end{array}$ & $\begin{array}{l}\text { fueron o son } \\
\text { arrancadas }\end{array}$ & & \\
\hline La policía & quemó & & \\
\hline
\end{tabular}


Texto 9

\begin{tabular}{|c|c|c|c|}
\hline ACTOR/OBJETIVO & $\frac{\text { PROCESOS }}{\text { MATERIALES }}$ & $\frac{\text { PROCESOS DE }}{\text { PROYECCIÓN }}$ & $\frac{\text { PROCESOS }}{\text { RELACIONALES }}$ \\
\hline & $\begin{array}{l}\text { Materiales / de } \\
\text { Conducta }\end{array}$ & Mentales / Verbales & $\begin{array}{c}\text { Relacionales / } \\
\text { Existenciales }\end{array}$ \\
\hline $\begin{array}{l}\text { los entrenadores } \\
\text { masculinos }\end{array}$ & fueron separados & & \\
\hline les/a los periodistas & se pusieron & & \\
\hline \multirow[t]{2}{*}{ eso } & & & era \\
\hline & & se dice & \\
\hline la decisión & podría afectar & & \\
\hline Ex atletas nacionales & & $\begin{array}{c}\text { encaran expectativas } \\
\text { de? }\end{array}$ & \\
\hline $\begin{array}{l}\text { La separación de los } \\
\text { hombres de los } \\
\text { deportes femeninos }\end{array}$ & $\begin{array}{c}\text { puede llegar a } \\
\text { promover }\end{array}$ & & \\
\hline El gobierno & estableció & & \\
\hline $\begin{array}{c}\text { Las autoridades del } \\
\text { Noroeste de la } \\
\text { provincia }\end{array}$ & excluyó & & \\
\hline
\end{tabular}

Texto 10

\begin{tabular}{|c|c|c|c|}
\hline ACTOR/OBJETIVO & $\begin{array}{c}\text { PROCESOS } \\
\text { MATERIALES } \\
\text { Materiales / de } \\
\text { Conducta }\end{array}$ & $\begin{array}{r}\frac{\text { PROCESOS DE }}{\text { PROYECCIÓN }} \\
\text { Mentales / Verbales }\end{array}$ & $\begin{array}{c}\text { PROCESOS } \\
\text { Relacionales / } \\
\text { Existenciales }\end{array}$ \\
\hline $\begin{array}{c}\text { Los entrenadores de } \\
\text { hombres }\end{array}$ & prohibieron & & es \\
\hline La información & fue dada & \\
\hline Esta última noticia & afecta & & \\
\hline $\begin{array}{c}\text { La medida } \\
\text { hombres con mujeres } \\
\text { en los deportes }\end{array}$ & está apuntando & & \\
\hline El gobernador & establecerá & & \\
\hline La provincia & eligió & & \\
\hline $\begin{array}{c}\text { Las autoridades de la } \\
\text { Frontera Noroeste }\end{array}$ & dispusieron & & \\
\hline
\end{tabular}




\section{Apéndice 4: Análisis de Modo/Temple}

\section{A) Textos más efectivos}

\section{Texto 1}

\begin{tabular}{|c|c|c|}
\hline \multicolumn{2}{|c|}{ BLOQUE MODO/TEMPLE } & \multirow[b]{2}{*}{ PREDICADOR } \\
\hline SUJETO & FINITO & \\
\hline & \multicolumn{2}{|c|}{ prohibieron } \\
\hline $\begin{array}{l}\text { Estas medidas, tomadas por el } \\
\text { Gabinete provincial, }\end{array}$ & fueron & impulsadas \\
\hline $\begin{array}{c}\text { (Estas medidas, tomadas por el } \\
\text { Gabinete provincial,) }\end{array}$ & \multicolumn{2}{|c|}{ afectarán } \\
\hline (mujeres) que & \multicolumn{2}{|c|}{ practican } \\
\hline (atletas retirados) que & \multicolumn{2}{|c|}{ trabajan } \\
\hline $\begin{array}{l}\text { La prohibición de que los hombres } \\
\text { se involucren en deportes de } \\
\text { mujeres }\end{array}$ & fue & orientada a promover \\
\hline El gobierno & \multicolumn{2}{|c|}{ establecerá } \\
\hline La provincia & \multicolumn{2}{|c|}{ eligió } \\
\hline $\begin{array}{l}\text { (un gobierno islámico de línea } \\
\text { dura) que }\end{array}$ & \multicolumn{2}{|c|}{ comparte } \\
\hline $\begin{array}{c}\text { Autoridades de la provincia de } \\
\text { Peshawar }\end{array}$ & \multicolumn{2}{|c|}{ prohibieron } \\
\hline $\begin{array}{c}\text { (Autoridades de la provincia de } \\
\text { Peshawar) }\end{array}$ & \multicolumn{2}{|c|}{ ordenaron } \\
\hline compact discs y videocassettes & fueron & incendiados \\
\hline
\end{tabular}


Texto 2

\begin{tabular}{|c|c|c|}
\hline \multicolumn{2}{|c|}{ BLOQUE MODO/TEMPLE } & \multirow[b]{2}{*}{ PREDICADOR } \\
\hline SUJETO & FINITO & \\
\hline El texto & \multicolumn{2}{|c|}{ trata } \\
\hline Esta línea dura de gobierno & \multicolumn{2}{|c|}{ asumió } \\
\hline (Esta línea dura de gobierno) & \multicolumn{2}{|c|}{ estaba } \\
\hline Las nuevas medidas & \multicolumn{2}{|c|}{ indican } \\
\hline las mujeres & (no) podrán & ser entrenadas \\
\hline (las mujeres) & (no) podrán & ser vistas \\
\hline Los periodistas hombres & podrán & cubrir \\
\hline Esta decisión & \multicolumn{2}{|c|}{ afectará } \\
\hline $\begin{array}{l}\text { (miles de mujeres y adolescentes) } \\
\text { que }\end{array}$ & \multicolumn{2}{|c|}{ participan } \\
\hline (esta decisión) & puede & afectar \\
\hline (varones) que & \multicolumn{2}{|c|}{ dan } \\
\hline Esta línea de gobierno islámica & había & prohibido \\
\hline (Esta línea de gobierno islámica) & \multicolumn{2}{|c|}{ ordenaron } \\
\hline La policía & \multicolumn{2}{|c|}{ secuestra } \\
\hline (la policía) & \multicolumn{2}{|c|}{ prenden fuego } \\
\hline Todo esto & es & \\
\hline
\end{tabular}

Texto 3

\begin{tabular}{|c|c|c|}
\hline \multicolumn{2}{|c|}{ BLOQUE MODO/TEMPLE } & \multirow[b]{2}{*}{ PREDICADOR } \\
\hline SUJETO & FINITO & \\
\hline $\begin{array}{c}\text { La alianza religiosa "El partido de } \\
\text { los seis" }\end{array}$ & decidió & separar \\
\hline $\begin{array}{l}\text { Muchos atletas retirados, los cuales } \\
\text { trabajan en escuelas de niñas como } \\
\text { entrenadores }\end{array}$ & temen & perder \\
\hline $\begin{array}{l}\text { (Muchos atletas retirados) los } \\
\text { cuales }\end{array}$ & \multicolumn{2}{|c|}{ trabajan } \\
\hline Dicha medida & \multicolumn{2}{|c|}{ tiene } \\
\hline Daudzai & \multicolumn{2}{|c|}{ agregó } \\
\hline La provincia & ha & elegido \\
\hline $\begin{array}{c}\text { (una línea islámica bastante dura) } \\
\text { que }\end{array}$ & ha & impulsado \\
\hline $\begin{array}{c}\text { (una línea islámica bastante dura) } \\
\text { que }\end{array}$ & ha & prohibido \\
\hline & & \\
\hline
\end{tabular}


Texto 4

\begin{tabular}{|c|c|c|}
\hline \multicolumn{2}{|c|}{ BLOQUE MODO/TEMPLE } & \multirow[b]{2}{*}{ PREDICADOR } \\
\hline SUJETO & FINITO & \\
\hline & \multicolumn{2}{|c|}{ se prohibió } \\
\hline & \multicolumn{2}{|c|}{ ocurrió } \\
\hline $\begin{array}{l}\text { (periodistas y espectadores } \\
\text { masculinos) que }\end{array}$ & quisieran & ver \\
\hline un vocero pakistaní & \multicolumn{2}{|c|}{ afirmó } \\
\hline $\begin{array}{l}\text { Las medidas, decididas en } \\
\text { Gabinete provincial, }\end{array}$ & fueron & tomadas \\
\hline La decisión & \multicolumn{2}{|c|}{ afecta } \\
\hline Atletas nacionales retirados & podrían & quedar \\
\hline \multirow[t]{2}{*}{ La proscripción a los hombres } & es & \\
\hline & \multicolumn{2}{|c|}{ explicaron } \\
\hline \multirow[t]{3}{*}{ Esta provincia } & \multicolumn{2}{|c|}{ eligió } \\
\hline & \multicolumn{2}{|c|}{ se prohibió } \\
\hline & \multicolumn{2}{|c|}{ se ordenó } \\
\hline $\begin{array}{l}\text { ver a la policía quemando discos } \\
\text { compactos y cassettes de video }\end{array}$ & es & \\
\hline
\end{tabular}


Texto 5

\begin{tabular}{|c|c|c|}
\hline \multicolumn{2}{|c|}{ BLOQUE MODO/TEMPLE } & \multicolumn{2}{|c|}{ PREDICADOR } \\
\hline El texto & prohibido \\
\hline & se ha \\
\hline $\begin{array}{c}\text { Estas nuevas medidas, decididas en } \\
\text { una reunión de gabinete, }\end{array}$ & \multicolumn{2}{|c|}{ se prohíbe } \\
\hline Esta decisión & se prohíbe \\
\hline (miles de mujeres) que & afectará \\
\hline Muchos atletas retirados & practican \\
\hline $\begin{array}{c}\text { La prohibición que no deja que los } \\
\text { hombres se desenvuelvan en } \\
\text { deportes femeninos }\end{array}$ & se quedarán \\
\hline (la prohibición) que & sigue \\
\hline los hombres & se desenvuelvan \\
\hline $\begin{array}{c}\text { Esta dura línea de gobierno } \\
\text { islámico }\end{array}$ & comparte \\
\hline (provincia vecina) que & limita \\
\hline $\begin{array}{c}\text { Las autoridades fronterizas de la } \\
\text { Provincia del Noroeste }\end{array}$ & prohibieron \\
\hline $\begin{array}{c}\text { (las autoridades fronterizas de la } \\
\text { Provincia del Noroeste) }\end{array}$ & ordenaron \\
\hline La policía & prendieron fuego \\
\hline (la policía) & incautó \\
\hline
\end{tabular}




\section{B) Textos menos efectivos}

Texto 6

\begin{tabular}{|c|c|c|}
\hline $\begin{array}{l}\text { BLOQUE MODO/TEMPLE } \\
\text { SUJETO }\end{array}$ & FINITO & PREDICADOR \\
\hline Entrenadores & fueron & $\begin{array}{l}\text { prohibidos de } \\
\text { entrenar }\end{array}$ \\
\hline Los espectadores hombres & serán & enrejados \\
\hline atletas femeninas & \multicolumn{2}{|c|}{ compitan } \\
\hline Los periodistas & \multicolumn{2}{|c|}{ se olvidan } \\
\hline $\begin{array}{c}\text { Asif Iqbal Daudzai, Ministro de Información del Noroeste de la } \\
\text { provincia de Frontera }\end{array}$ & \multicolumn{2}{|c|}{ dijo } \\
\hline Las noticias tomadas, & \multicolumn{2}{|c|}{ marcan } \\
\hline el gabinete & \multicolumn{2}{|c|}{ decidió } \\
\hline La decisión & \multicolumn{2}{|c|}{ afectará } \\
\hline (cientos de chicas y mujeres en la provincia) que & \multicolumn{2}{|c|}{ compiten } \\
\hline Varios atletas nacionales retirados & fueron & anticipados a perder \\
\hline $\begin{array}{l}\text { La prohibición sobre la participación de hombres en deportes de } \\
\text { mujeres }\end{array}$ & fue & dirigida \\
\hline Daudzai & \multicolumn{2}{|c|}{ dijo } \\
\hline El gobierno & \multicolumn{2}{|c|}{ establecerá } \\
\hline La provincia & \multicolumn{2}{|c|}{ eligió } \\
\hline Línea dura & \multicolumn{2}{|c|}{ repartió } \\
\hline Ambas provincias & \multicolumn{2}{|c|}{ bordean } \\
\hline Autoridades del noroeste de la frontera de la provincia & han & prohibido \\
\hline (autoridades...) & \multicolumn{2}{|c|}{ controlan } \\
\hline Policía & \multicolumn{2}{|c|}{ gasolina } \\
\hline (policía) & envía & en llamas \\
\hline
\end{tabular}

Texto 7

\begin{tabular}{|c|c|c|}
\hline $\begin{array}{c}\text { BLOQUE MODO/TEMPLE } \\
\text { SUJETO }\end{array}$ & FINITO & PREDICADOR \\
\hline Los profesores & estaban & prohibidos \\
\hline Los espectadores & \multicolumn{2}{|c|}{ tienen el deseo? } \\
\hline mujeres & \multicolumn{2}{|c|}{ compitan } \\
\hline Los periodistas & están & prohibidos \\
\hline Asif Iqbal Daudzai, Ministro de Información del Noroeste de la \\
Provincia de Pakistán & \multicolumn{2}{|c|}{ contaba } \\
\hline La nueva medida tomada por el Concejo de Ministros & \multicolumn{2}{|c|}{ marca } \\
\hline Varios atletas nacionales retirados & \multicolumn{2}{|c|}{ estaban } \\
\hline La provincia & \multicolumn{2}{|c|}{ estableció } \\
\hline La policía & \multicolumn{2}{|c|}{ compraba } \\
\hline
\end{tabular}


Texto 8

\begin{tabular}{|c|c|c|}
\hline $\begin{array}{l}\text { BLOQUE MODO/TEMPLE } \\
\text { SUJETO }\end{array}$ & FINITO & PREDICADOR \\
\hline Los profesores & estaban & prohibidos \\
\hline Los espectadores & \multicolumn{2}{|c|}{ tienen el deseo } \\
\hline mujeres & \multicolumn{2}{|c|}{ compitan } \\
\hline Los periodistas & están & prohibidos \\
\hline $\begin{array}{l}\text { Asif Iqbal Daudzai, Ministro de Información del Noroeste de la } \\
\text { Provincia de Pakistán }\end{array}$ & \multicolumn{2}{|r|}{ contaba } \\
\hline La nueva medida tomada por el Concejo de Ministros & \multicolumn{2}{|r|}{ marca } \\
\hline Varios atletas nacionales retirados & \multicolumn{2}{|r|}{ estaban } \\
\hline La provincia & \multicolumn{2}{|r|}{ estableció } \\
\hline La policía & \multicolumn{2}{|c|}{ compraba } \\
\hline
\end{tabular}

Texto 9

\begin{tabular}{|c|c|c|}
\hline $\begin{array}{c}\text { BLOQUE MODO/TEMPLE } \\
\text { SUJETO }\end{array}$ & FINITO & PREDICADOR \\
\hline los entrenadores masculinos & fueron & separados \\
\hline eso & \multicolumn{2}{|c|}{ se pusieron } \\
\hline & \multicolumn{2}{|c|}{ era } \\
\hline Ee dice \\
\hline La atletas nacionales & \multicolumn{2}{c|}{ encaran } \\
\hline El gobierno & puede & llegar a promover \\
\hline Las autoridableció \\
\hline
\end{tabular}

Texto 10

\begin{tabular}{|c|c|c|}
\hline $\begin{array}{c}\text { BLOQUE MODO/TEMPLE } \\
\text { SUJETO }\end{array}$ & FINITO & PREDICADOR \\
\hline Los entrenadores de hombres & \multicolumn{2}{|c|}{ prohibieron } \\
\hline La información & fue & dada \\
\hline Esta última noticia & es & afecta \\
\hline La medida & \multicolumn{2}{|c|}{$\begin{array}{c}\text { apuntando a } \\
\text { promover }\end{array}$} \\
\hline La prohibición de hombres con mujeres en los deportes & está & \multicolumn{2}{|c|}{ establecerá } \\
\hline El gobenador & \multicolumn{2}{|c|}{ eligió } \\
\hline La provincia & \multicolumn{2}{|c|}{ dispusieron } \\
\hline Las autoridades de la Frontera Noroeste &
\end{tabular}




\section{Apéndice 5: Análisis de Tema/Rema}

\section{A) Textos más logrados}

Texto 1

\begin{tabular}{|c|c|c|c|c|}
\hline \multicolumn{4}{|c|}{ TEMA } & \multirow[b]{2}{*}{ REMA } \\
\hline Textual & Interpersonal & $\begin{array}{c}\text { Marcado } \\
\text { Tópico }\end{array}$ & $\begin{array}{l}\text { No marcado } \\
\text { Tópico }\end{array}$ & \\
\hline & & $\begin{array}{l}\text { En Peshawar, } \\
\text { una provincia } \\
\text { del Noroeste de } \\
\text { Pakistan }\end{array}$ & & $\begin{array}{l}\text { prohibieron a entrenadores, } \\
\text { espectadores y periodistas } \\
\text { varones el participar de } \\
\text { cualquier manera en deports de } \\
\text { mujeres }\end{array}$ \\
\hline & & & $\begin{array}{l}\text { Estas medidas, } \\
\text { tomadas por el } \\
\text { Gabinete } \\
\text { provincial, }\end{array}$ & $\begin{array}{l}\text { fueron impulsadas por una } \\
\text { alianza religios islámica }\end{array}$ \\
\hline \multirow[t]{5}{*}{$\mathrm{y}$} & & & afectarán & $\begin{array}{l}\text { a muchas mujeres } \\
\text { que practican deportes y a atletas } \\
\text { retirados que trabajan en } \\
\text { escuelas de mujeres }\end{array}$ \\
\hline & & & $\begin{array}{l}\text { La prohibición } \\
\text { de que los } \\
\text { hombres se } \\
\text { involucren en } \\
\text { deportes de } \\
\text { mujeres }\end{array}$ & $\begin{array}{l}\text { fue orientada a promover un } \\
\text { estilo tradicional de deports } \\
\text { islámicos }\end{array}$ \\
\hline & & & El gobierno & $\begin{array}{l}\text { establecerá grupos deportivos } \\
\text { separados de hombres y mujeres }\end{array}$ \\
\hline & & & La provincia & $\begin{array}{l}\text { eligió en octubre un gobierno } \\
\text { islámico de línea dura que } \\
\text { comparte el poder también en la } \\
\text { provincia vecina de Baluchistán }\end{array}$ \\
\hline & & & $\begin{array}{l}\text { Autoridades } \\
\text { de la provincia } \\
\text { de Peshawar }\end{array}$ & $\begin{array}{c}\text { prohibieron también la música } \\
\text { en los colectivos públicos y } \\
\text { ordenaron quitar toda la } \\
\text { publicidad con imágenes de } \\
\text { mujeres }\end{array}$ \\
\hline $\mathrm{y}$ & & & ordenaron & $\begin{array}{l}\text { quitar toda la publicidad con } \\
\text { imágenes de mujeres }\end{array}$ \\
\hline también & & & $\begin{array}{c}\text { fueron } \\
\text { incendiados }\end{array}$ & $\begin{array}{l}\text { por la policía compact discs y } \\
\text { videocassettes secuestrados en } \\
\text { campañas anti-obsenidad }\end{array}$ \\
\hline
\end{tabular}


Texto 2

\begin{tabular}{|c|c|c|c|c|}
\hline \multicolumn{4}{|c|}{ TEMA } & \multirow[b]{2}{*}{ REMA } \\
\hline Textual & Interpersonal & $\begin{array}{l}\text { Marcado } \\
\text { Tópico }\end{array}$ & $\begin{array}{l}\text { No marcado } \\
\text { Tópico }\end{array}$ & \\
\hline & & & El texto & $\begin{array}{l}\text { trata sobre las decisiones } \\
\text { tomadas por un gobierno muy } \\
\text { conservador y muy estricto en } \\
\text { Pakistan, más específicamente } \\
\text { en la provincia de la Frontera } \\
\text { Noroeste ubicada junto a la } \\
\text { frontera con Afganistán }\end{array}$ \\
\hline & & & $\begin{array}{c}\text { Esta línea de } \\
\text { gobierno }\end{array}$ & $\begin{array}{l}\text { asumió en las últimas elecciones } \\
\text { nacionales }\end{array}$ \\
\hline \multirow[t]{2}{*}{$\mathrm{y}$} & & ya & & $\begin{array}{c}\text { estaba en otra provincia, } \\
\text { Baluchistan }\end{array}$ \\
\hline & & & $\begin{array}{l}\text { Las nuevas } \\
\text { medidas }\end{array}$ & $\begin{array}{l}\text { indican que las mujeres ya no } \\
\text { podrán ser entrenadas a nivel } \\
\text { deportivo por los hombres }\end{array}$ \\
\hline tampoco & & & $\begin{array}{l}\text { podrán ser } \\
\text { vistas }\end{array}$ & $\begin{array}{c}\text { por espectadores del sexo } \\
\text { masculino }\end{array}$ \\
\hline \multirow[t]{2}{*}{ ni } & & & $\begin{array}{l}\text { los periodistas } \\
\text { hombres }\end{array}$ & $\begin{array}{c}\text { podrán cubrir los eventos en los } \\
\text { cuales participen mujeres }\end{array}$ \\
\hline & & & Esta decisión & $\begin{array}{l}\text { afectará a miles de mujeres y } \\
\text { adolescentes que participan en } \\
\text { varios deportes a nivel } \\
\text { internacional }\end{array}$ \\
\hline \multirow[t]{2}{*}{$\begin{array}{l}\text { por otra } \\
\text { parte, } \\
\text { también }\end{array}$} & & & puede & $\begin{array}{c}\text { afectar a varones que dan clases } \\
\text { en escuelas para mujeres, } \\
\text { ocasionando esto la p'rdida de } \\
\text { trabajos }\end{array}$ \\
\hline & & & $\begin{array}{l}\text { Esta línea de } \\
\text { gobierno } \\
\text { islámica }\end{array}$ & $\begin{array}{l}\text { anteriormente había prohibido } \\
\text { que se escuche música en micros } \\
\text { públicos }\end{array}$ \\
\hline $\mathrm{y}$ & & & ordenaron & $\begin{array}{l}\text { derribar carteles publicitarios } \\
\text { con imágene de mujeres }\end{array}$ \\
\hline además & & $\begin{array}{l}\text { de vez en } \\
\text { cuando }\end{array}$ & & $\begin{array}{c}\text { la policía } \\
\text { secuestravideocassettes y } \\
\text { compact discs }\end{array}$ \\
\hline \multirow[t]{2}{*}{$\mathrm{y}$} & & & $\operatorname{los}$ & prenden fuego \\
\hline & & & Todo esto & $\begin{array}{l}\text { es parte de una cmpaña anti- } \\
\text { obsenidad }\end{array}$ \\
\hline
\end{tabular}


Texto 3

\begin{tabular}{|c|c|c|c|c|}
\hline \multicolumn{4}{|c|}{ TEMA } & \multirow[b]{2}{*}{ REMA } \\
\hline Textual & Interpersonal & $\begin{array}{c}\text { Marcado } \\
\text { Tópico } \\
\end{array}$ & $\begin{array}{l}\text { No marcado } \\
\text { Tópico }\end{array}$ & \\
\hline & & & $\begin{array}{l}\text { La alianza } \\
\text { religiosa "El } \\
\text { partido de los } \\
\text { seis" }\end{array}$ & $\begin{array}{l}\text { a través de su vocero Asif Iqbal } \\
\text { Daudzai, Ministro de } \\
\text { Información de la provincia de } \\
\text { Peshawar, Pakistán, en un } \\
\text { intento de imponer una estricta } \\
\text { versión del Islam, decidió } \\
\text { separar de los eventos deportivos } \\
\text { femeninos toda actividad } \\
\text { desarrollada por hombres } \\
\text { (entrenadores, } \\
\text { periodistas que cubren dichos } \\
\text { eventos.) }\end{array}$ \\
\hline & & & $\begin{array}{l}\text { Muchos } \\
\text { atletas } \\
\text { retirados, } \\
\end{array}$ & $\begin{array}{l}\text { los cuales trabajan en escuelas } \\
\text { de niñas como entrenadores, } \\
\text { temen perder su trabajo }\end{array}$ \\
\hline & & & Dicha medida & $\begin{array}{l}\text { tiene como objeto promover el } \\
\text { tradicional estilo del deporte } \\
\text { islámico, agregó Daudzai }\end{array}$ \\
\hline & & & La provincia & $\begin{array}{l}\text { ha elegido una línea islámica } \\
\text { bastante dura en las últimas } \\
\text { elecciones }\end{array}$ \\
\hline $\begin{array}{c}\text { (una } \\
\text { línea } \\
\text { islámica } \\
\text { bastante } \\
\text { dura)qu }\end{array}$ & & & ue & $\begin{array}{l}\text { además de la anterior medida, ha } \\
\text { impulsado una campaña anti- } \\
\text { obsenidad, quemando pilas de } \\
\text { cassettes y compact discs }\end{array}$ \\
\hline también & & & ha prohibido & $\begin{array}{l}\text { la música en autobuses públicos, } \\
\text { publicidades de películas o } \\
\text { productos con mujeres en ellas }\end{array}$ \\
\hline
\end{tabular}




\section{Texto 4}

\begin{tabular}{|c|c|c|c|c|}
\hline \multicolumn{4}{|c|}{ TEMA } & \multirow[b]{2}{*}{ REMA } \\
\hline Textual & Interpersonal & $\begin{array}{c}\text { Marcado } \\
\text { Tópico }\end{array}$ & $\begin{array}{l}\text { No marcado } \\
\text { Tópico }\end{array}$ & \\
\hline & & & Se prohibió & $\begin{array}{l}\text { a entrenadores hombres entrenar } \\
\text { deportistas mujeres en una } \\
\text { provincia pakistaní }\end{array}$ \\
\hline $\begin{array}{l}\text { Lo } \\
\text { mismo }\end{array}$ & & & les & $\begin{array}{l}\text { ocurrió a periodistas y } \\
\text { espectadores masculinos que } \\
\text { quisieran ver deportes } \\
\text { femeninos, afirmó un vocero } \\
\text { pakistaní }\end{array}$ \\
\hline & & & $\begin{array}{l}\text { Las medidas, } \\
\text { decididas en } \\
\text { Gabinete } \\
\text { provincial, }\end{array}$ & $\begin{array}{l}\text { fueron tomadas por la alianza } \\
\text { religiosa del Islam }\end{array}$ \\
\hline & & & La decisión & $\begin{array}{l}\text { afecta a todas las deportistas } \\
\text { femeninas de deportes como } \\
\text { tenis, tenis de mesa y jockey } \\
\text { sobre césped }\end{array}$ \\
\hline & & & $\begin{array}{l}\text { Atletas nacionales } \\
\text { retirados }\end{array}$ & $\begin{array}{c}\text { podrían quedar sin trabajo por } \\
\text { esta nueva regla }\end{array}$ \\
\hline & & & $\begin{array}{l}\text { La proscripción a } \\
\text { los hombres }\end{array}$ & $\begin{array}{l}\text { es para fomentar el tradicional } \\
\text { estilo de los deportes islámicos, } \\
\text { explicaron }\end{array}$ \\
\hline & & & Esta provincia & $\begin{array}{l}\text { eligió una política dura del } \\
\text { gobierno islámico como su } \\
\text { provincia vecina de Baluchistan, } \\
\text { ambas fronterizas con } \\
\text { Afganistán }\end{array}$ \\
\hline También & & & se prohibió & música en autobuses públicos \\
\hline $\mathrm{y}$ & & & se ordenó & $\begin{array}{c}\text { demoler toda cartelera y anuncio } \\
\text { publicitario con imágenes } \\
\text { femeninas }\end{array}$ \\
\hline & & & Es & $\begin{array}{c}\text { común ver a la policía } \\
\text { quemando discos compactos y } \\
\text { cassettes de video en campañas } \\
\text { anti-obsenidad }\end{array}$ \\
\hline
\end{tabular}


Texto 5

\begin{tabular}{|c|c|c|c|c|}
\hline \multicolumn{4}{|c|}{ TEMA } & \multirow[b]{2}{*}{ REMA } \\
\hline Textual & Interpersonal & $\begin{array}{l}\text { Marcado } \\
\text { Tópico }\end{array}$ & $\begin{array}{l}\text { No marcado } \\
\text { Tópico }\end{array}$ & \\
\hline & & & El texto & $\begin{array}{l}\text { se refiere a que se le ha } \\
\text { prohibido a entrenadores } \\
\text { masculinos entrenar atletas } \\
\text { femeninas y equipos integrados } \\
\text { por mujeres en una provincia } \\
\text { conservadora de Pakistán }\end{array}$ \\
\hline También & & & se prohíbe & $\begin{array}{l}\text { a los espectadores concurrir a } \\
\text { eventos disputados por mujeres }\end{array}$ \\
\hline \multirow[t]{8}{*}{$\begin{array}{l}\text { así como } \\
\text { también }\end{array}$} & & & se prohíbe & $\begin{array}{l}\text { a los periodistas masculinos } \\
\text { cubrir dichos eventos }\end{array}$ \\
\hline & & & $\begin{array}{c}\text { Estas nuevas } \\
\text { medidas, decididas } \\
\text { en una reunión de } \\
\text { gabinete, }\end{array}$ & $\begin{array}{l}\text { son otras de las que caracterizan } \\
\text { esta dura versión del Islam }\end{array}$ \\
\hline & & & Esta decisión & $\begin{array}{c}\text { afectará a miles de mujeres que } \\
\text { practican deportes como el tenis, } \\
\text { el ping pong y el jockey sobre } \\
\text { césped. }\end{array}$ \\
\hline & & & $\begin{array}{l}\text { Muchos atletas } \\
\text { retirados }\end{array}$ & se quedarán sin trabajo \\
\hline & & & $\begin{array}{l}\text { La prohibición que } \\
\text { no deja que los } \\
\text { hombres se } \\
\text { desenvuelvan en } \\
\text { deportes } \\
\text { femeninos }\end{array}$ & $\begin{array}{l}\text { sigue el estilo tradicional de los } \\
\text { deportes islámicos, } \\
\text { estableciendo así grupos } \\
\text { deportivos femeninos separados }\end{array}$ \\
\hline & & & $\begin{array}{l}\text { Esta dura línea del } \\
\text { gobierno islámico }\end{array}$ & $\begin{array}{l}\text { fue elegida en las elecciones que } \\
\text { se realizaron en el mes de } \\
\text { octubre último }\end{array}$ \\
\hline & & & $\begin{array}{l}\text { Esta línea dura de } \\
\text { gobierno }\end{array}$ & $\begin{array}{c}\text { comparte el poder en una } \\
\text { provincia vecina que también } \\
\text { limita con Afghanistan }\end{array}$ \\
\hline & & & $\begin{array}{l}\text { Las autoridades } \\
\text { fronterizas de la } \\
\text { Provincia del } \\
\text { Noroeste } \\
\end{array}$ & $\begin{array}{l}\text { también prohibieron toda la } \\
\text { música en ómnibus públicos }\end{array}$ \\
\hline \multirow[t]{2}{*}{$\mathrm{y}$} & & & ordenaron & $\begin{array}{l}\text { sacar carteleras con imágenes de } \\
\text { mujeres publicitando películas o } \\
\text { productos }\end{array}$ \\
\hline & & & La policía & $\begin{array}{c}\text { incautó videos y discos } \\
\text { compactos durante campañas } \\
\text { anti-obsenidad }\end{array}$ \\
\hline $\mathrm{y}$ & & & los & prendieron fuego \\
\hline
\end{tabular}




\section{B) Textos menos efectivos}

Texto 6

\begin{tabular}{|c|c|c|c|c|}
\hline & & TEMA & & \\
\hline Textual & Interpersonal & $\begin{array}{l}\text { Marcado } \\
\text { Tópico }\end{array}$ & $\begin{array}{l}\text { No marcado } \\
\text { Tópico }\end{array}$ & REMA \\
\hline & & & Entrenadores & $\begin{array}{l}\text { ayer fueron prohibidos de } \\
\text { entrenar atletas femeninos y } \\
\text { deportes de equipos en una } \\
\text { profunda y conservadora } \\
\text { provincia de Pakistán }\end{array}$ \\
\hline & & & $\begin{array}{l}\text { Los espectadores } \\
\text { hombres }\end{array}$ & $\begin{array}{c}\text { serán enrejados de mirar eventos } \\
\text { deportivos en donde compiten } \\
\text { atletas femeninas }\end{array}$ \\
\hline $\mathrm{y}$ & & & los periodistas & se olvidan de cubrir a ellas, \\
\hline & & & $\begin{array}{l}\text { Asif Iqbal Daudzai, } \\
\text { Ministro de } \\
\text { Información del } \\
\text { Noroeste de la } \\
\text { provincia de Frontera, }\end{array}$ & Dijo a las noticias informativas \\
\hline & & & $\begin{array}{l}\text { Las noticias tomadas, } \\
\text { (¿el gabinete decidió } \\
\text { encontrarse ayer?) }\end{array}$ & $\begin{array}{l}\text { marcan el último intento de la } \\
\text { alianza religiosa por la fiesta - } \\
\text { seis para imponer una estricta } \\
\text { versión del Islam. }\end{array}$ \\
\hline & & & La decisión & $\begin{array}{c}\text { afectará a cientos de chicas y } \\
\text { mujeres en la provincia }\end{array}$ \\
\hline $\mathrm{qu}$ & & & ue & $\begin{array}{l}\text { compiten en deportes tales como } \\
\text { tenis, tenis de mesa y jockey } \\
\text { sobre césped. }\end{array}$ \\
\hline & & & $\begin{array}{c}\text { Varios atletas } \\
\text { nacionales retirados }\end{array}$ & $\begin{array}{l}\text { fueron anticipados a perder sus } \\
\text { empleos en escuelas de chicas a } \\
\text { causa de las reglas. }\end{array}$ \\
\hline & & & $\begin{array}{l}\text { La prohibición sobre la } \\
\text { participación de } \\
\text { hombres en deportes de } \\
\text { mujeres }\end{array}$ & $\begin{array}{c}\text { fue dirigida a promoción de } \\
\text { estilos tradicionales de deportes } \\
\text { islámicos. }\end{array}$ \\
\hline & & & Daudzai & dijo sin elaboración. \\
\hline & & & El gobierno & $\begin{array}{l}\text { establecerá una separación de } \\
\text { deportes grupales para mujeres }\end{array}$ \\
\hline & & & La provincia & $\begin{array}{l}\text { eligió una línea dura en el } \\
\text { gobierno islámico en las últimas } \\
\text { elecciones nacionales de octubre }\end{array}$ \\
\hline & & & Línea dura & $\begin{array}{c}\text { también repartió autoridad en la } \\
\text { provincia de Neighboring y } \\
\text { Baluchistan. }\end{array}$ \\
\hline & & & Ambas provincias & bordean Afganistán. \\
\hline & & & $\begin{array}{c}\text { Autoridades del } \\
\text { noroeste de la frontera } \\
\text { de la provincia }\end{array}$ & $\begin{array}{l}\text { aún han prohibido toda música } \\
\text { sobre autobuses públicos }\end{array}$ \\
\hline $\mathrm{y}$ & & & controlan & carteleras con aspecto de \\
\hline
\end{tabular}




\begin{tabular}{|c|c|c|c|c|}
\hline \multicolumn{4}{|c|}{ TEMA } & \multirow[b]{2}{*}{ REMA } \\
\hline Textual & Interpersonal & $\begin{array}{c}\text { Marcado } \\
\text { Tópico }\end{array}$ & $\begin{array}{l}\text { No marcado } \\
\text { Tópico }\end{array}$ & \\
\hline & & & & $\begin{array}{l}\text { imágenes de mujeres o } \\
\text { productos para ser difamados. }\end{array}$ \\
\hline & & & Policía & $\begin{array}{c}\text { Frecuentemente gasolina sobre } \\
\text { pilas de cassettes y compacts } \\
\text { durante campañas anti- } \\
\text { obsenidad }\end{array}$ \\
\hline $\mathrm{y}$ & & & envía & a ellos en llamas. \\
\hline
\end{tabular}

Texto 7

\begin{tabular}{|c|c|c|c|c|}
\hline & & TEMA & & \\
\hline Textual & Interpersonal & $\begin{array}{l}\text { Marcado } \\
\text { Tópico }\end{array}$ & $\begin{array}{l}\text { No marcado } \\
\text { Tópico }\end{array}$ & REMA \\
\hline & & & Los profesores & $\begin{array}{l}\text { estaban prohibidos desde } \\
\text { ayer de entrenar atletas } \\
\text { femeninos. }\end{array}$ \\
\hline & & & Los espectadores & $\begin{array}{c}\text { tienen el deseo de estar } \\
\text { mirando eventos donde } \\
\text { compitan mujeres } \\
\end{array}$ \\
\hline & & & Los periodistas & $\begin{array}{c}\text { están prohibidos de } \\
\text { cubrirlos. }\end{array}$ \\
\hline & & & $\begin{array}{c}\text { Asif Iqbal Daudzai, } \\
\text { Ministro de Información } \\
\text { del Noroeste d la Provincia } \\
\text { de Pakistan }\end{array}$ & contaba una noticia concisa. \\
\hline & & & $\begin{array}{l}\text { La nueva medida tomada } \\
\text { por el Concejo de Ministros }\end{array}$ & $\begin{array}{l}\text { marca el último intento de } \\
\text { establecer una estricta } \\
\text { versión por la sexta } \\
\text { religiosa. }\end{array}$ \\
\hline & & & $\begin{array}{c}\text { Varios atletas nacionles } \\
\text { retirados } \\
\end{array}$ & $\begin{array}{l}\text { estaban expectantes a } \\
\text { perder sus beneficios. }\end{array}$ \\
\hline & & & La provincia & $\begin{array}{c}\text { estableció una dura raya } \\
\text { con el gobierno para } \\
\text { alcanzar las elecciones } \\
\text { nacinales en octubre. }\end{array}$ \\
\hline & & & La policía & $\begin{array}{c}\text { durante campañas en contra } \\
\text { a la obsenidad compraba } \\
\text { video casetes y compact } \\
\text { discs. }\end{array}$ \\
\hline
\end{tabular}




\section{Texto 8}

\begin{tabular}{|c|c|c|c|c|}
\hline \multicolumn{4}{|c|}{ TEMA } & \multirow[b]{2}{*}{ REMA } \\
\hline Textual & Interpersonal & $\begin{array}{l}\text { Marcado } \\
\text { Tópico }\end{array}$ & $\begin{array}{l}\text { No marcado } \\
\text { Tópico }\end{array}$ & \\
\hline & & & $\begin{array}{l}\text { El gobierno de } \\
\text { Pakistan }\end{array}$ & $\begin{array}{l}\text { no permite que mujeres } \\
\text { ingresen como espectadoras } \\
\text { de eventos deportivos. }\end{array}$ \\
\hline & & & Esto & fue decidido en Cabinet \\
\hline & & & La decisión & $\begin{array}{l}\text { afecta a miles de mujeres } \\
\text { que compiten en tenis, tenis } \\
\text { de mesa y jockey sobre } \\
\text { césped. }\end{array}$ \\
\hline & & & $\begin{array}{l}\text { Las bandas de } \\
\text { hombres } \\
\text { involucradas en } \\
\text { deportes } \\
\end{array}$ & son reelaboradas \\
\hline & & & El gobierno & $\begin{array}{l}\text { estableció separar el deporte } \\
\text { en equipo para mujeres }\end{array}$ \\
\hline & & $\begin{array}{c}\text { En las } \\
\text { elecciones } \\
\text { nacionales de } \\
\text { octubre }\end{array}$ & & $\begin{array}{c}\text { la provincia eligió un firme } \\
\text { gobierno islámico }\end{array}$ \\
\hline & & & Las autoridades & $\begin{array}{l}\text { pusieron carteleras de las } \\
\text { imágenes de futuras mujeres } \\
\text { publicitando películas o } \\
\text { productos, que fueron o son } \\
\text { arrancadas }\end{array}$ \\
\hline \multirow{2}{*}{$\begin{array}{c}\text { (películas o } \\
\text { productos) } \\
\mathrm{qu} \\
\end{array}$} & & & ue & fueron o son arrancadas \\
\hline & & & La policía & $\begin{array}{l}\text { quemó videocasetes y } \\
\text { compact discs hechos en } \\
\text { campañas anti-obsenidad }\end{array}$ \\
\hline
\end{tabular}


Texto 9

\begin{tabular}{|c|c|c|c|c|}
\hline \multicolumn{4}{|c|}{ TEMA } & \multirow[b]{2}{*}{ REMA } \\
\hline Textual & Interpersonal & $\begin{array}{l}\text { Marcado } \\
\text { Tópico }\end{array}$ & $\begin{array}{l}\text { No marcado } \\
\text { Tópico }\end{array}$ & \\
\hline & & $\begin{array}{c}\text { En } \\
\text { Pakistán }\end{array}$ & & $\begin{array}{l}\text { los entrenadores masculinos } \\
\text { fueron separados de las atletas } \\
\text { femeninas por la profunda } \\
\text { conservadora provincia de } \\
\text { Pakistan }\end{array}$ \\
\hline \multirow[t]{7}{*}{ también } & & & se (les) pusieron & $\begin{array}{c}\text { prohibiciones a los periodistas } \\
\text { de cubrir dichos eventos }\end{array}$ \\
\hline & & & eso & $\begin{array}{c}\text { era lo que informaba el } \\
\text { Ministerio del Noroeste de dicha } \\
\text { provincia }\end{array}$ \\
\hline & & & se dice & $\begin{array}{l}\text { que la decisión podría afectar a } \\
\text { miles de varones y mujeres de } \\
\text { dicha provincia para competir en } \\
\text { diferentes disciplinas }\end{array}$ \\
\hline & & & Ex atletas nacionales & $\begin{array}{c}\text { encaran expectativas de abrir } \\
\text { escuelas para mujeres para } \\
\text { diferentes deportes }\end{array}$ \\
\hline & & & $\begin{array}{l}\text { La separación de los } \\
\text { hombres d los } \\
\text { deportes femeninos }\end{array}$ & $\begin{array}{c}\text { puede llegar a promover el } \\
\text { tradicional estilo de los deportes } \\
\text { de la Islam }\end{array}$ \\
\hline & & & El gobierno & $\begin{array}{l}\text { estableció la separación de los } \\
\text { deportes por grupo }\end{array}$ \\
\hline & & & $\begin{array}{l}\text { Las autoridades del } \\
\text { Noroeste de la } \\
\text { provincia }\end{array}$ & $\begin{array}{l}\text { también excluyó música, } \\
\text { publicidad, productos e } \\
\text { imágenes masculinos }\end{array}$ \\
\hline
\end{tabular}


Texto 10

\begin{tabular}{|c|c|c|c|c|}
\hline \multicolumn{4}{|c|}{ TEMA } & \multirow[b]{2}{*}{ REMA } \\
\hline Textual & Interpersonal & $\begin{array}{c}\text { Marcado } \\
\text { Tópico }\end{array}$ & $\begin{array}{l}\text { No marcado } \\
\text { Tópico }\end{array}$ & \\
\hline & & & $\begin{array}{l}\text { Los entrenadores de } \\
\text { hombres }\end{array}$ & $\begin{array}{l}\text { prohibieron la enseñanza de } \\
\text { atletas femeninos en aquellos } \\
\text { deportes que eran considerados } \\
\text { femeninos, no tan sólo la } \\
\text { enseñanza sino la inclusión en } \\
\text { los equipos }\end{array}$ \\
\hline & & & La información & $\begin{array}{l}\text { fue dada por el ministro de la } \\
\text { frontera del noroeste de Pakistan }\end{array}$ \\
\hline & & & Esta última noticia & $\begin{array}{l}\text { es el último intento por } \\
\text { imponerse al islam }\end{array}$ \\
\hline & & & La medida & $\begin{array}{c}\text { afecta a chicas y mujeres que } \\
\text { practican los deportes de tenis, } \\
\text { etcétera }\end{array}$ \\
\hline & & & $\begin{array}{c}\text { La prohibición de } \\
\text { hombres con mujeres } \\
\text { en los deportes }\end{array}$ & $\begin{array}{c}\text { está apuntando a promover el } \\
\text { estilo deportivo tradicional de } \\
\text { ese país }\end{array}$ \\
\hline & & & El gobernador & $\begin{array}{c}\text { establecerá una orden para } \\
\text { separar los grupos que } \\
\text { pertenecen a los deportes de las } \\
\text { mujeres }\end{array}$ \\
\hline & & & La provincia & $\begin{array}{l}\text { eligió en el pasado octubre (en } \\
\text { las elecciones nacionales) un } \\
\text { firme representante del islam }\end{array}$ \\
\hline & & & $\begin{array}{l}\text { Las autoridades de la } \\
\text { Frontera Noroeste }\end{array}$ & $\begin{array}{l}\text { dispusieron la prohibición de } \\
\text { música sobre los micros } \\
\text { públicos y pancartas }\end{array}$ \\
\hline
\end{tabular}

